Supporting information for

\title{
Synthesis and Spectroscopic Properties of 1,2,3-Triazole BOPAHY Dyes and their Water-Soluble Triazolium Salts
}

Tomas Horsten, ${ }^{\mathrm{a}}$ Flip de Jong, ${ }^{\mathrm{b}}$ Dries Theunissen, ${ }^{\mathrm{a}}$ Mark Van der Auweraer, ${ }^{\mathrm{b}}$ Wim Dehaen*a ${ }^{a}$ Molecular Design and Synthesis, Department of Chemistry, KU Leuven, Celestijnenlaan 200F, 3001 Leuven, Belgium

${ }^{b}$ Molecular Imaging and Photonics, Department of Chemistry, KU Leuven, Celestijnenlaan 200F, 3001 Leuven, Belgium

E-mail: Wim Dehaen - wim.dehaen@kuleuven.be

* Corresponding author

\section{Contents}

NMR Spectra S2-S34 


\section{NMR Spectra}

$4\left({ }^{1} \mathrm{H}\right.$ NMR, $\left.400 \mathrm{MHz}, \mathrm{CDCl}_{3}\right)$

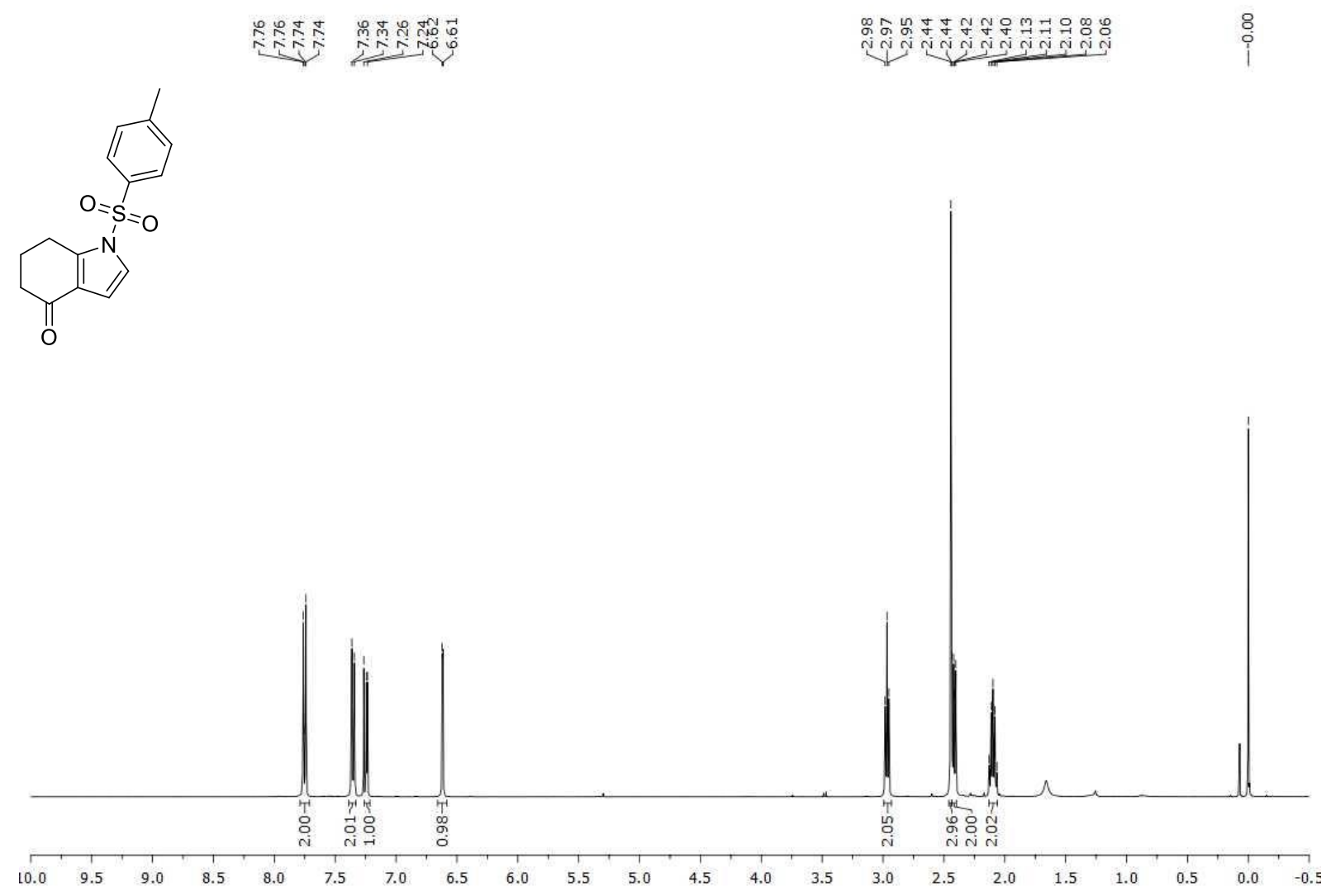

$5\left({ }^{1} \mathrm{H}\right.$ NMR, $\left.300 \mathrm{MHz}, \mathrm{CDCl}_{3}\right)$

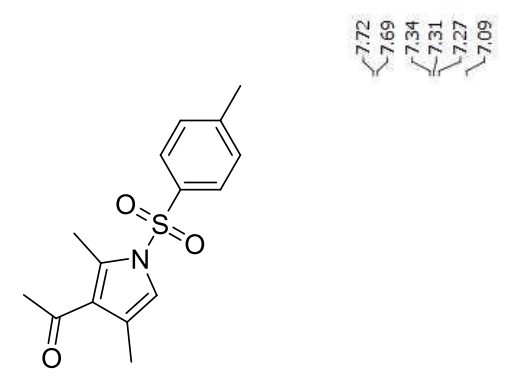

\section{ฝูกูำกำ}

$\stackrel{8}{i}$

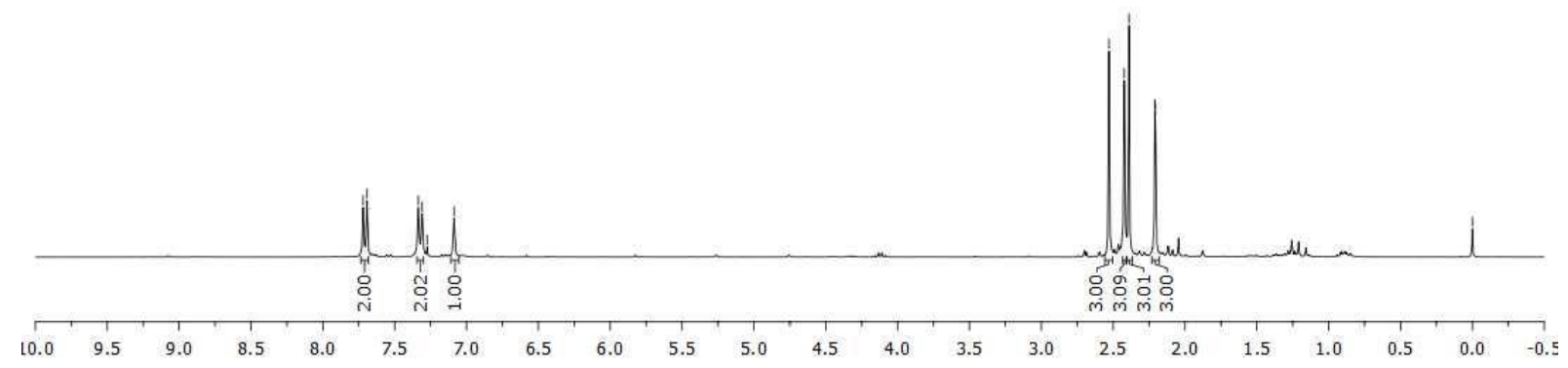


7a $\left({ }^{1} \mathrm{H}\right.$ NMR, $\left.400 \mathrm{MHz}, \mathrm{CDCl}_{3}\right)$

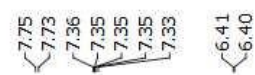

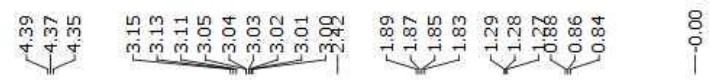
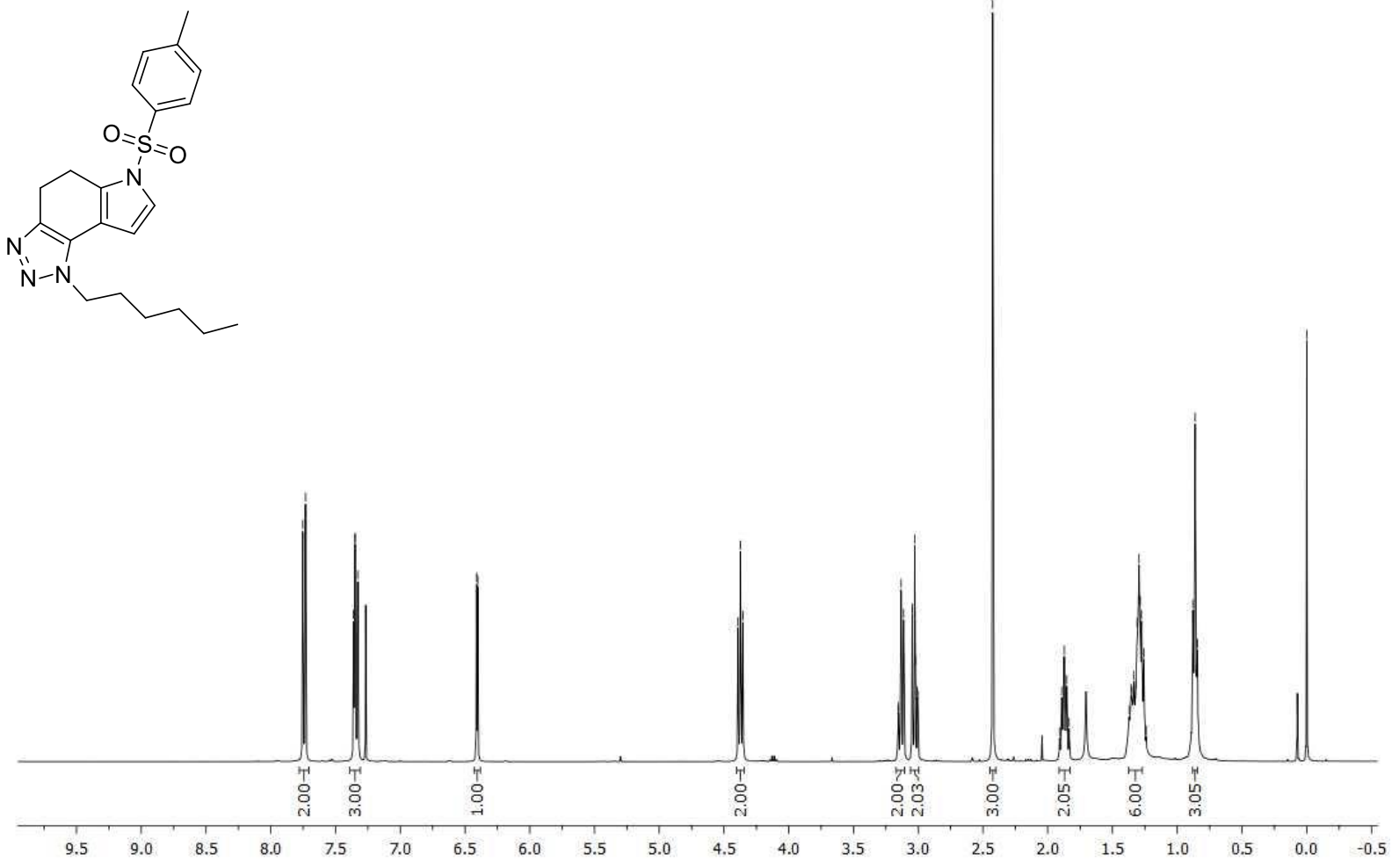

7a $\left({ }^{13} \mathrm{C}\left\{{ }^{1} \mathrm{H}\right\}\right.$ NMR, $\left.101 \mathrm{MHz}, \mathrm{CDCl}_{3}\right)$

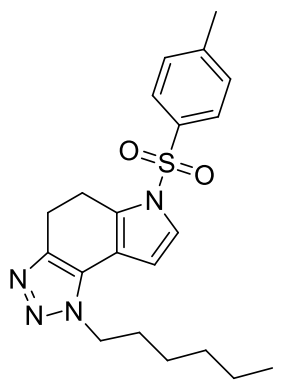

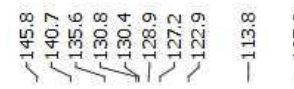
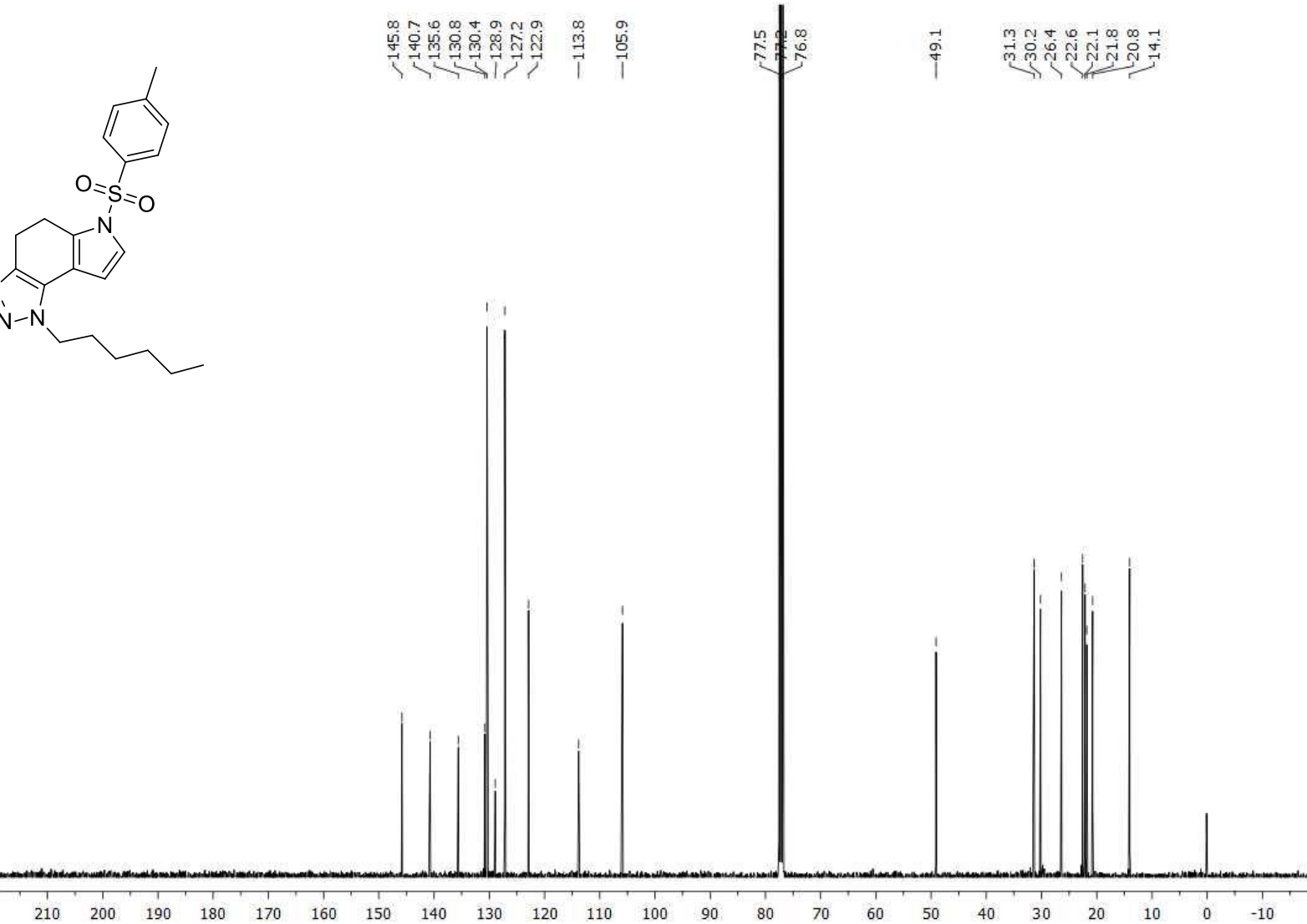
7b $\left({ }^{1} \mathrm{H}\right.$ NMR, $\left.300 \mathrm{MHz}, \mathrm{CDCl}_{3}\right)$

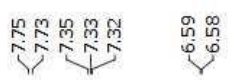

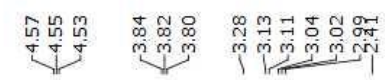

:

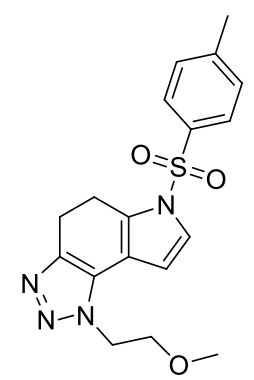
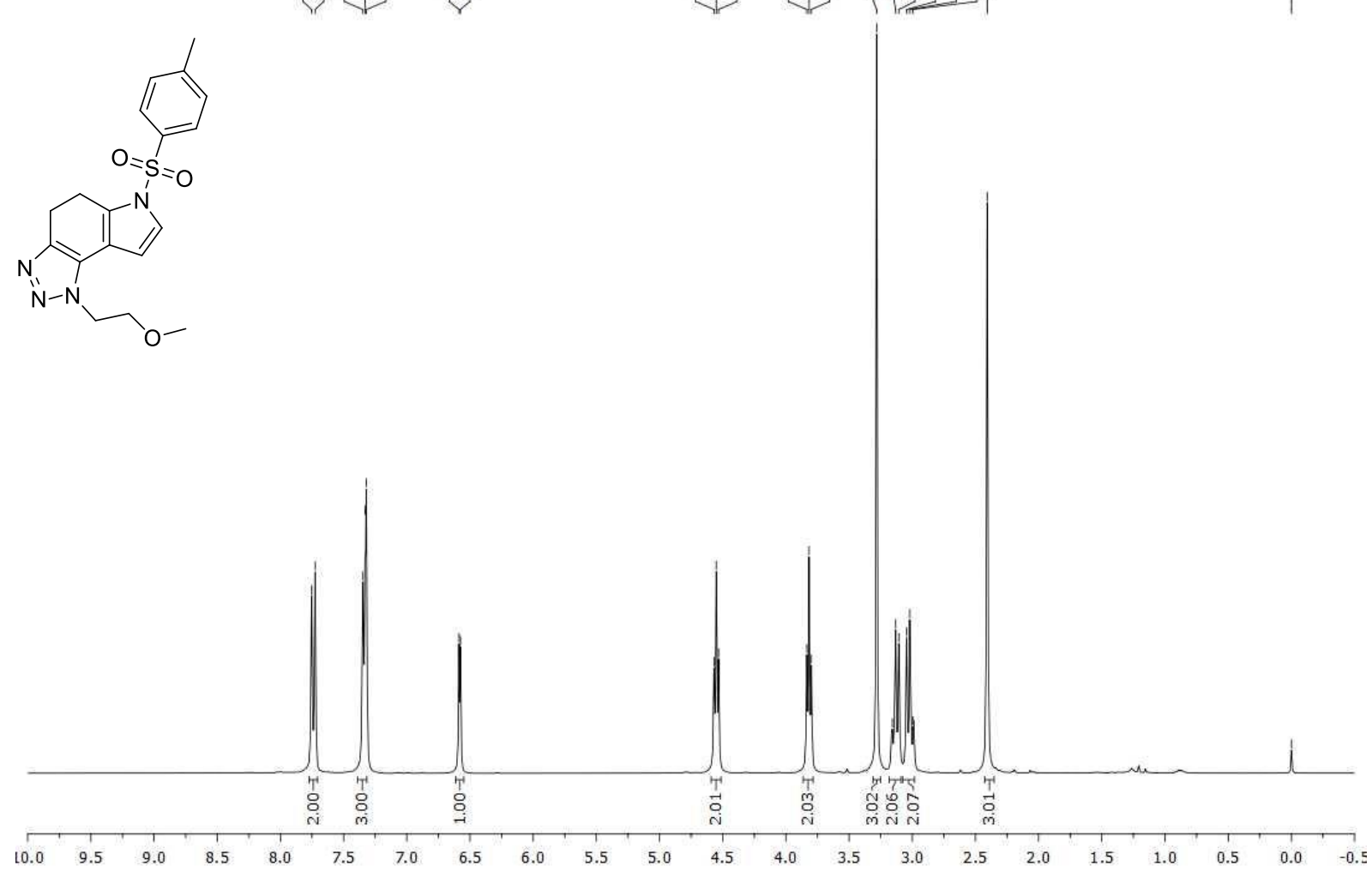

7b $\left({ }^{13} \mathrm{C}\left\{{ }^{1} \mathrm{H}\right\}\right.$ NMR, $\left.75 \mathrm{MHz}, \mathrm{CDCl}_{3}\right)$

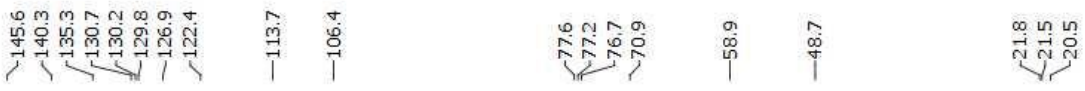

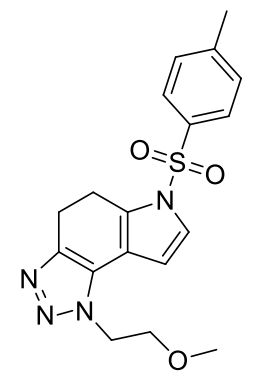

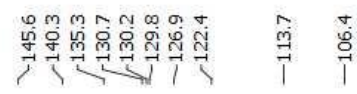

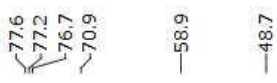

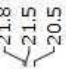
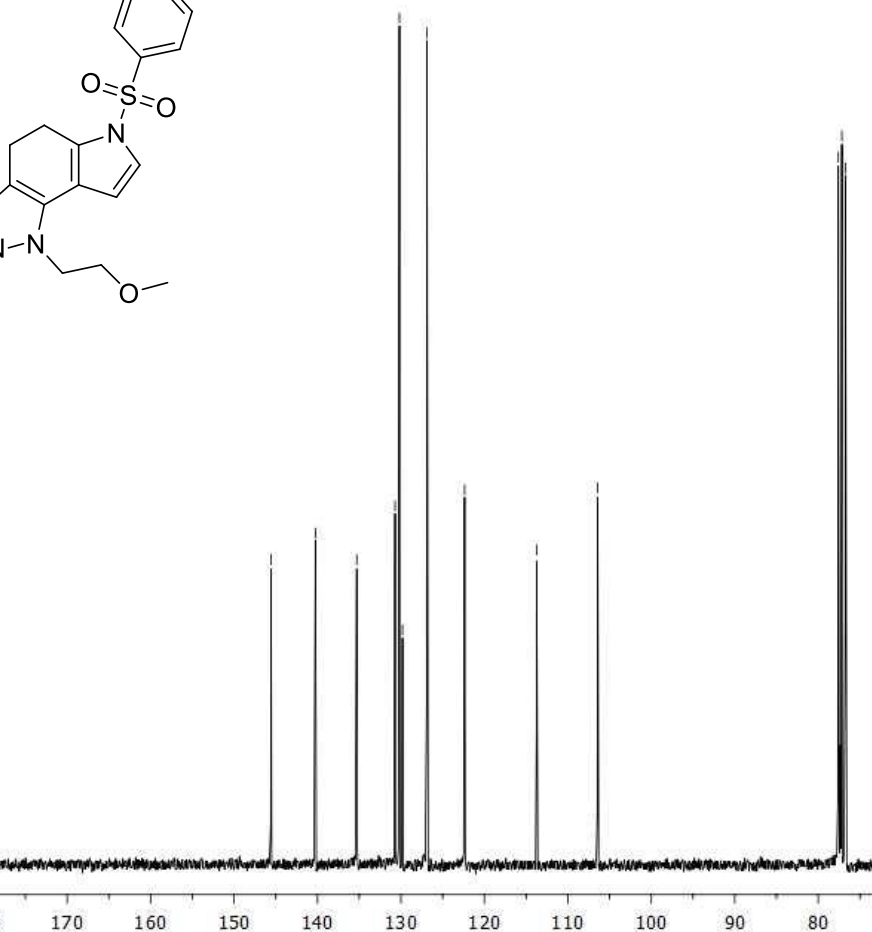
8a $\left({ }^{1} \mathrm{H}\right.$ NMR, $\left.400 \mathrm{MHz}, \mathrm{CDCl}_{3}\right)$

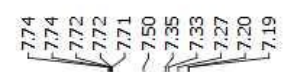

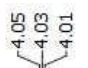

寺
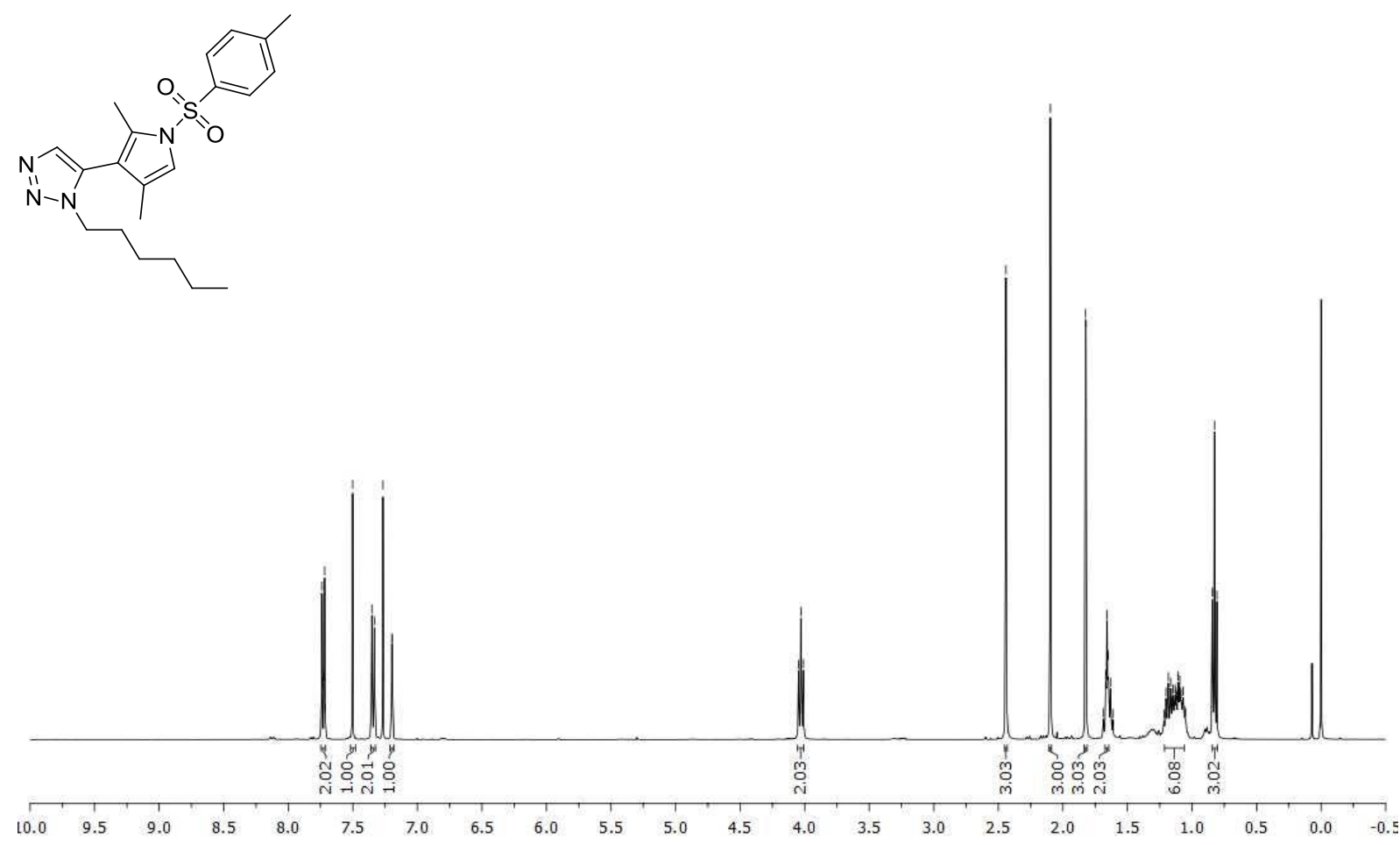

8a $\left({ }^{13} \mathrm{C}\left\{{ }^{1} \mathrm{H}\right\} \mathrm{NMR}, 101 \mathrm{MHz}, \mathrm{CDCl}_{3}\right)$

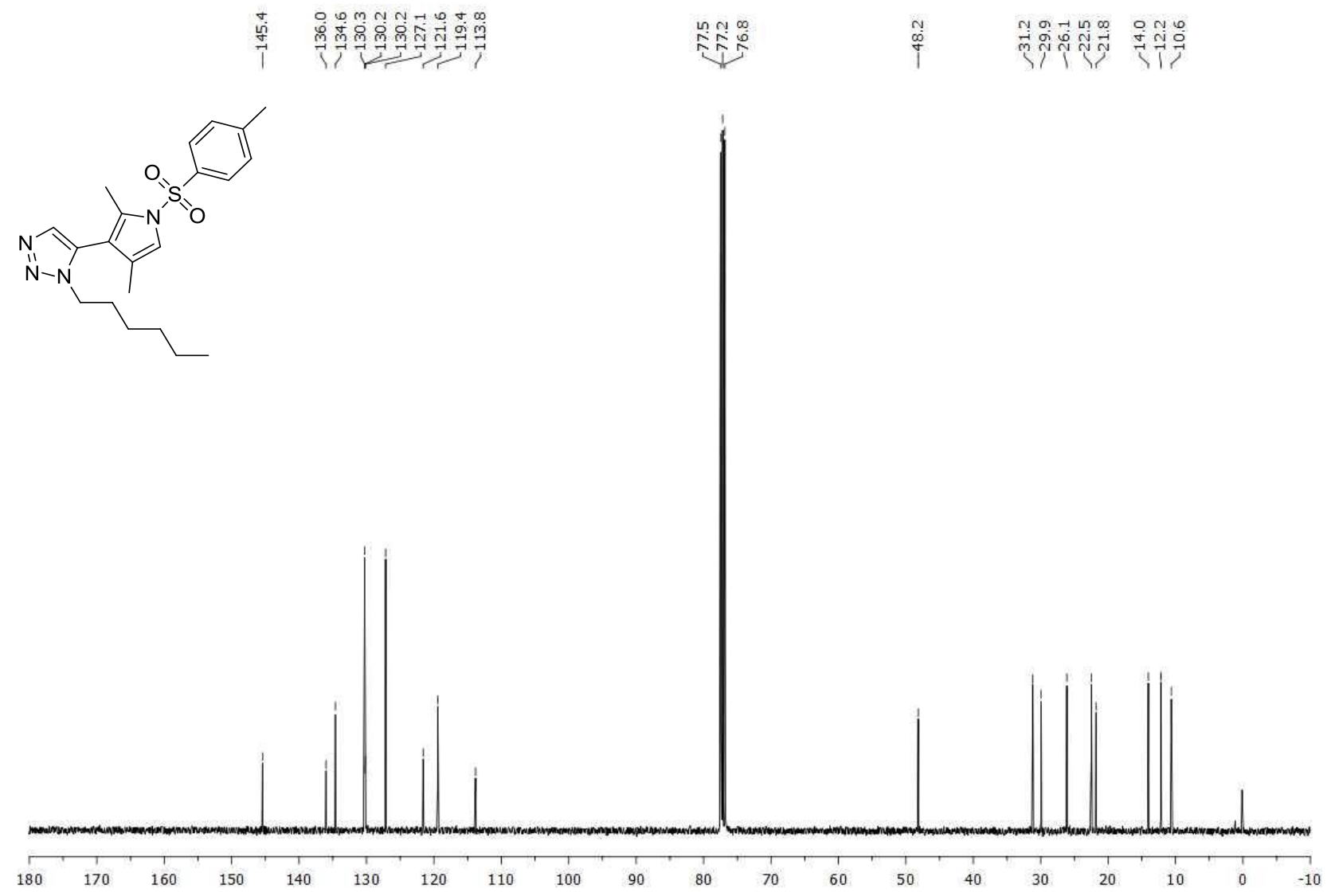


8b $\left({ }^{1} \mathrm{H}\right.$ NMR, $\left.300 \mathrm{MHz}, \mathrm{CDCl}_{3}\right)$

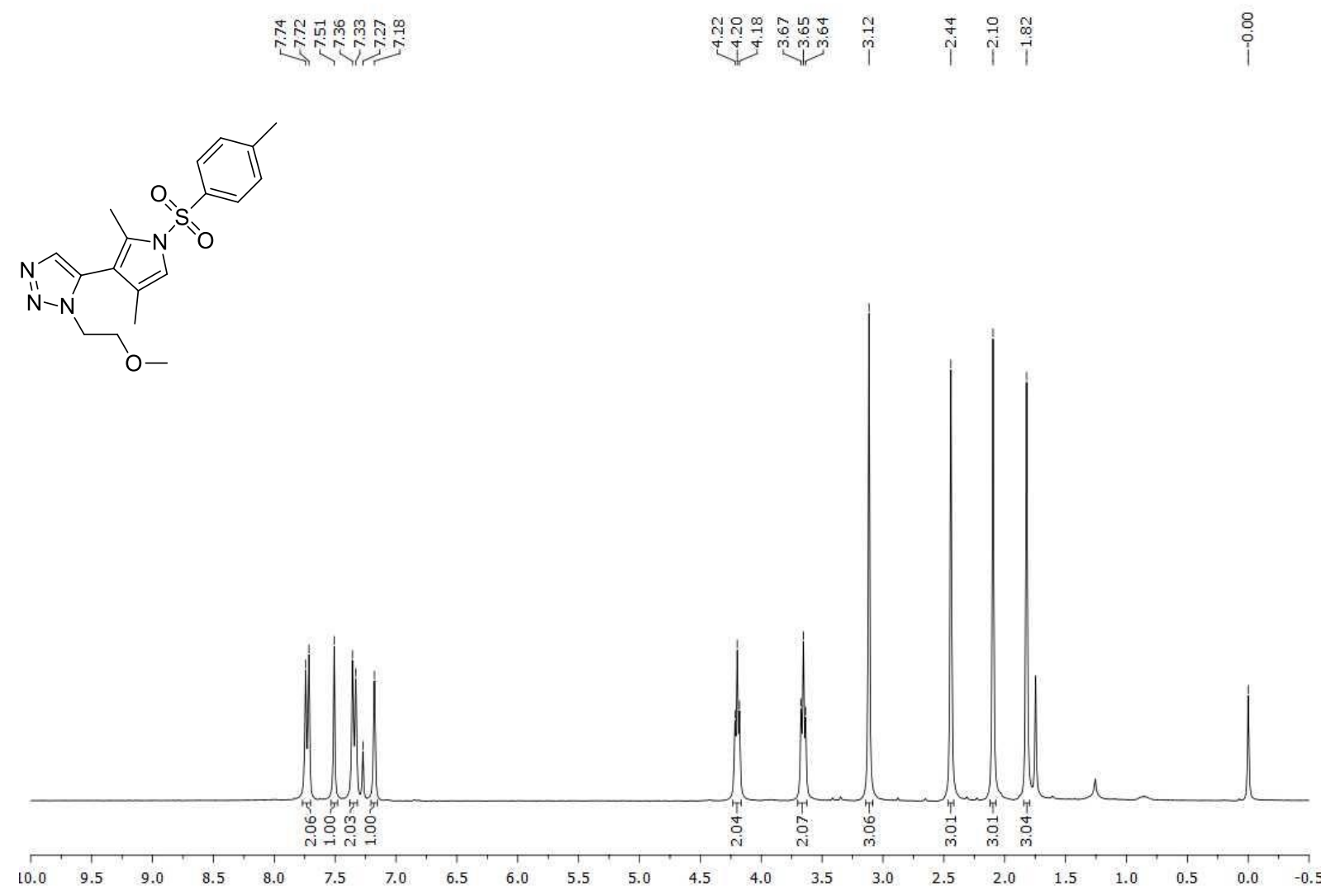

8b $\left({ }^{13} \mathrm{C}\left\{{ }^{1} \mathrm{H}\right\} \mathrm{NMR}, 75 \mathrm{MHz}, \mathrm{CDCl}_{3}\right)$

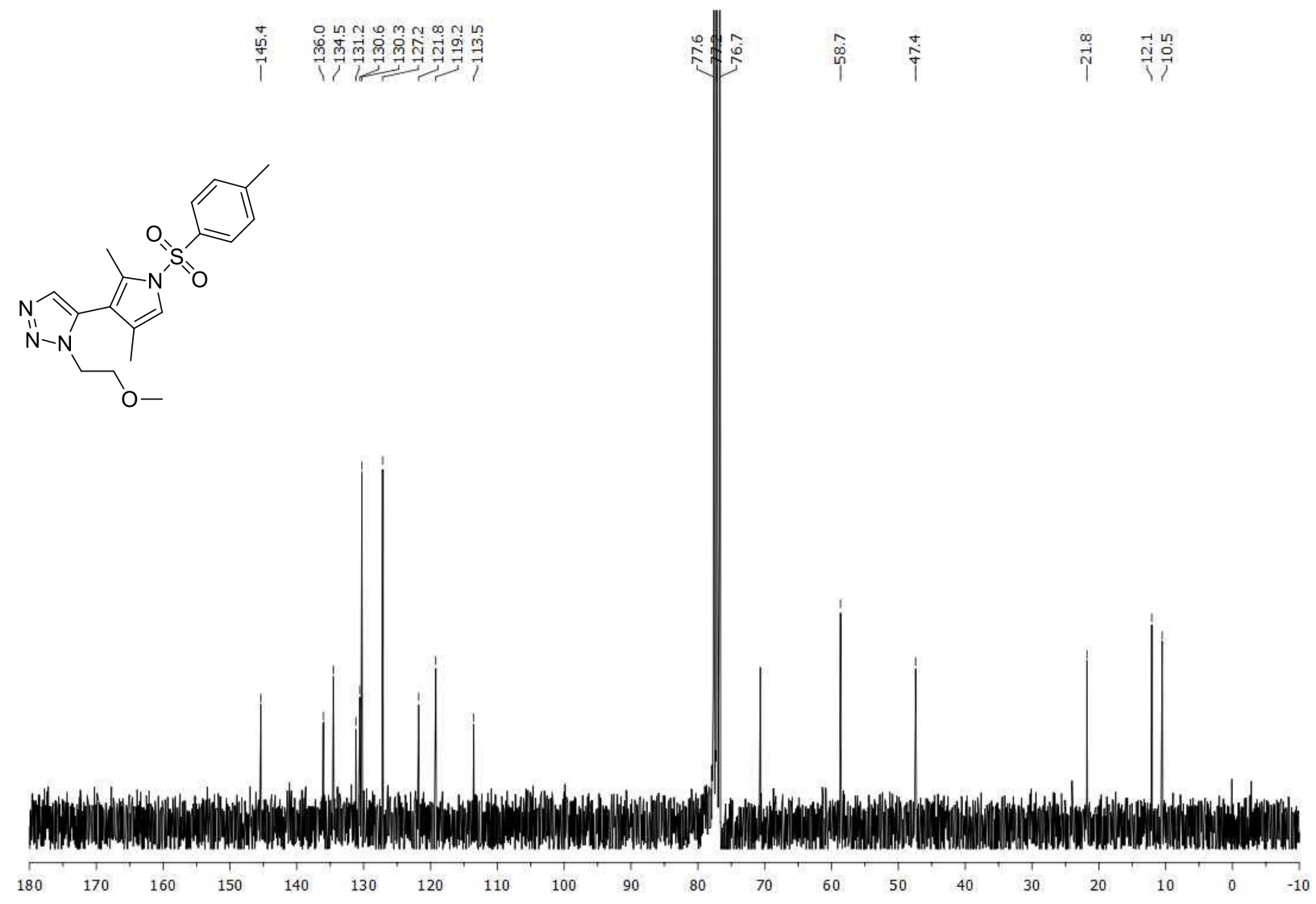


9a $\left({ }^{1} \mathrm{H} \mathrm{NMR}, 400 \mathrm{MHz}, \mathrm{CDCl}_{3}\right)$

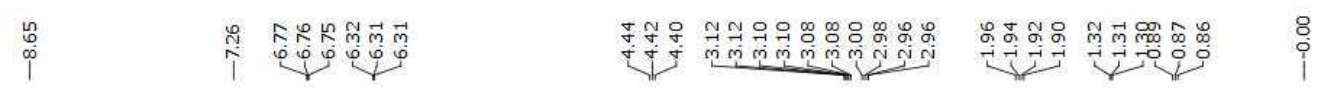<smiles>CCCCCCn1nnc2c1-c1cc[nH]c1CC2</smiles>

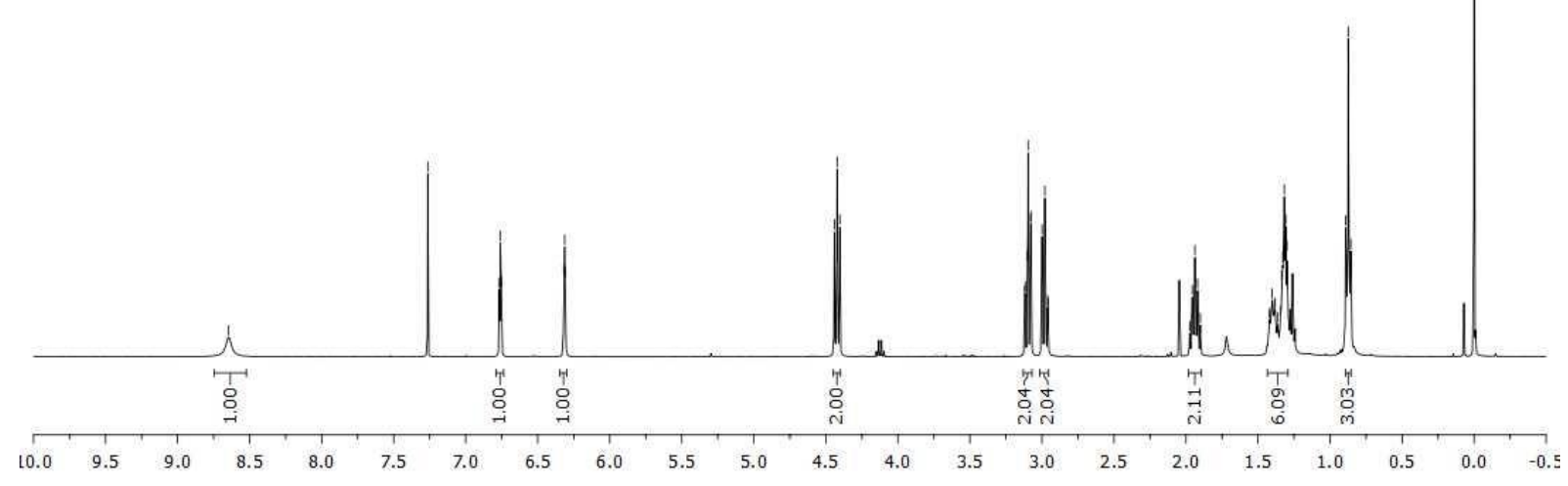

9a $\left({ }^{13} \mathrm{C}\left\{{ }^{1} \mathrm{H}\right\} \mathrm{NMR}, 101 \mathrm{MHz}, \mathrm{CDCl}_{3}\right)$
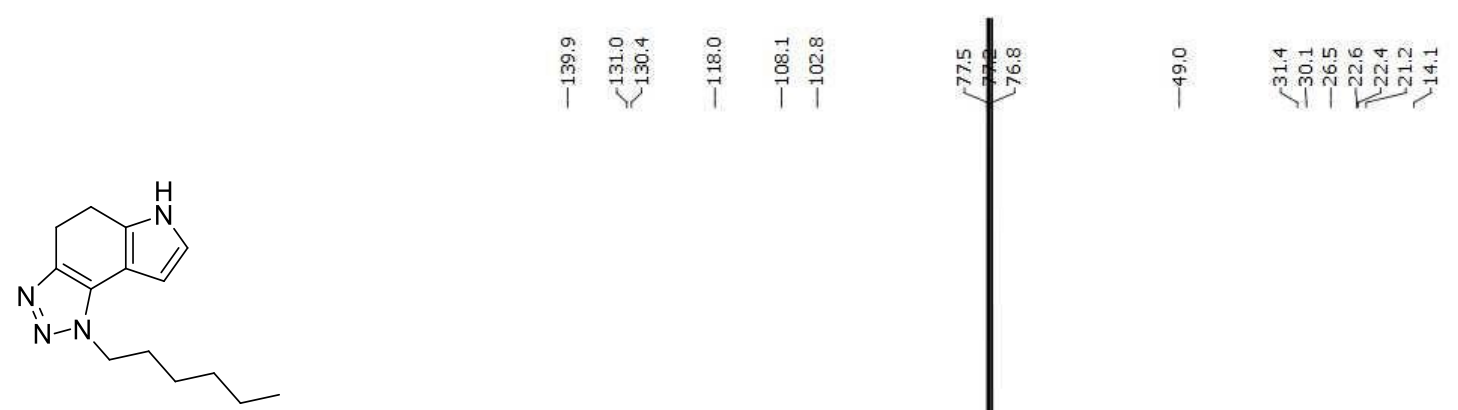

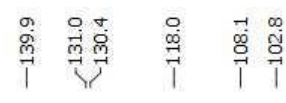

i m minn

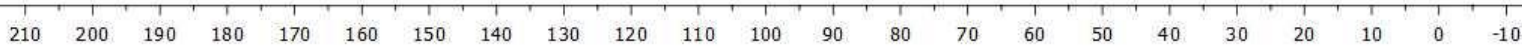


9b ( ${ }^{1} \mathrm{H}$ NMR, $\left.300 \mathrm{MHz}, \mathrm{CDCl}_{3}\right)$
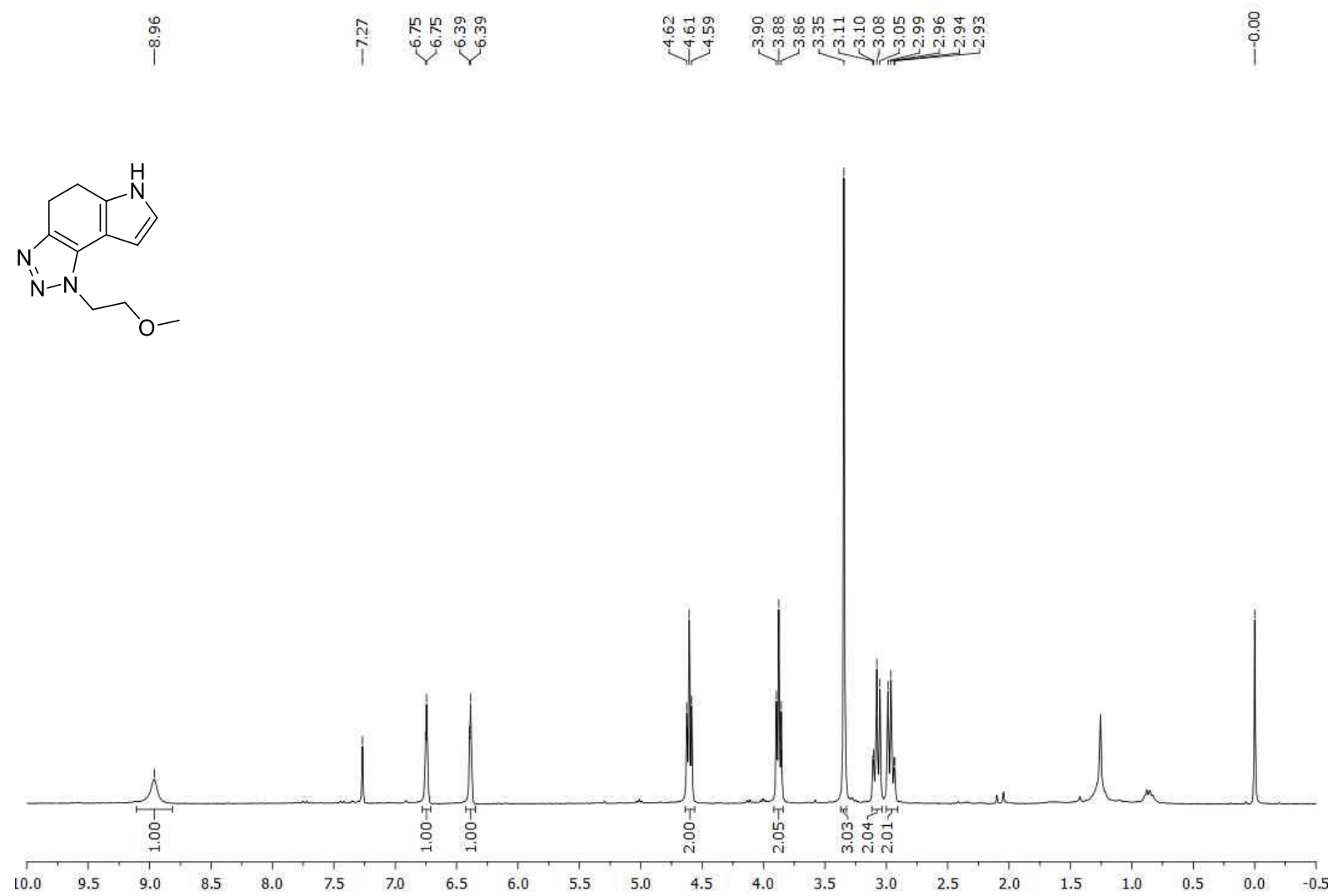

9b $\left({ }^{13} \mathrm{C}\left\{{ }^{1} \mathrm{H}\right\} \mathrm{NMR}, 75 \mathrm{MHz}, \mathrm{CDCl}_{3}\right)$

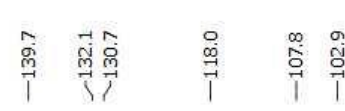

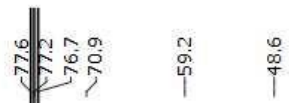

$\stackrel{m}{N} \underset{N}{N}$
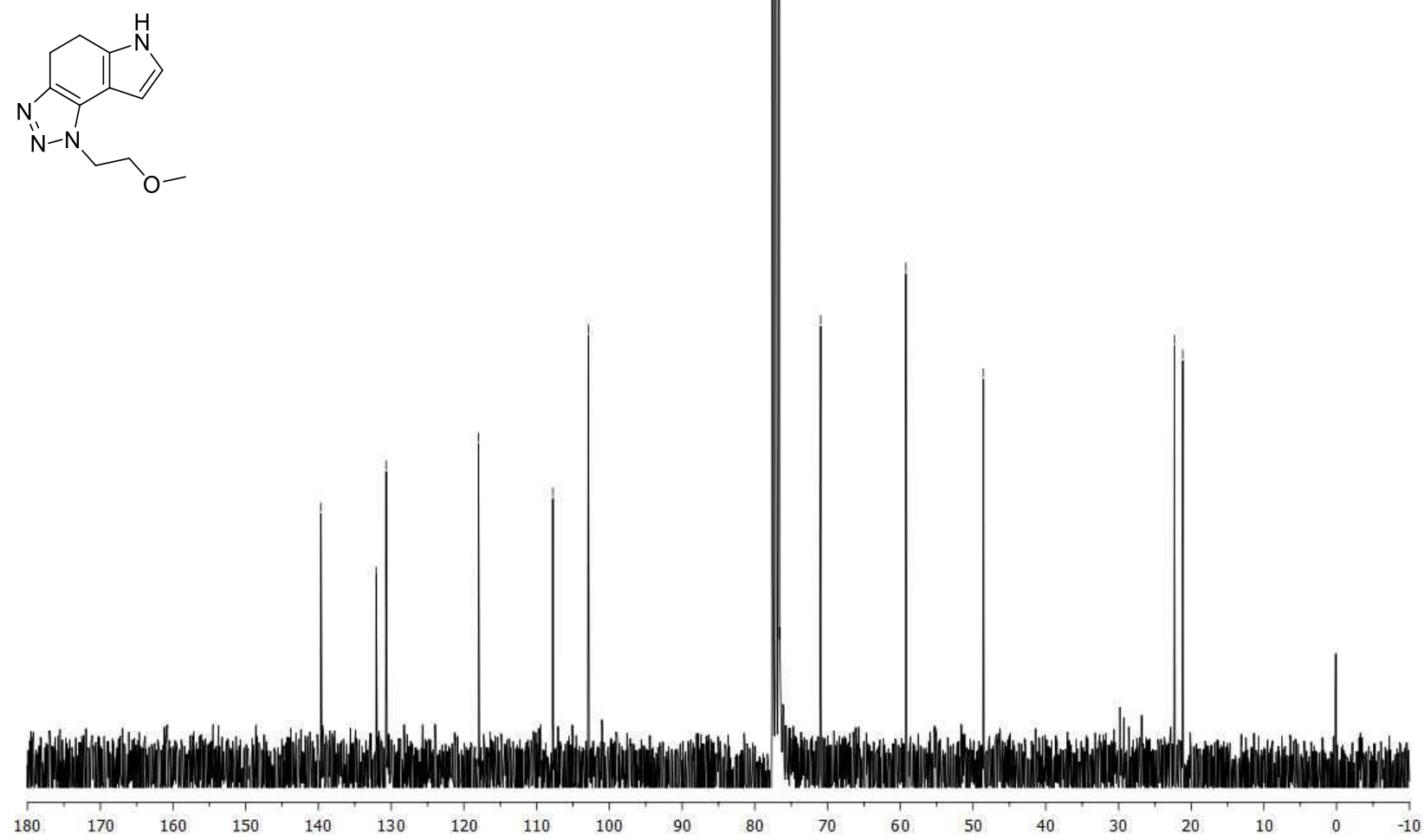
10a $\left({ }^{1} \mathrm{H} \mathrm{NMR}, 400 \mathrm{MHz}, \mathrm{CDCl}_{3}\right)$

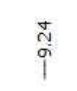

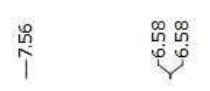

东正告

군

$\stackrel{\circ}{i}$
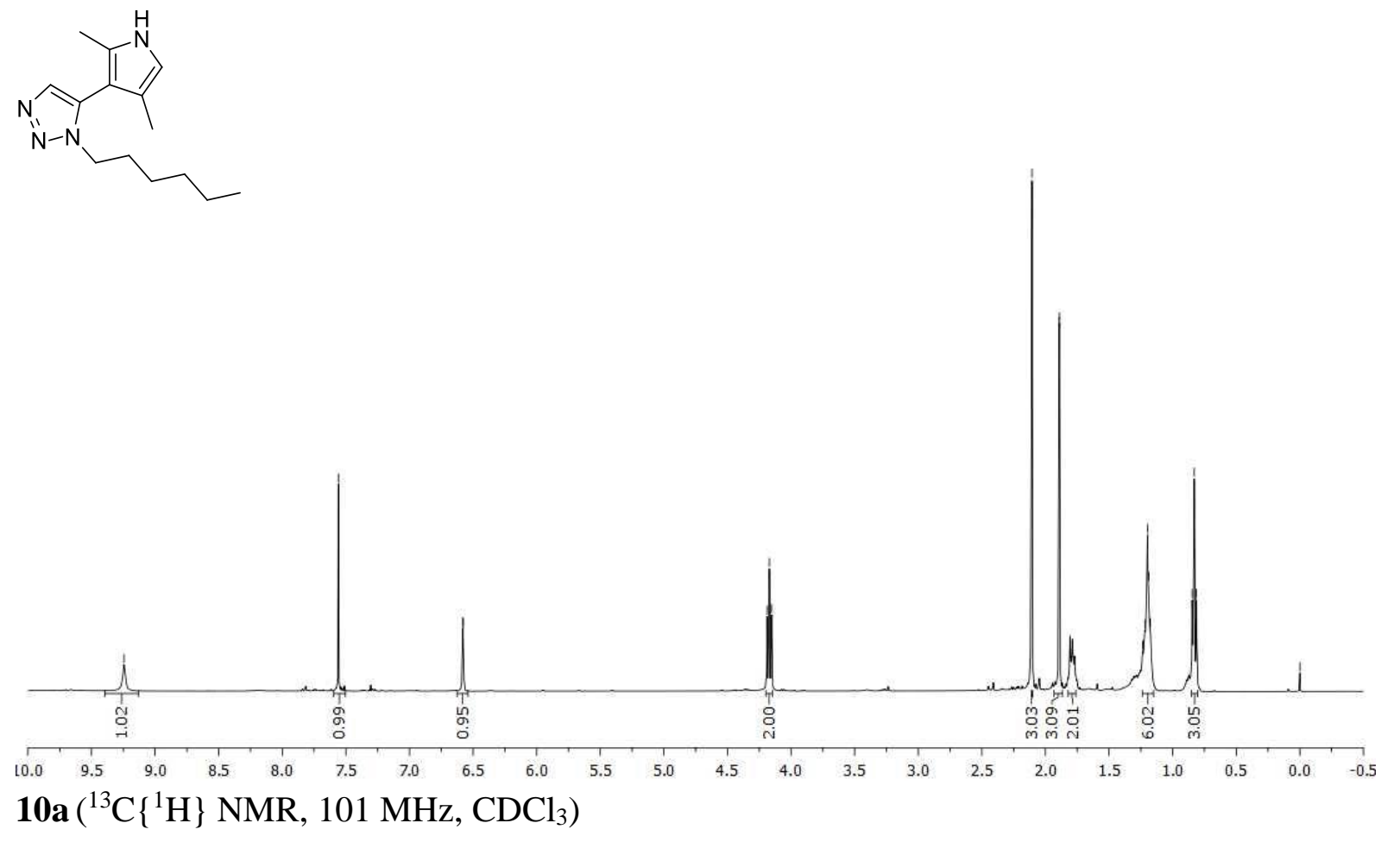

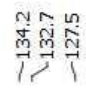

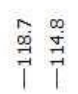

$\overrightarrow{\mathrm{i}}$

$\sqrt{n-1}$

$\stackrel{8}{\stackrel{9}{9}}$

구ํ음ำำำ

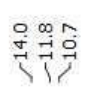
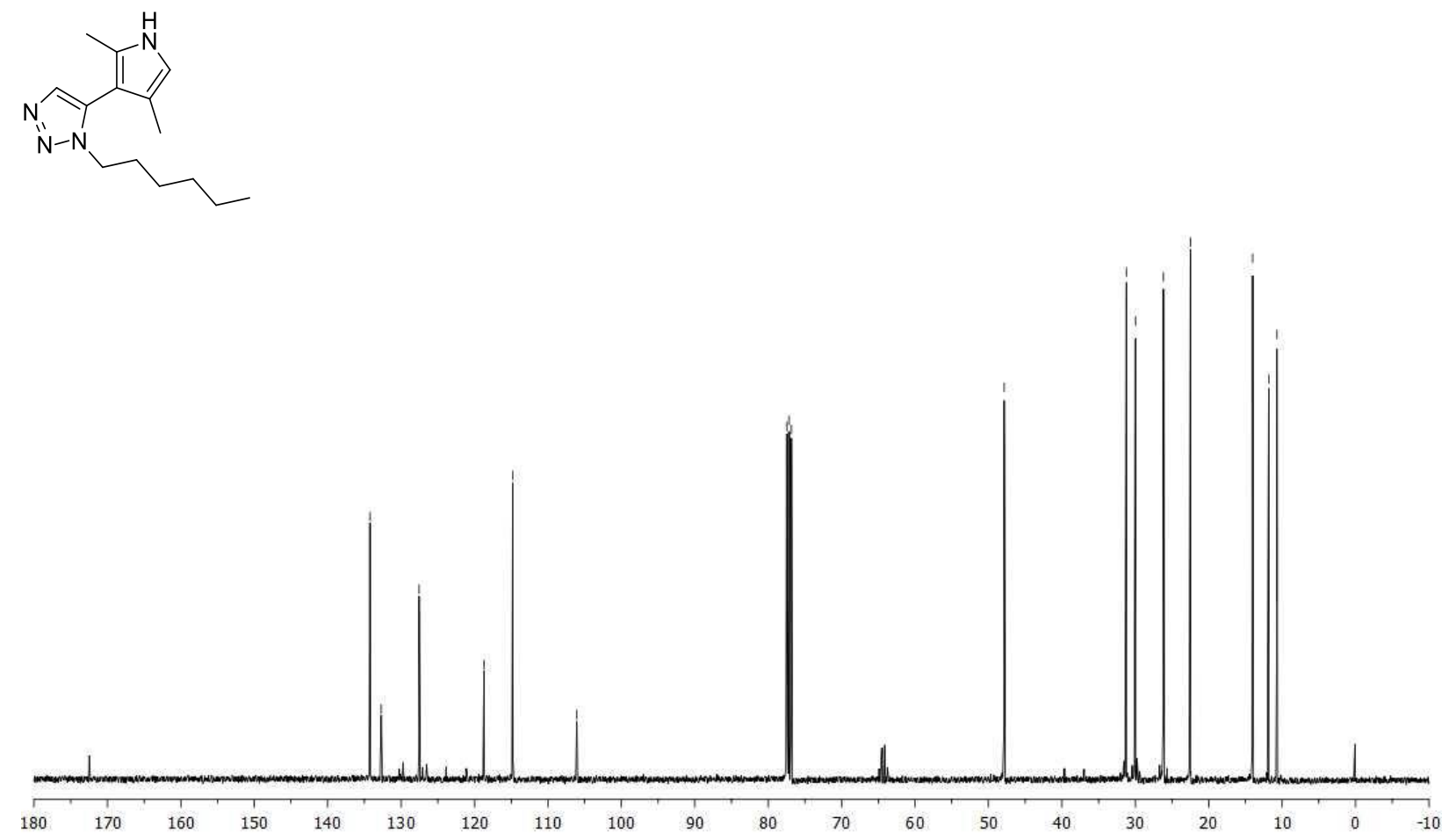

S9 
10b $\left({ }^{1} \mathrm{H} \mathrm{NMR}, 400 \mathrm{MHz}, \mathrm{CDCl}_{3}\right)$

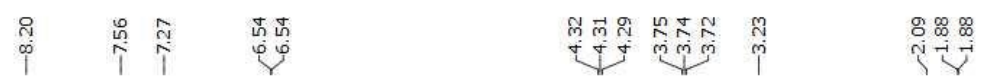<smiles>COCCn1nncc1-c1c(C)c[nH]c1C</smiles>

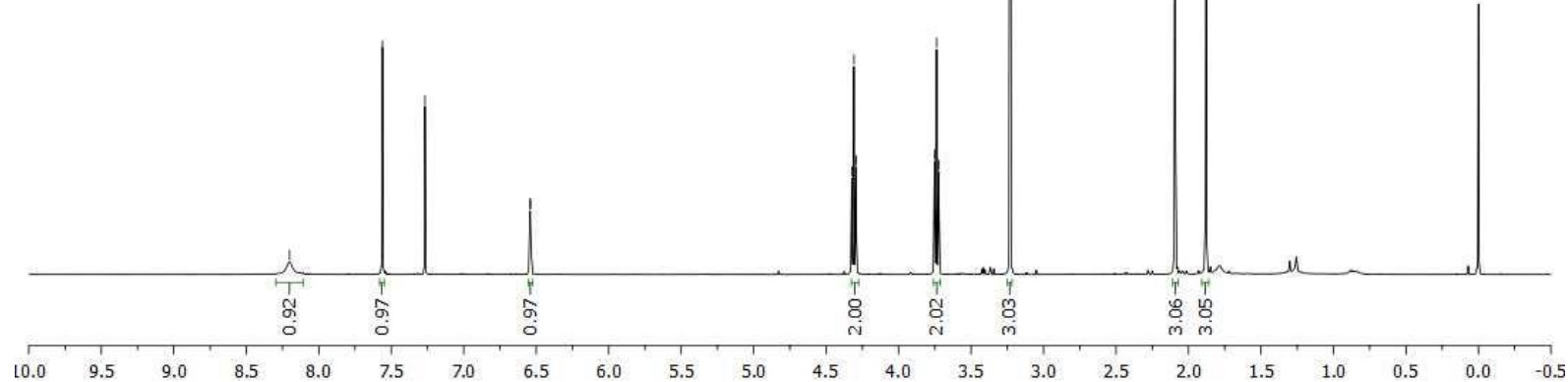

10b $\left({ }^{13} \mathrm{C}\left\{{ }^{1} \mathrm{H}\right\} \mathrm{NMR}, 75 \mathrm{MHz}, \mathrm{CDCl}_{3}\right)$

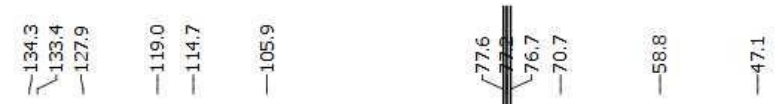<smiles>COCCn1nncc1-c1c(C)c[nH]c1C</smiles>

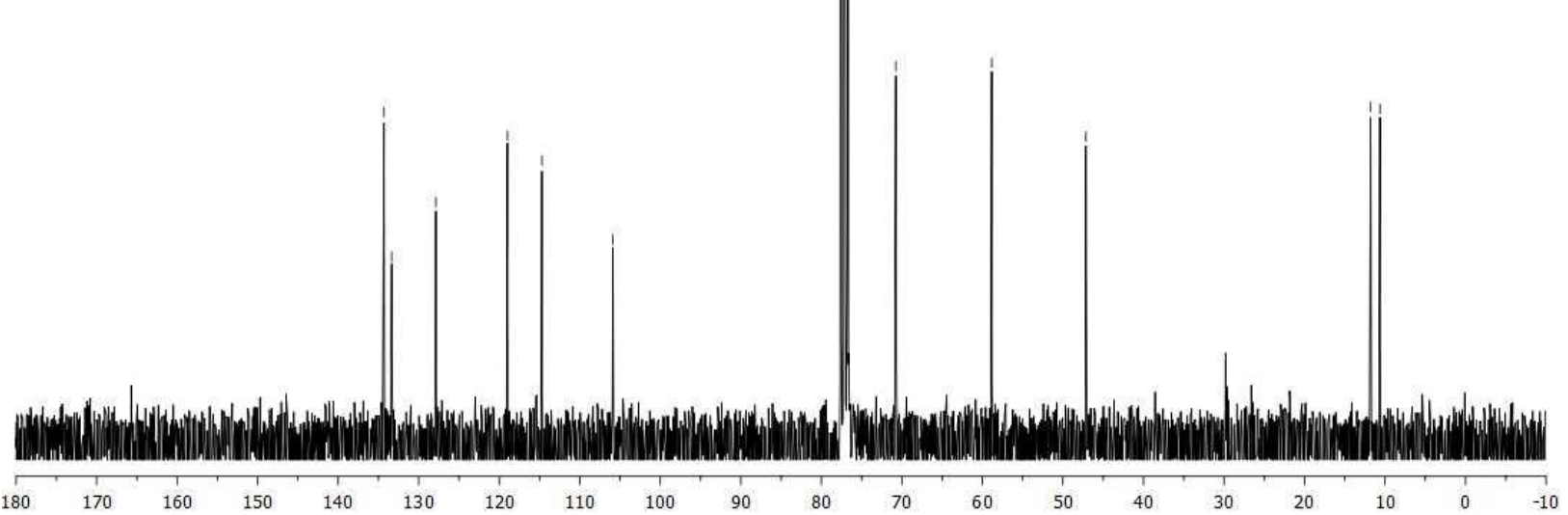


11a $\left({ }^{1} \mathrm{H} \mathrm{NMR}, 300 \mathrm{MHz}, \mathrm{CDCl} 3\right)$

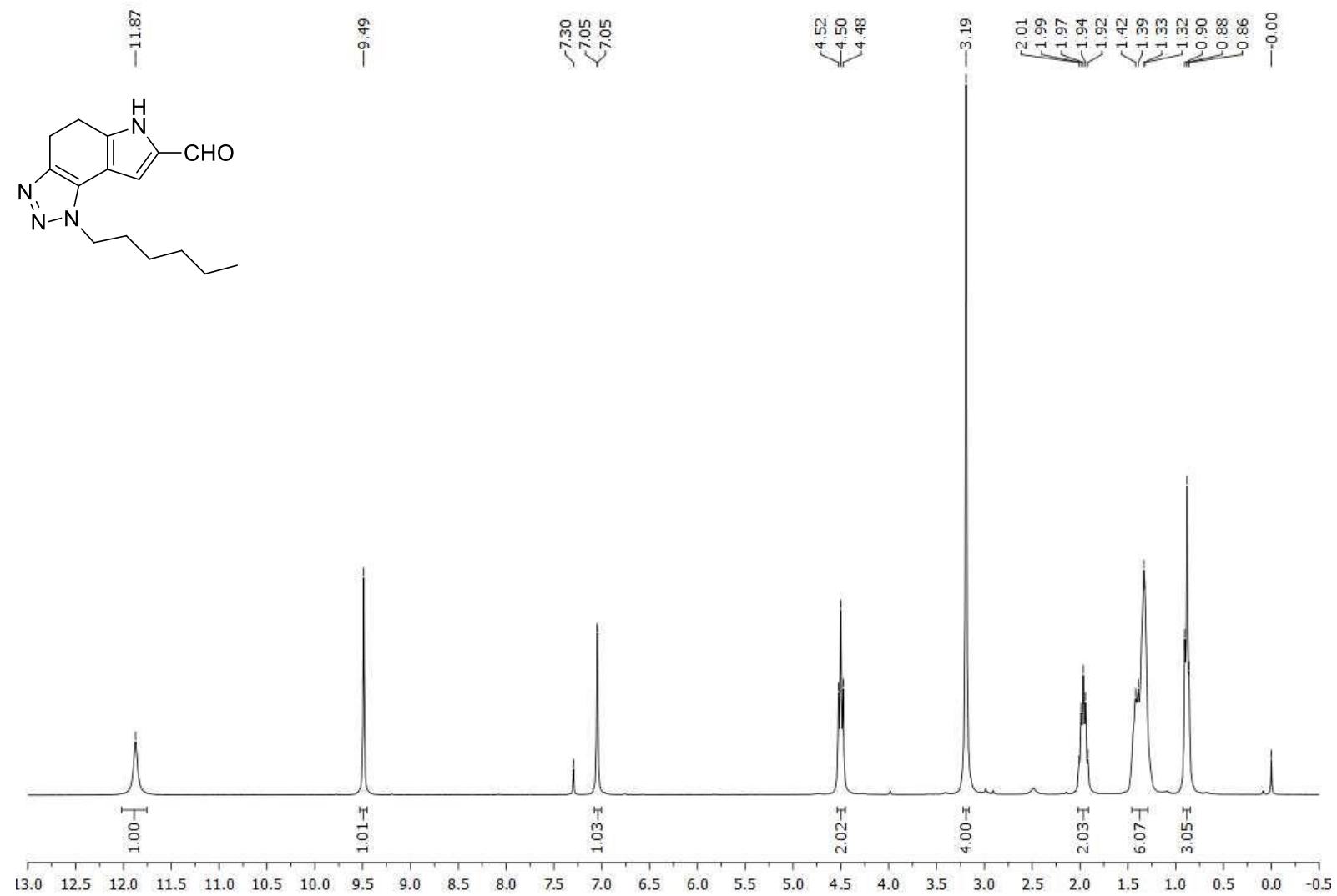

11a $\left({ }^{13} \mathrm{C}\left\{{ }^{1} \mathrm{H}\right\} \mathrm{NMR}, 75 \mathrm{MHz}, \mathrm{CDCl}_{3}\right)$
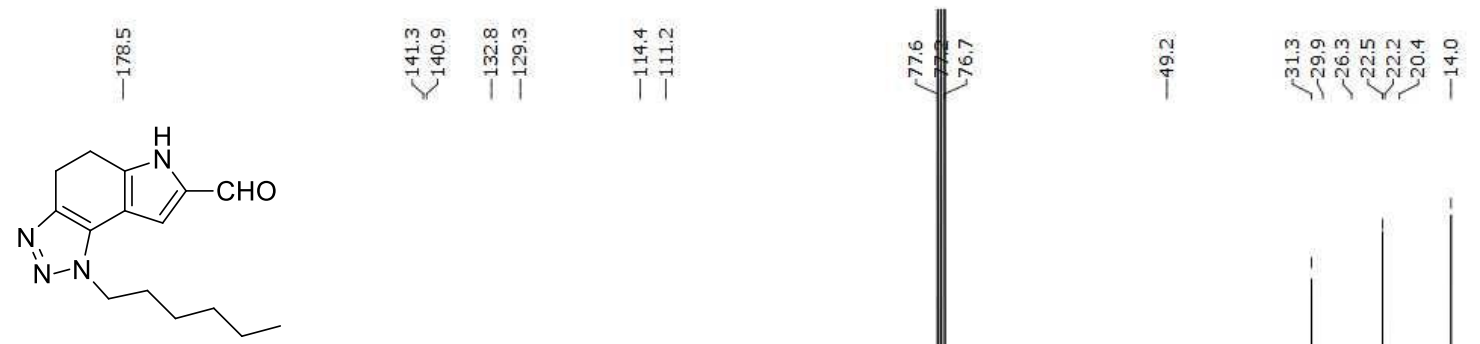

市 
11b $\left({ }^{1} \mathrm{H}\right.$ NMR, $400 \mathrm{MHz}$, DMSO- $\left.d_{6}\right)$

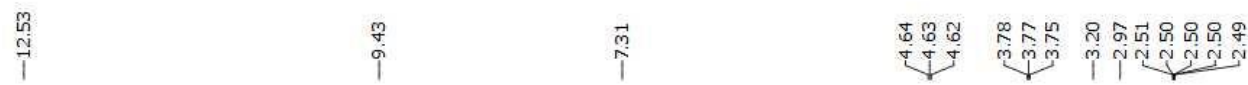<smiles>COCCn1nnc2c1-c1cc(C=O)[nH]c1CC2</smiles>

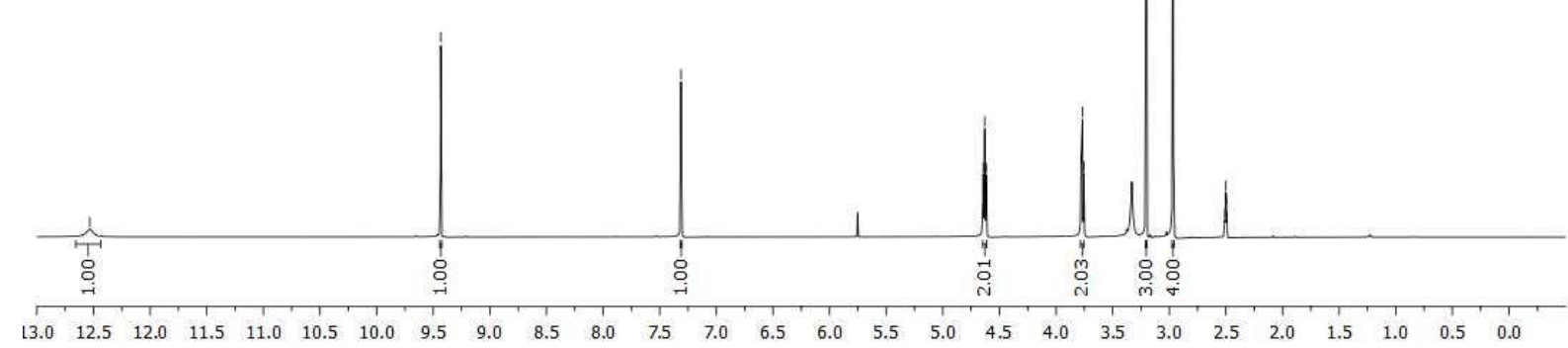

11b $\left({ }^{13} \mathrm{C}\left\{{ }^{1} \mathrm{H}\right\}\right.$ NMR, $101 \mathrm{MHz}$, DMSO- $\left.d_{6}\right)$

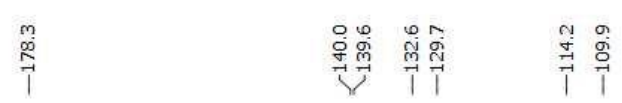<smiles>COCCn1nnc2c1C1=C(CC2)CCc2[nH]c(C=O)cc21</smiles>

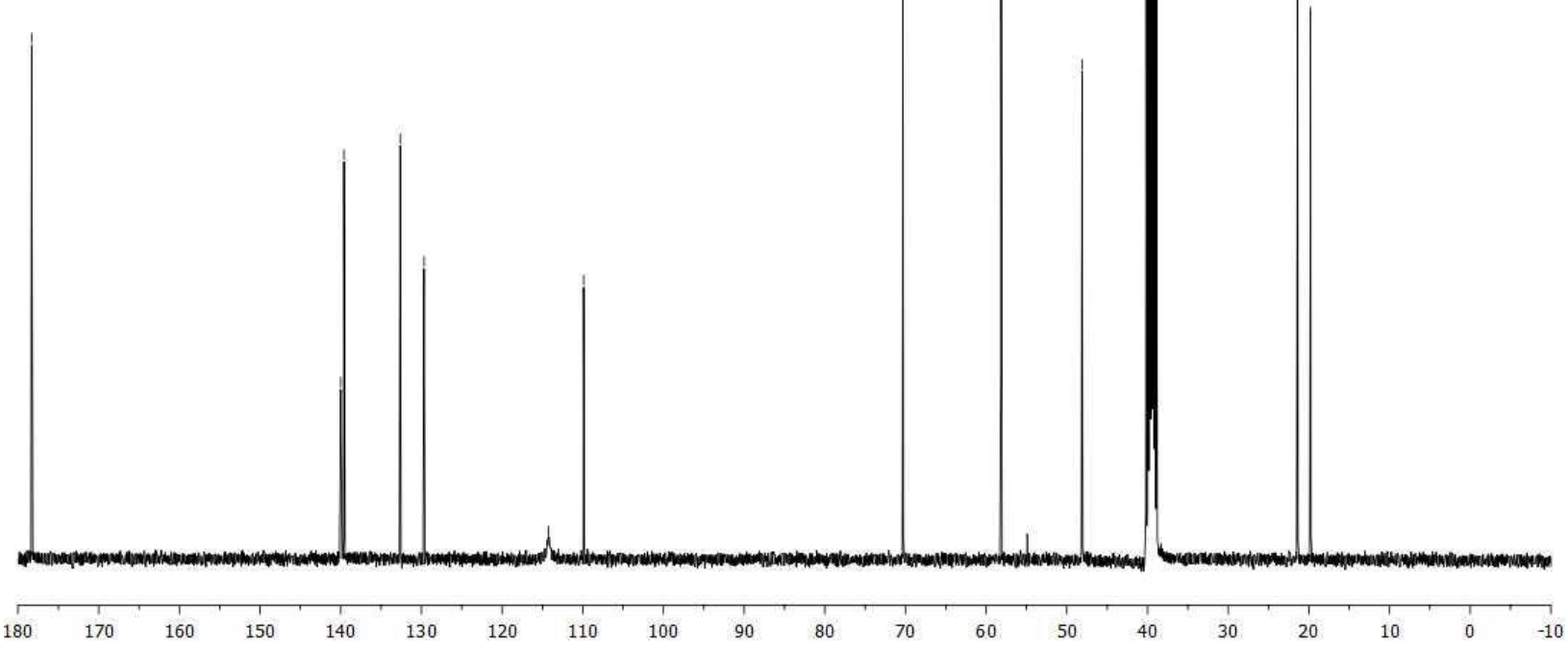


12a $\left({ }^{1} \mathrm{H} \mathrm{NMR}, 400 \mathrm{MHz}, \mathrm{CDCl}_{3}\right)$

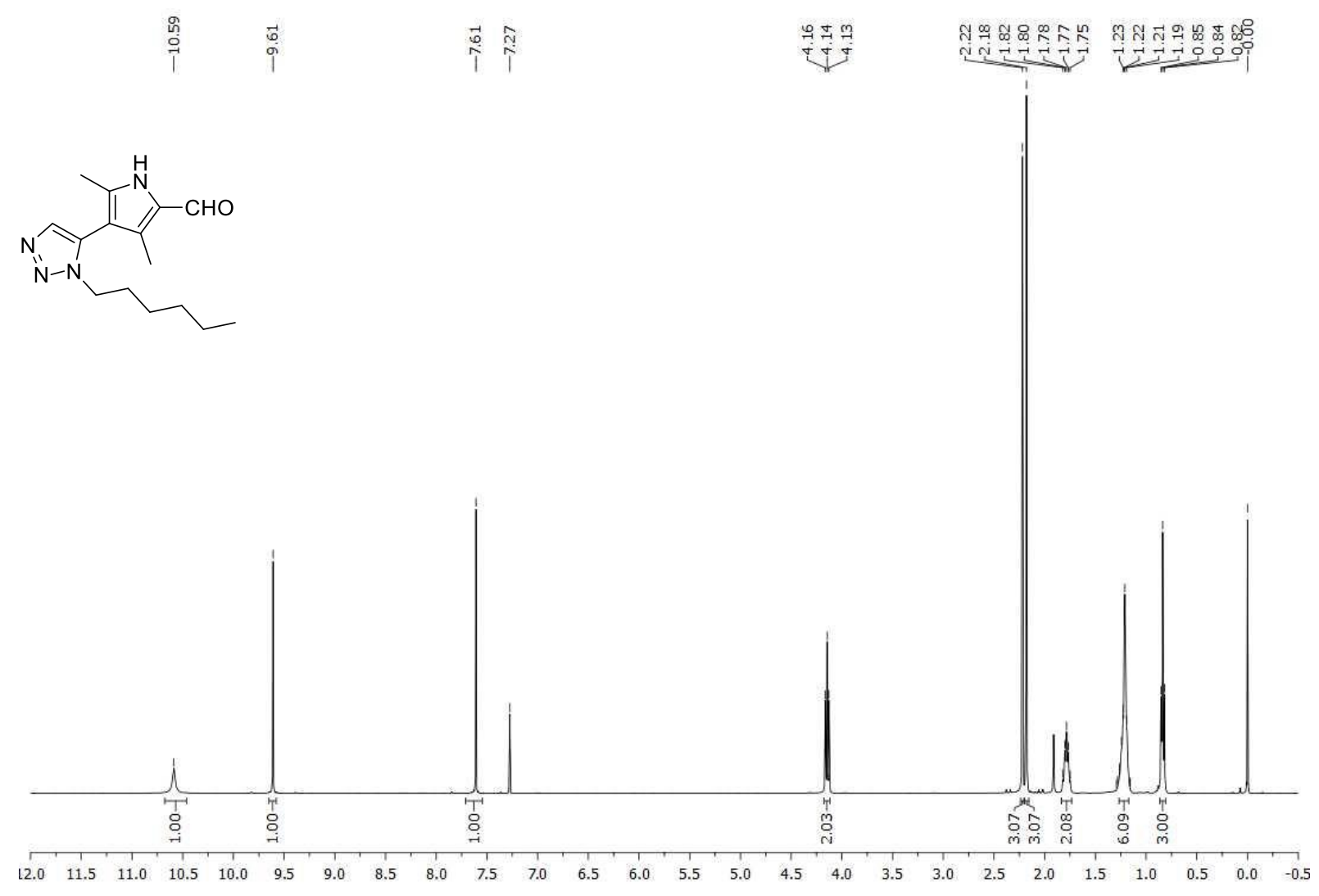

12a $\left({ }^{13} \mathrm{C}\left\{{ }^{1} \mathrm{H}\right\} \mathrm{NMR}, 101 \mathrm{MHz}, \mathrm{CDCl}_{3}\right)$

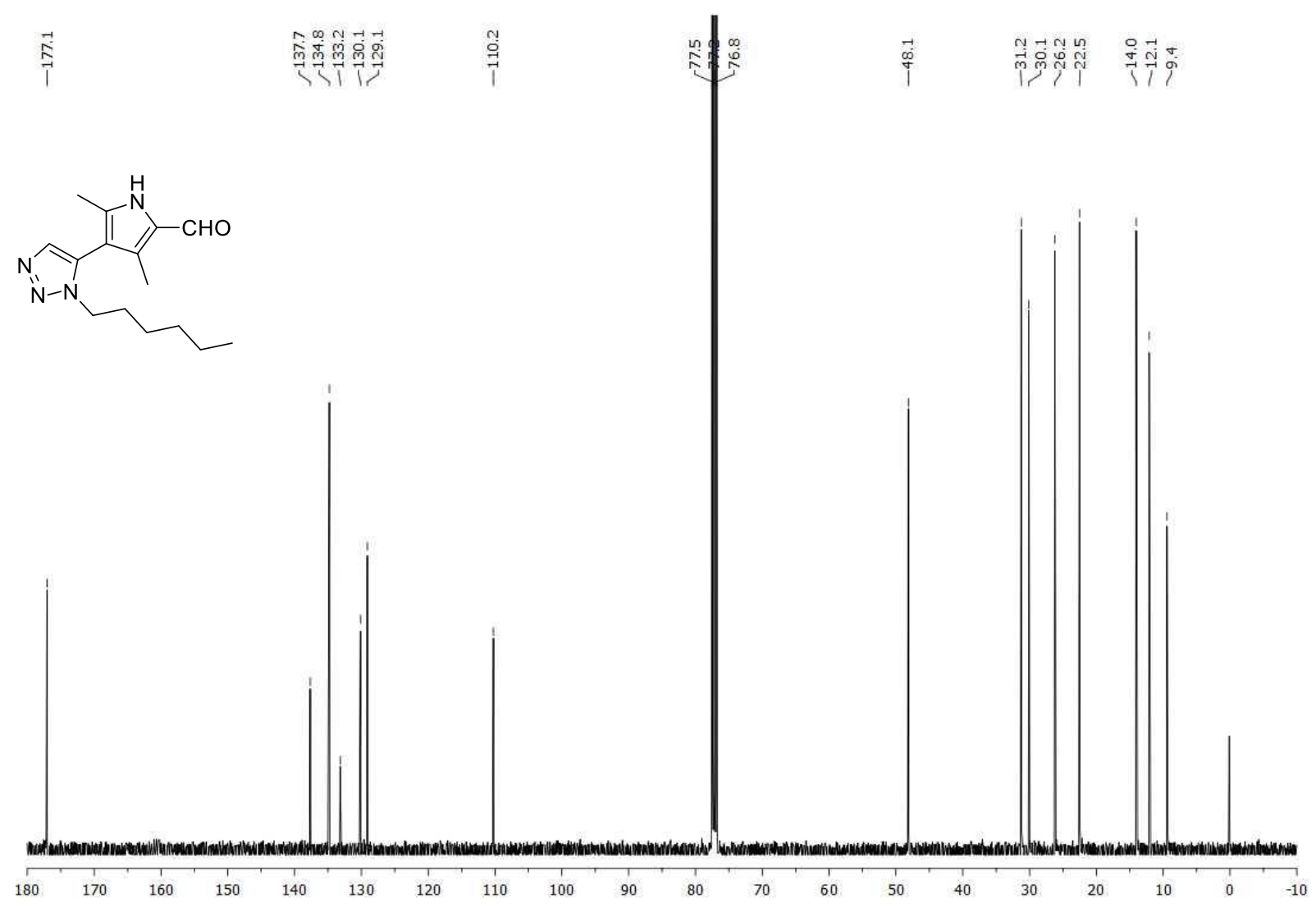


12b $\left({ }^{1} \mathrm{H} \mathrm{NMR,} 300 \mathrm{MHz}, \mathrm{CDCl}_{3}\right)$
电
$\stackrel{\overrightarrow{0}}{i} \stackrel{N}{i}$

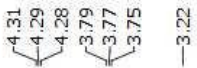
ชิ่<smiles>COCCn1nncc1-c1c(C)[nH]c(C=O)c1C</smiles>

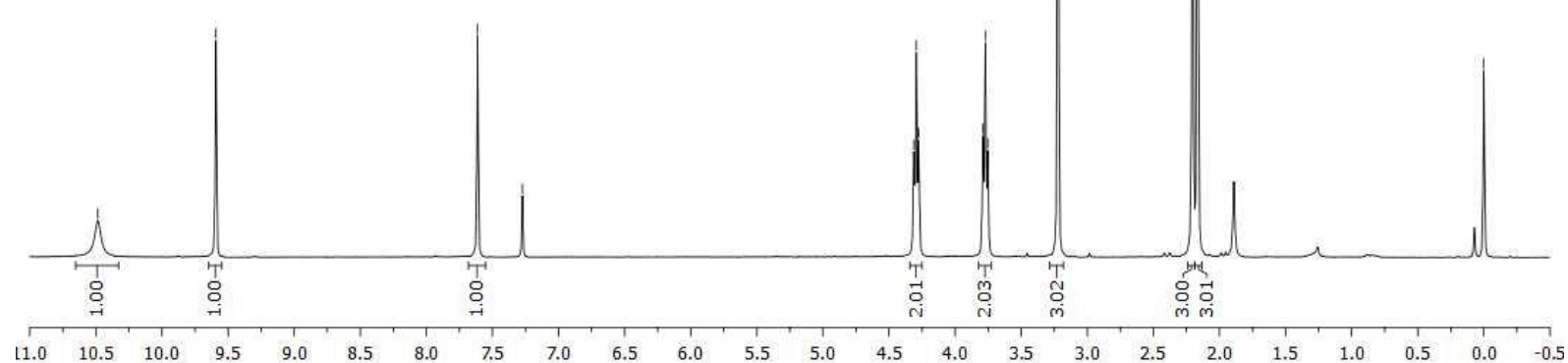

12b $\left({ }^{13} \mathrm{C}\left\{{ }^{1} \mathrm{H}\right\} \mathrm{NMR}, 75 \mathrm{MHz}, \mathrm{CDCl}_{3}\right)$
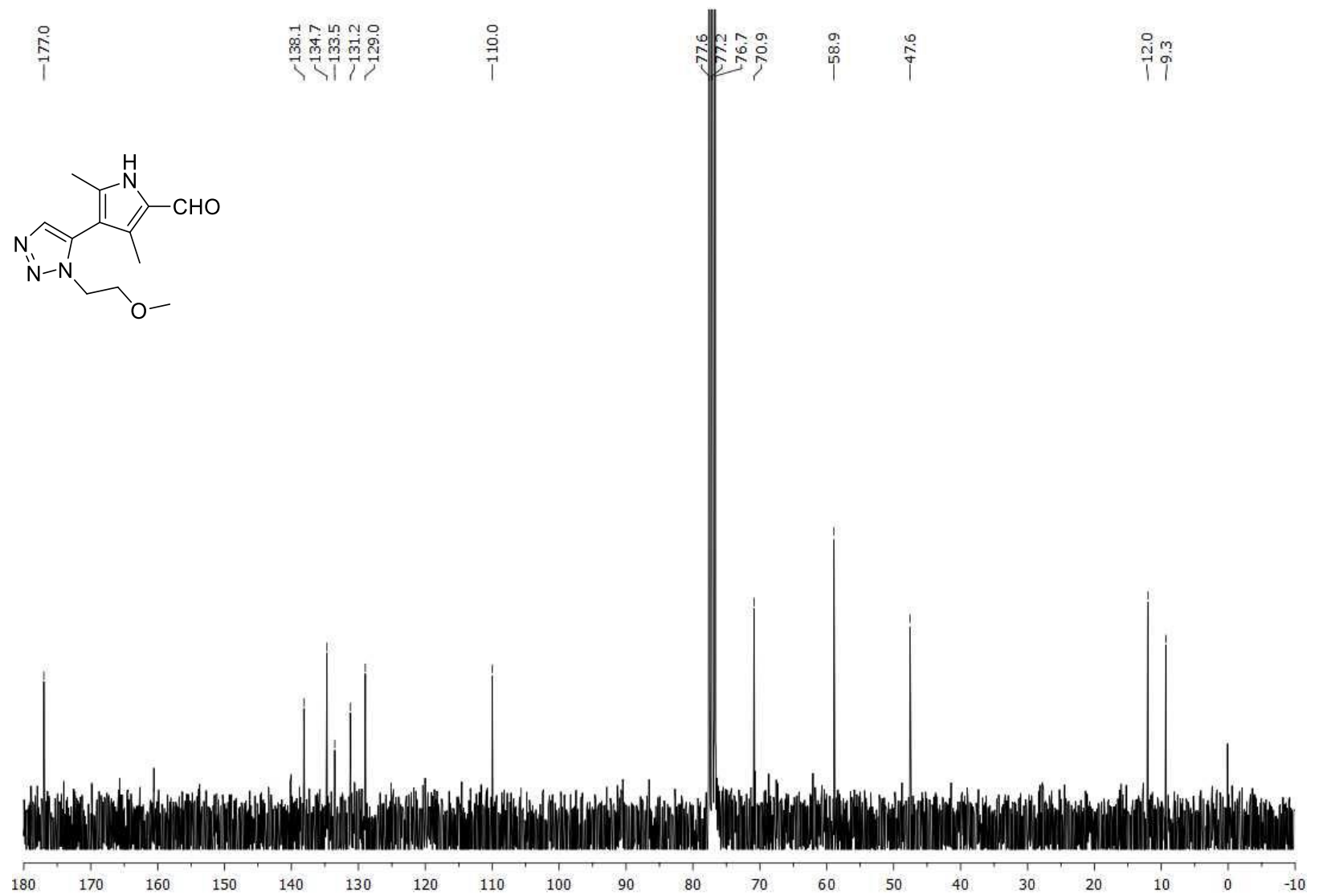
13a $\left({ }^{1} \mathrm{H}\right.$ NMR, $\left.400 \mathrm{MHz}, \mathrm{DMSO}-d_{6}\right)$

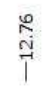
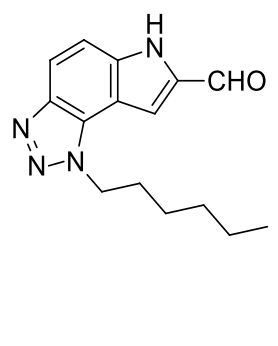

$\stackrel{\substack{\infty \\ i}}{\infty}$

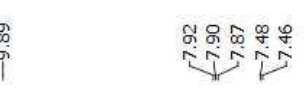

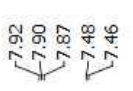

露

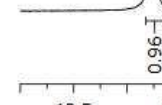

13a $\left({ }^{13} \mathrm{C}\left\{{ }^{1} \mathrm{H}\right\}\right.$ NMR, $\left.101 \mathrm{MHz}, \mathrm{DMSO}-d_{6}\right)$

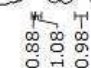

要
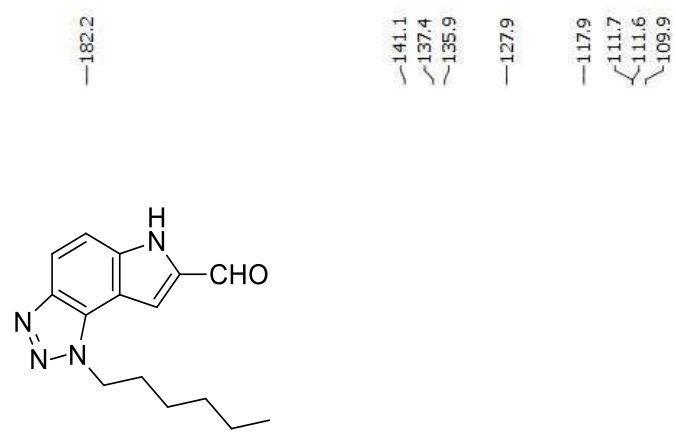
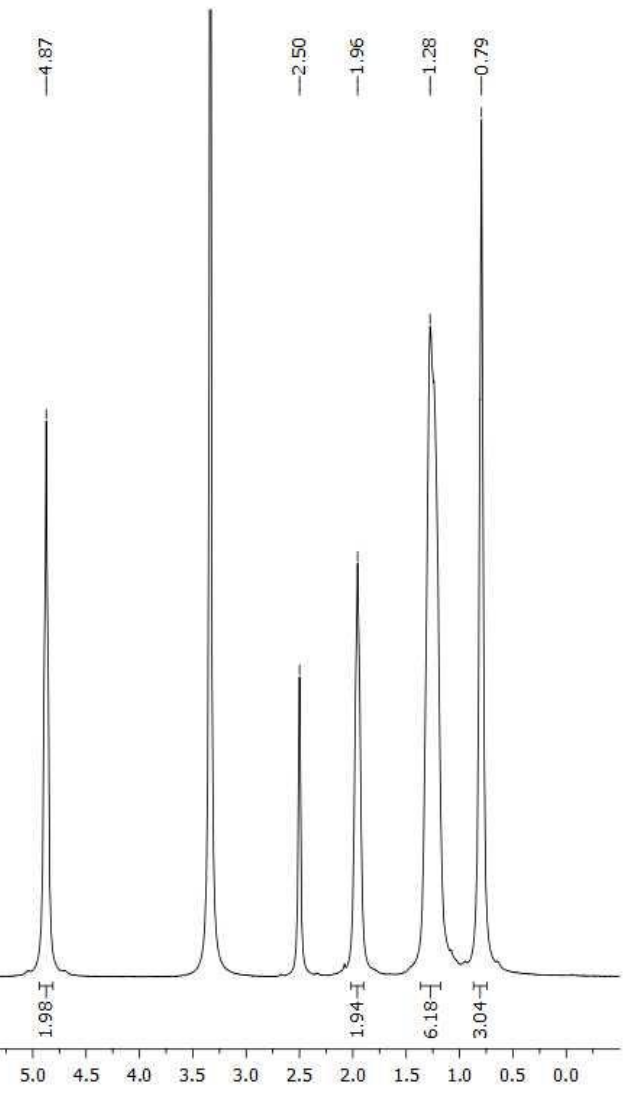
15aa' $\left({ }^{1} \mathrm{H} \mathrm{NMR}, 400 \mathrm{MHz}, \mathrm{CDCl}_{3}\right)$
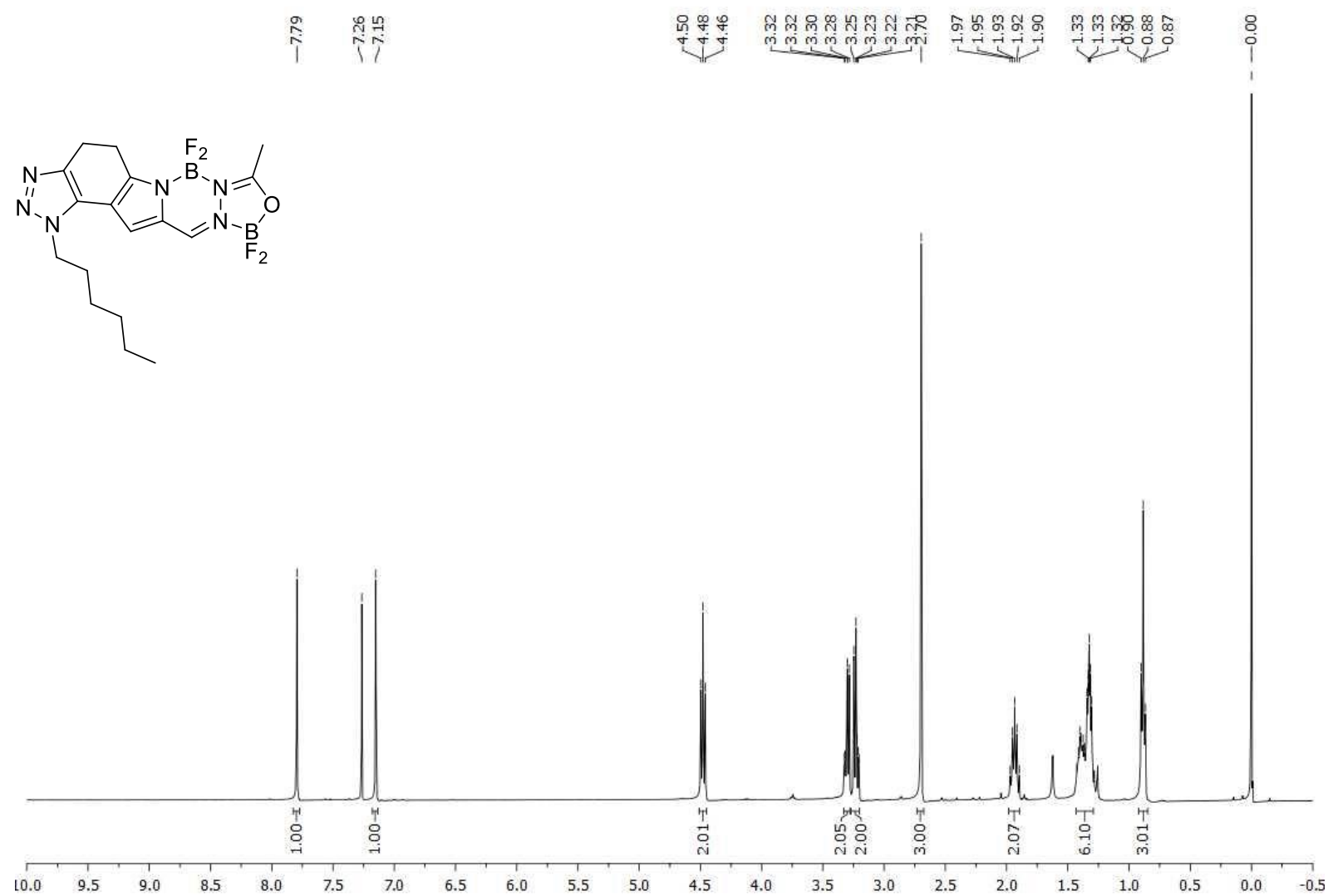

15aa' $\left({ }^{13} \mathrm{C}\left\{{ }^{1} \mathrm{H}\right\}\right.$ NMR, $\left.101 \mathrm{MHz}, \mathrm{CDCl}_{3}\right)$

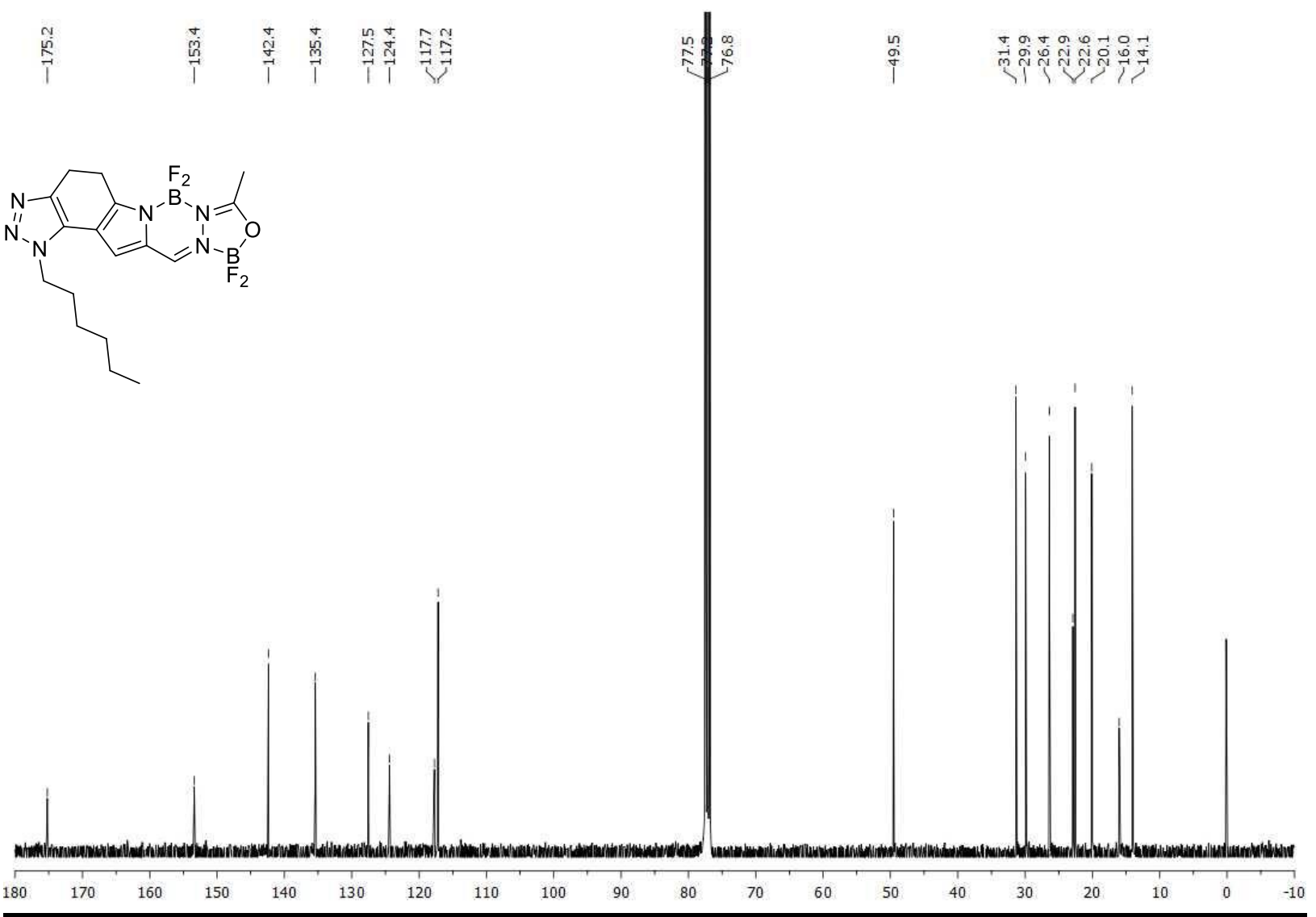


15ab' ( $\left.{ }^{1} \mathrm{H} \mathrm{NMR}, 300 \mathrm{MHz}, \mathrm{CDCl}_{3}\right)$
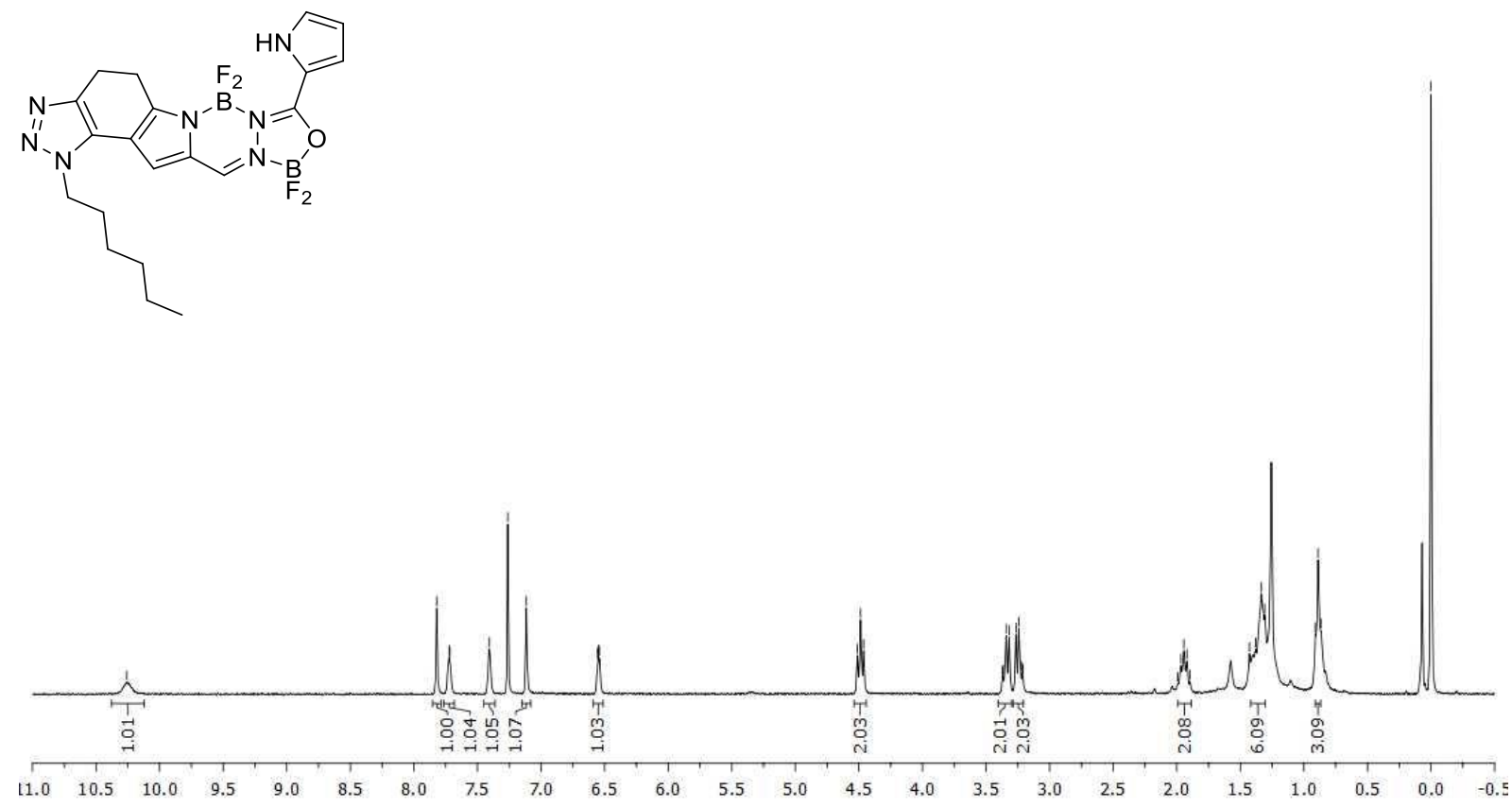

15ab' $\left({ }^{13} \mathrm{C}\left\{{ }^{1} \mathrm{H}\right\} \mathrm{NMR}, 151 \mathrm{MHz}, \mathrm{CDCl}_{3}\right)$

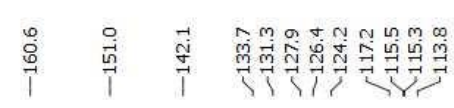

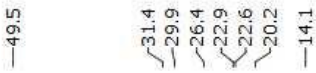
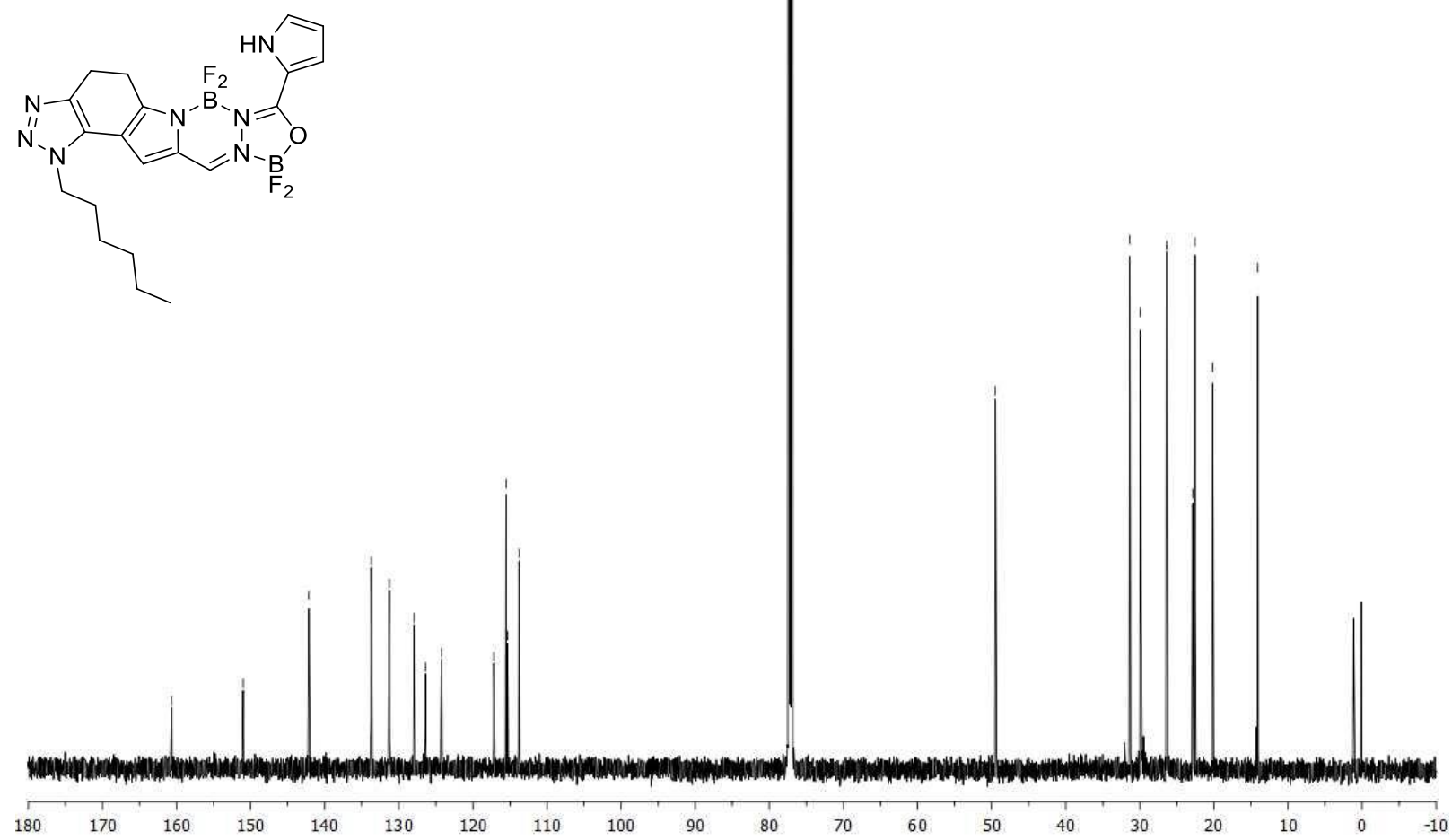
15ac' $\left({ }^{1} \mathrm{H} \mathrm{NMR}, 300 \mathrm{MHz}, \mathrm{CDCl}_{3}\right)$
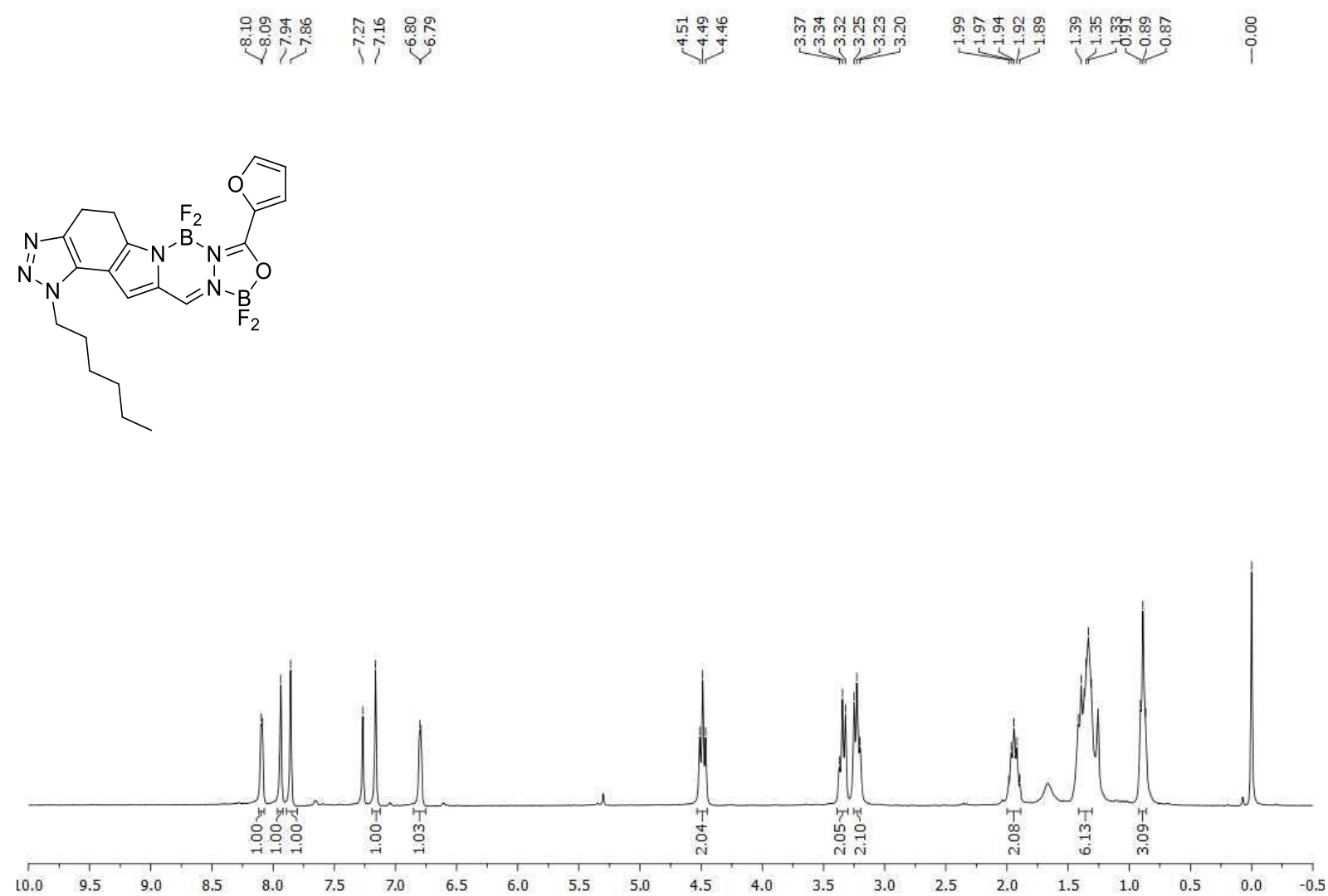

15ac' $\left({ }^{13} \mathrm{C}\left\{{ }^{1} \mathrm{H}\right\}\right.$ NMR, $\left.151 \mathrm{MHz}, \mathrm{CDCl}_{3}\right)$

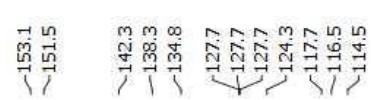

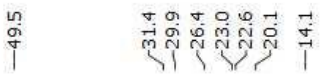
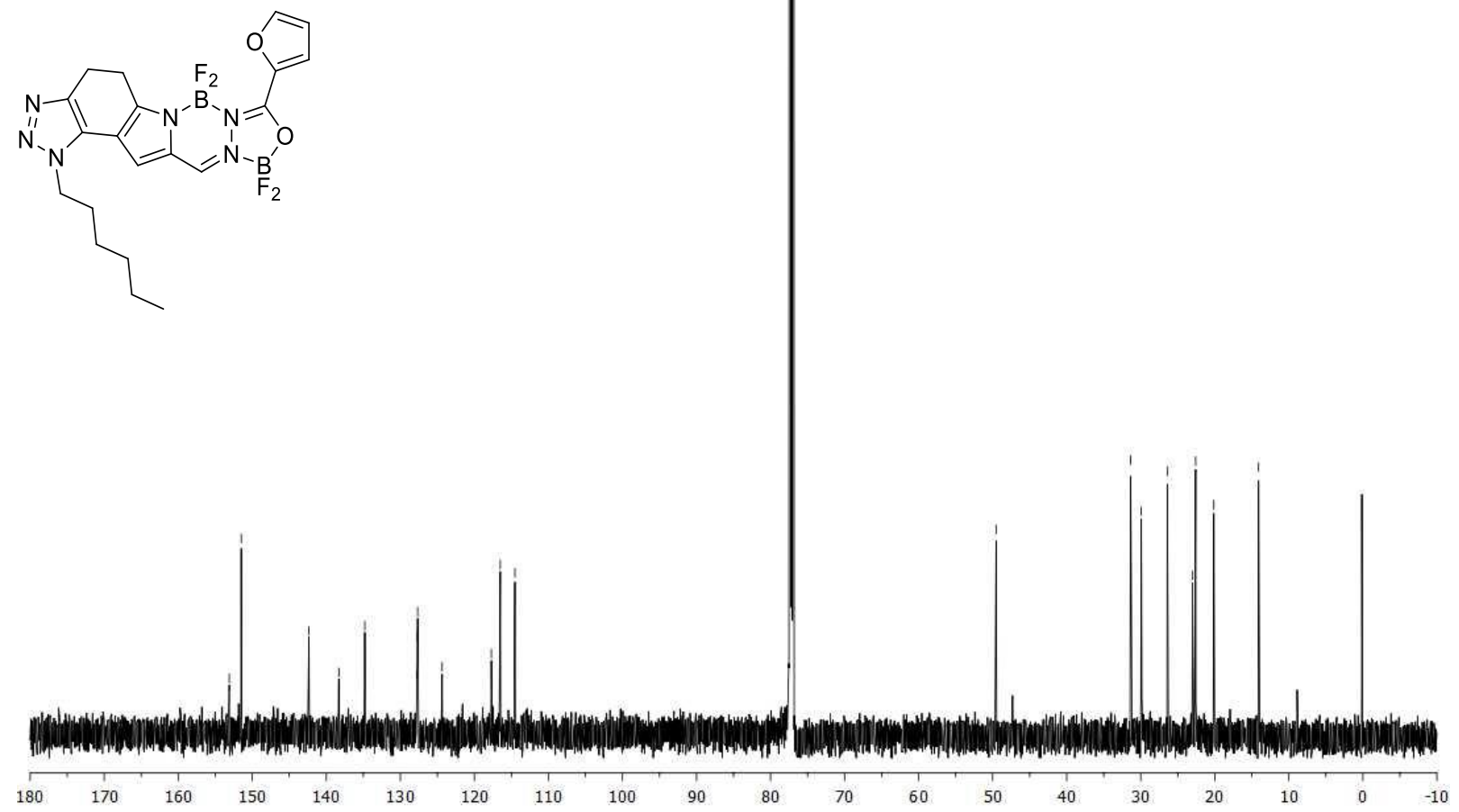
15ba' ( $\left.{ }^{1} \mathrm{H} \mathrm{NMR}, 400 \mathrm{MHz}, \mathrm{CDCl}_{3}\right)$

$\stackrel{i}{i} \underset{i}{i}$
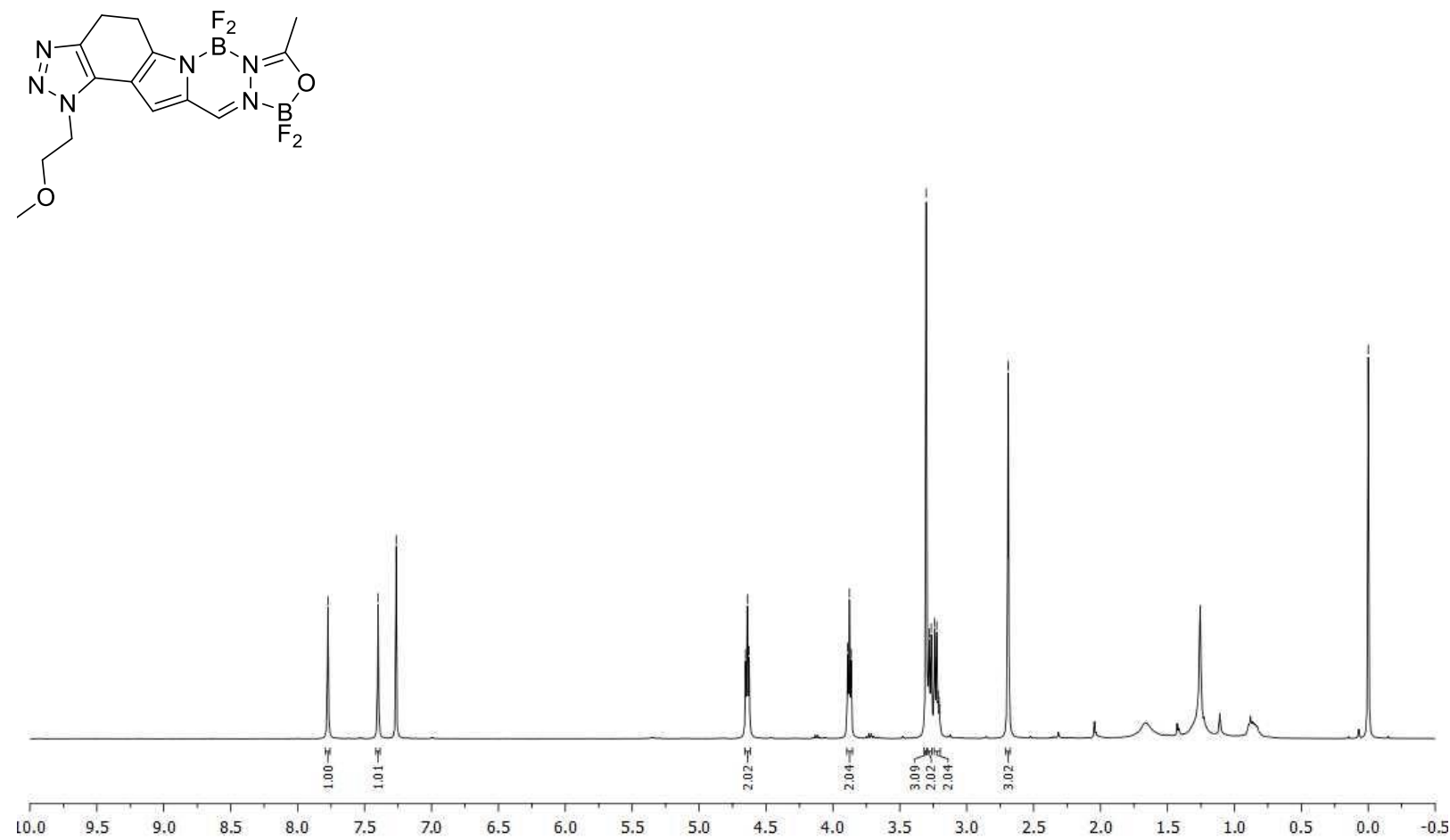

15ba' $\left({ }^{13} \mathrm{C} \mathrm{NMR}, 101 \mathrm{MHz}, \mathrm{CDCl}_{3}\right)$

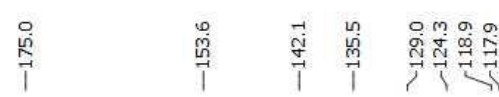

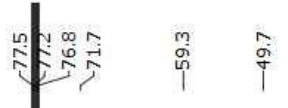

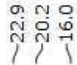
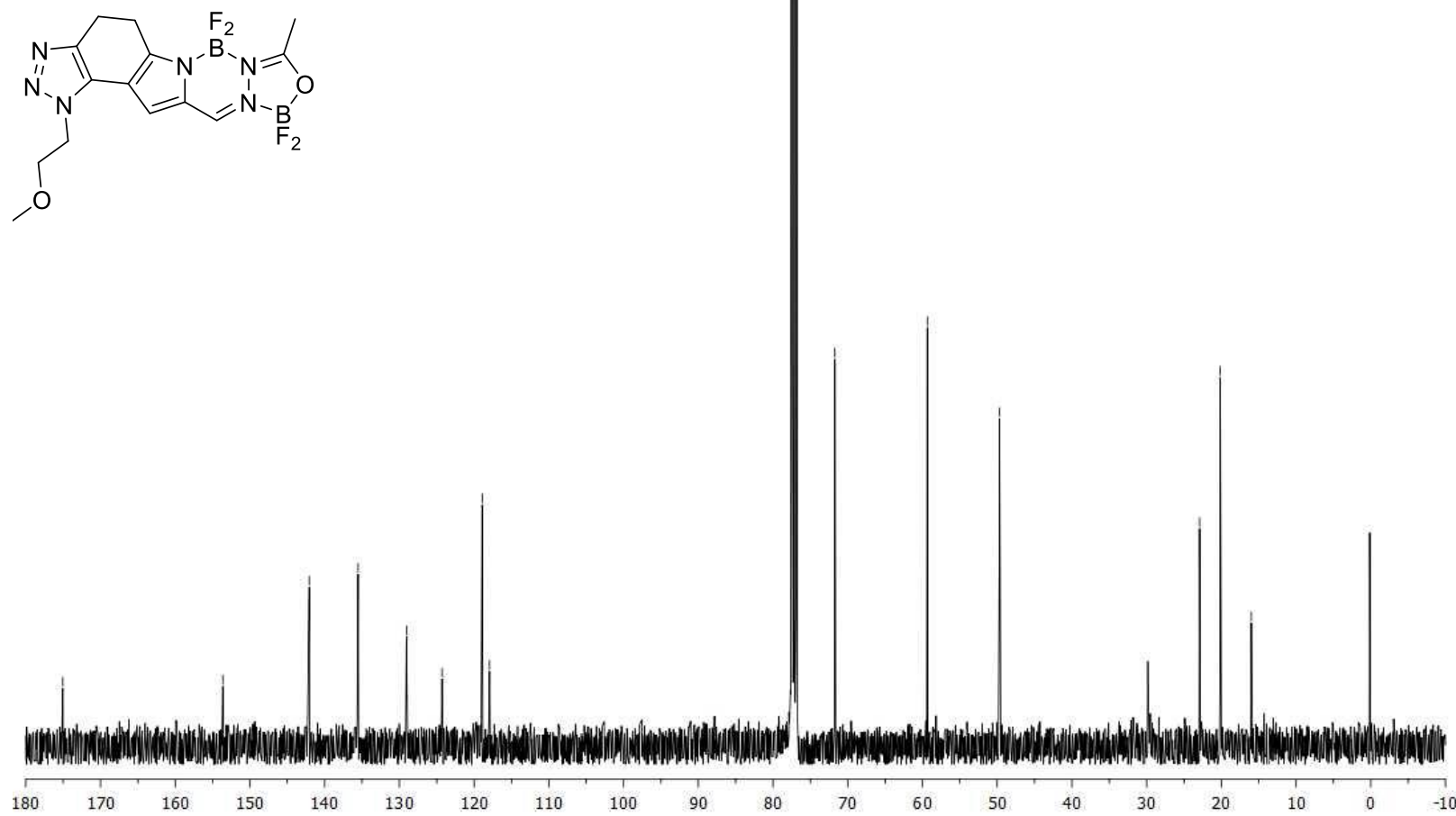
15bb' ( $\left.{ }^{1} \mathrm{H} \mathrm{NMR}, 400 \mathrm{MHz}, \mathrm{CDCl}_{3}\right)$

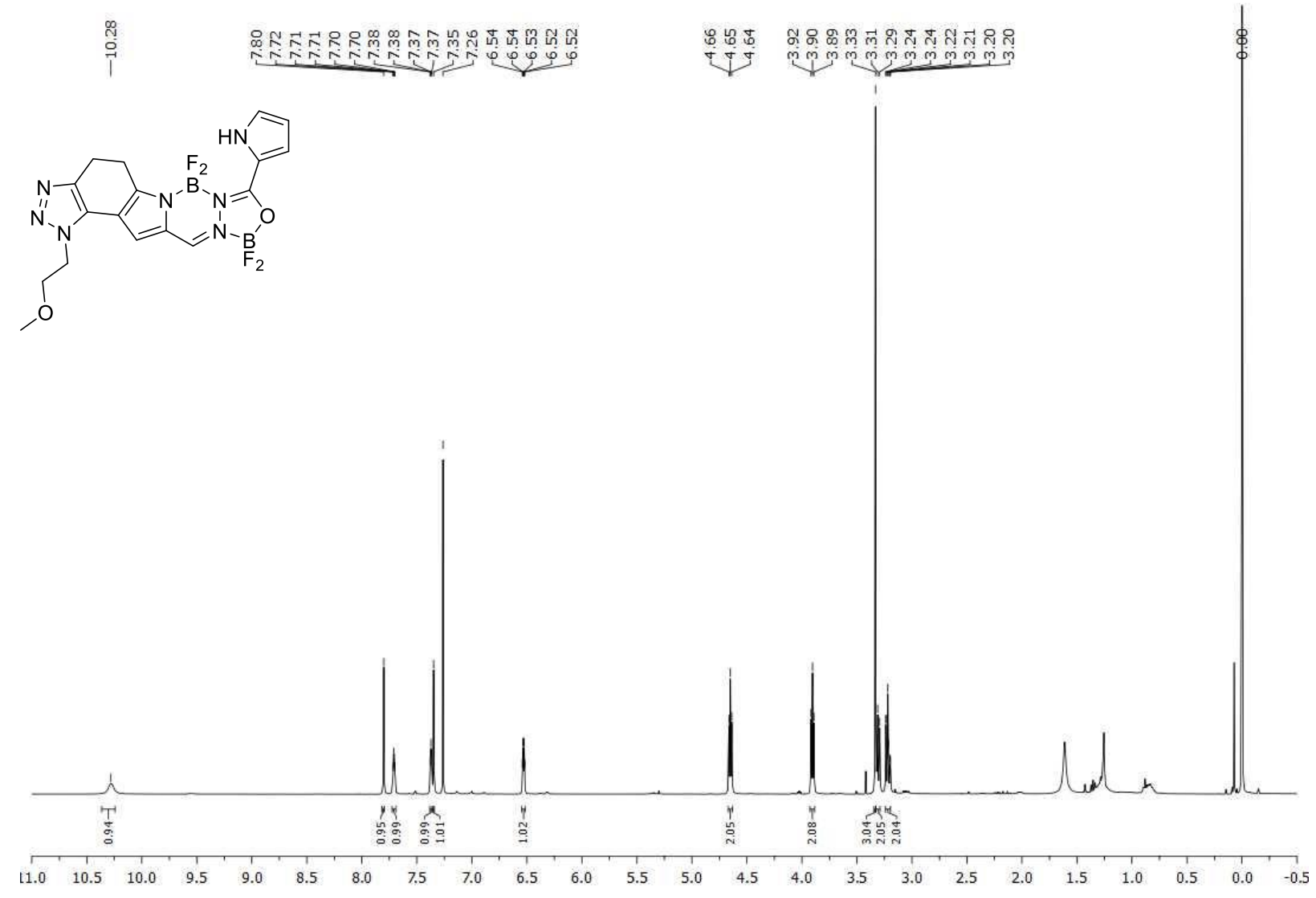

15bb' $\left({ }^{13} \mathrm{C}\right.$ NMR, $\left.101 \mathrm{MHz}, \mathrm{CDCl}_{3}\right)$
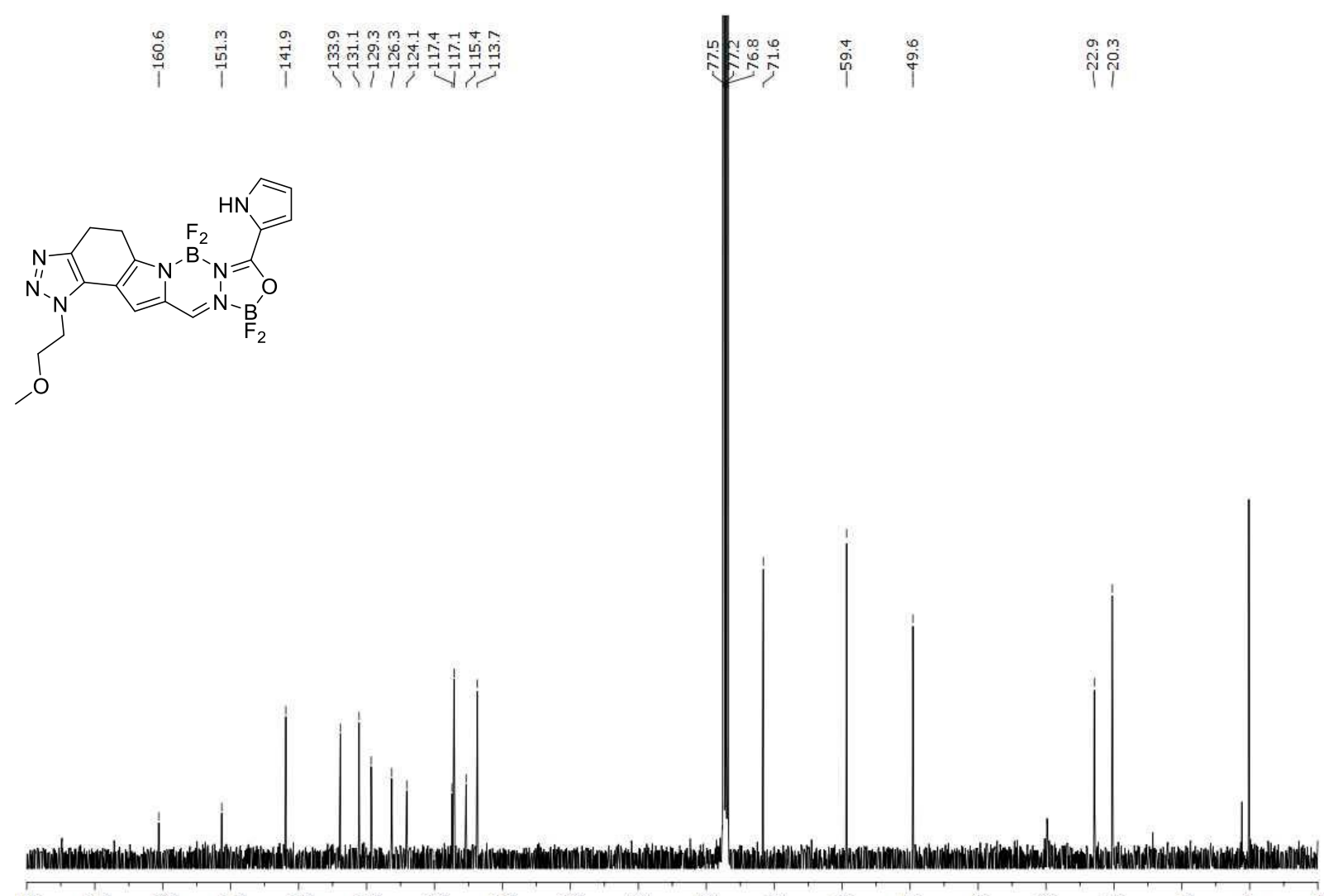
16aa' ( $\left.{ }^{\mathrm{H}} \mathrm{NMR}, 300 \mathrm{MHz}, \mathrm{CDCl}_{3}\right)$
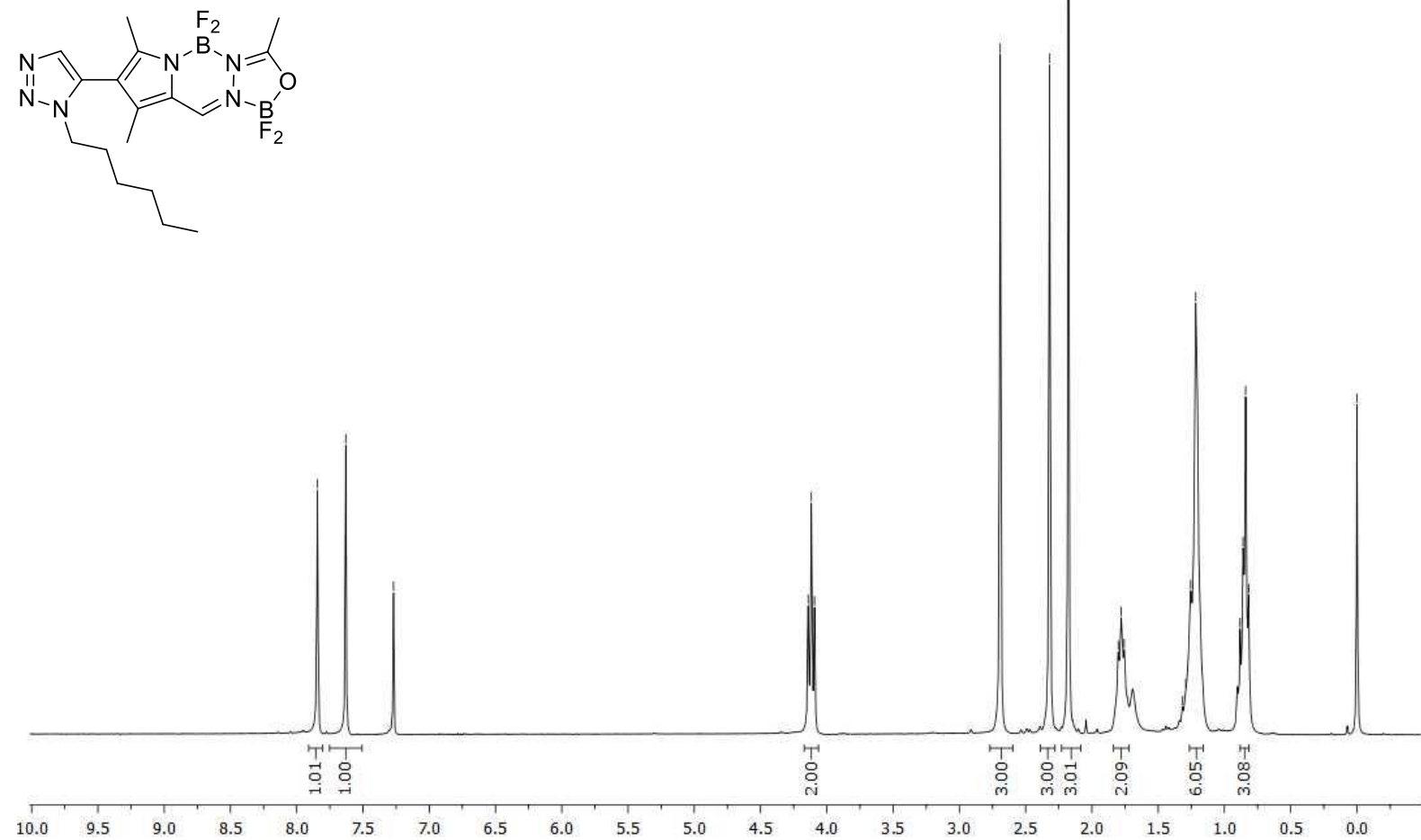

16aa' $\left({ }^{13} \mathrm{C}\left\{{ }^{1} \mathrm{H}\right\} \mathrm{NMR}, 151 \mathrm{MHz}, \mathrm{CDCl}_{3}\right)$

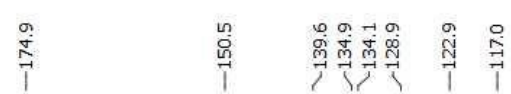

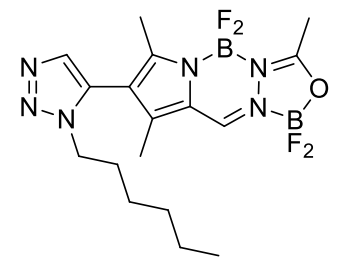

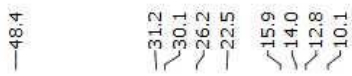

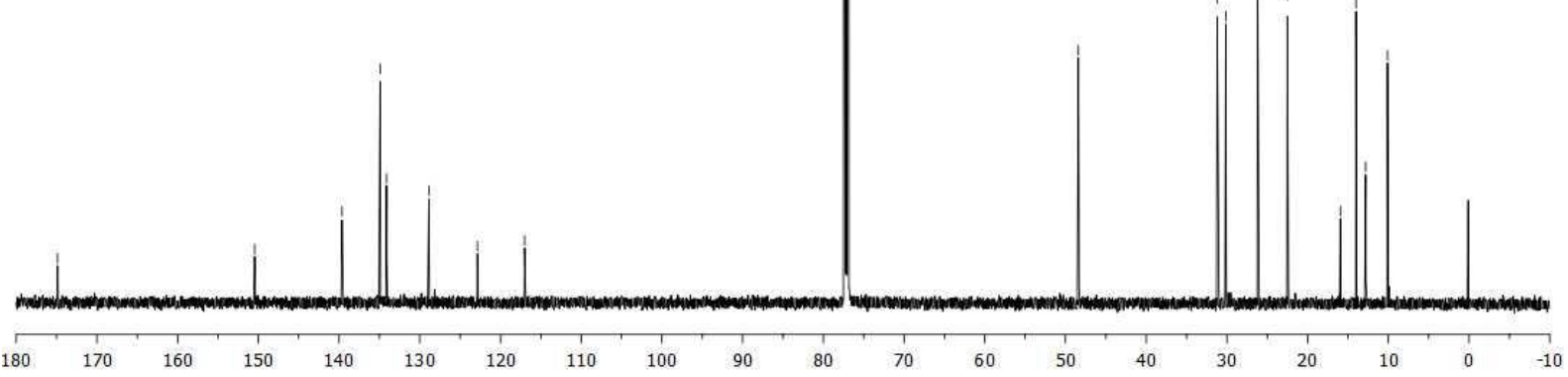


16ab' ( $\left.{ }^{1} \mathrm{H} \mathrm{NMR}, 300 \mathrm{MHz}, \mathrm{CDCl}_{3}\right)$

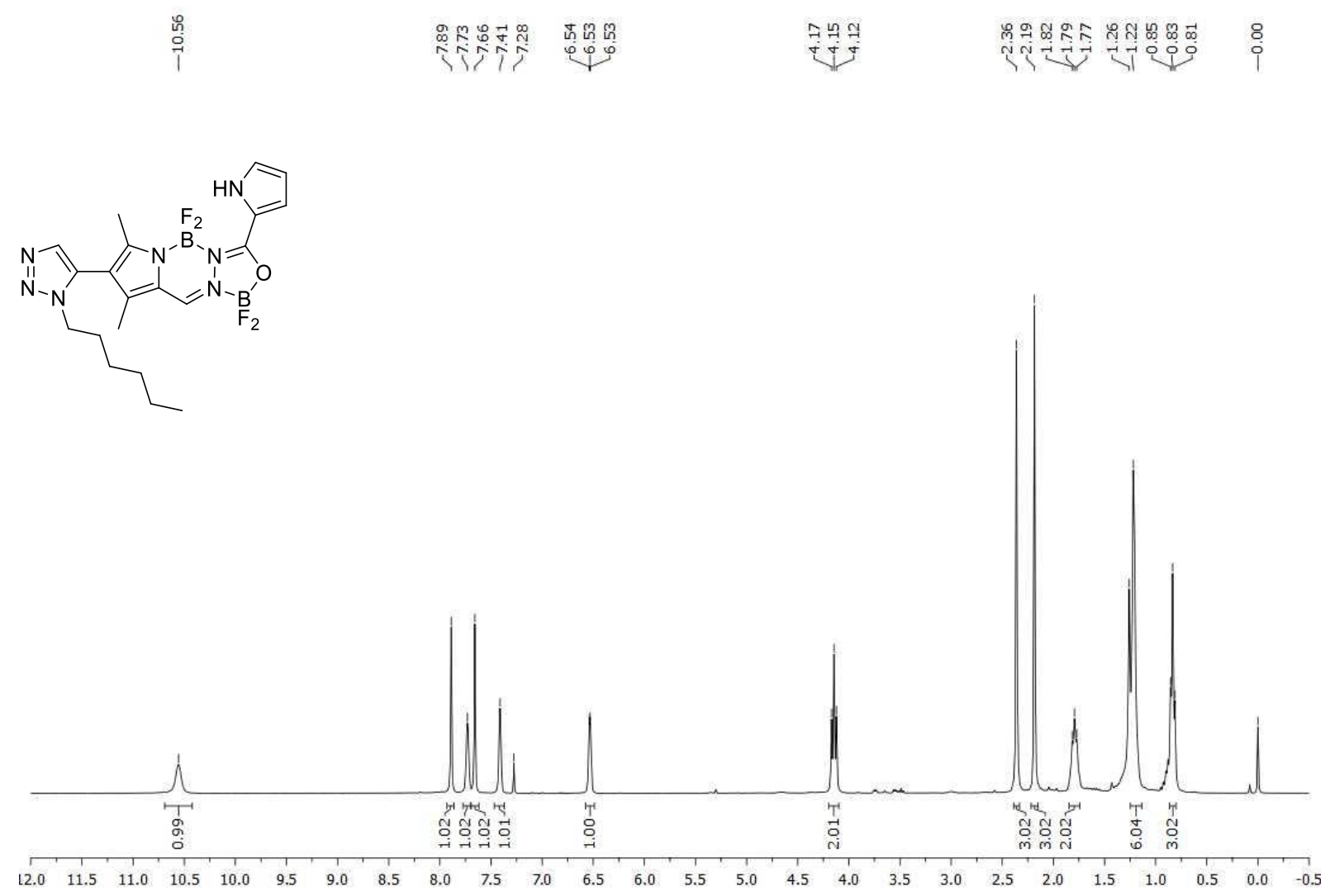

16ab' $\left({ }^{13} \mathrm{C}\left\{{ }^{1} \mathrm{H}\right\} \mathrm{NMR}, 75 \mathrm{MHz}, \mathrm{CDCl}_{3}\right)$

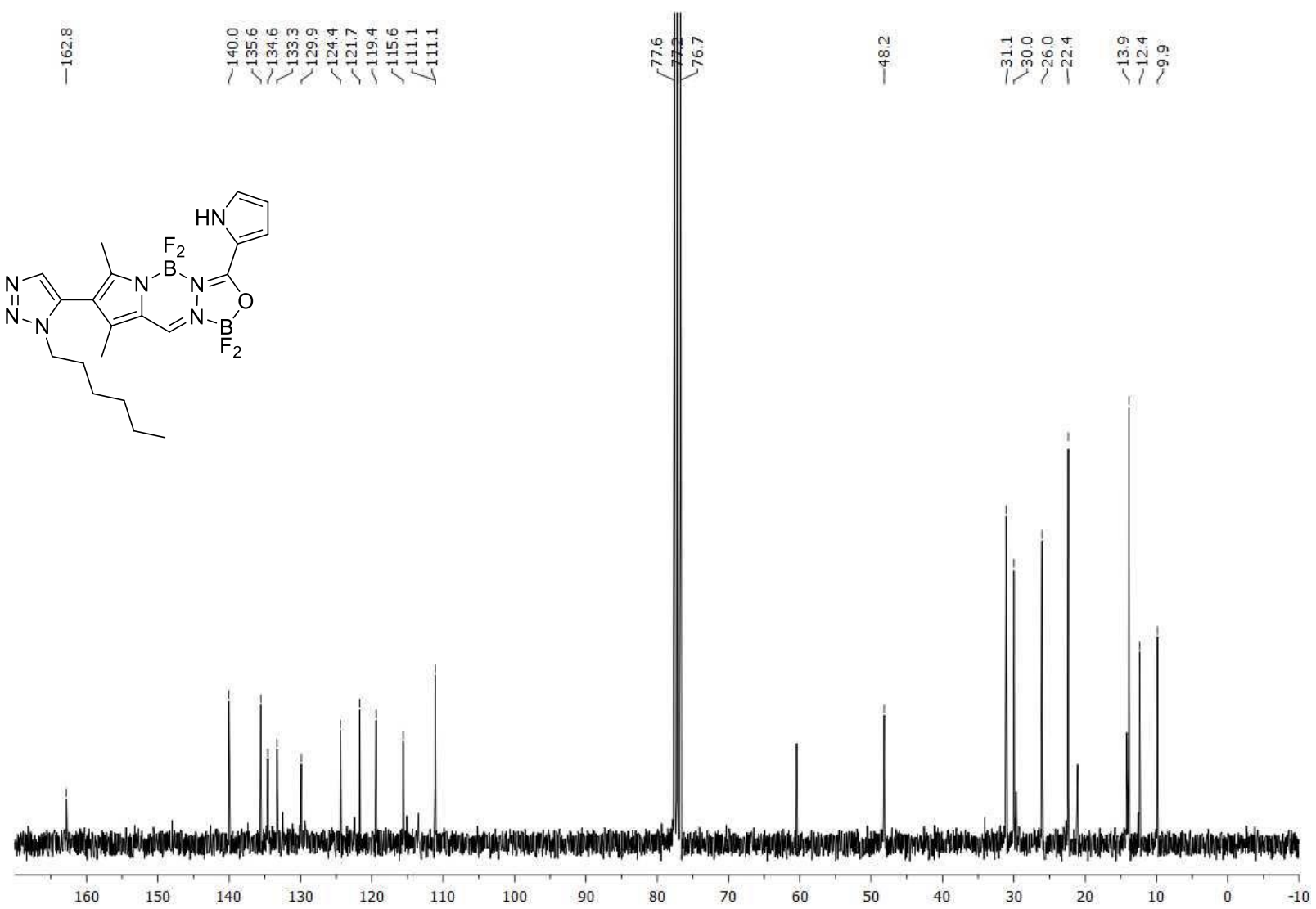


16ba' $\left({ }^{1} \mathrm{H} \mathrm{NMR}, 400 \mathrm{MHz}, \mathrm{CDCl}_{3}\right)$
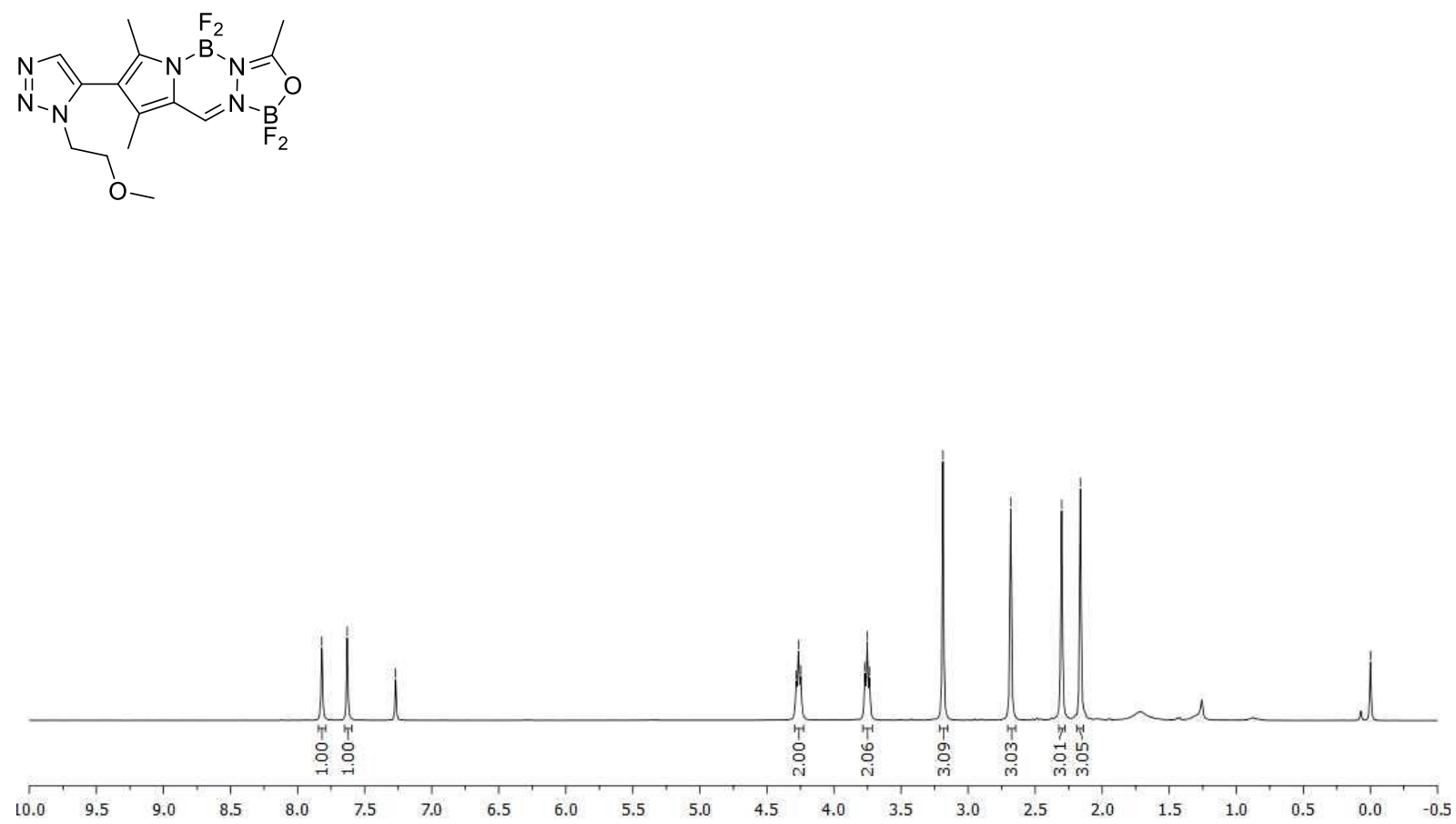

16ba' $\left({ }^{13} \mathrm{C}\left\{{ }^{1} \mathrm{H}\right\}\right.$ NMR, $\left.75 \mathrm{MHz}, \mathrm{CDCl}_{3}\right)$

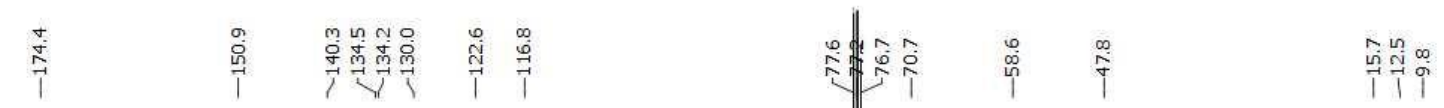

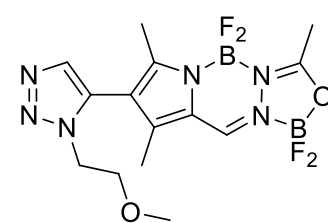

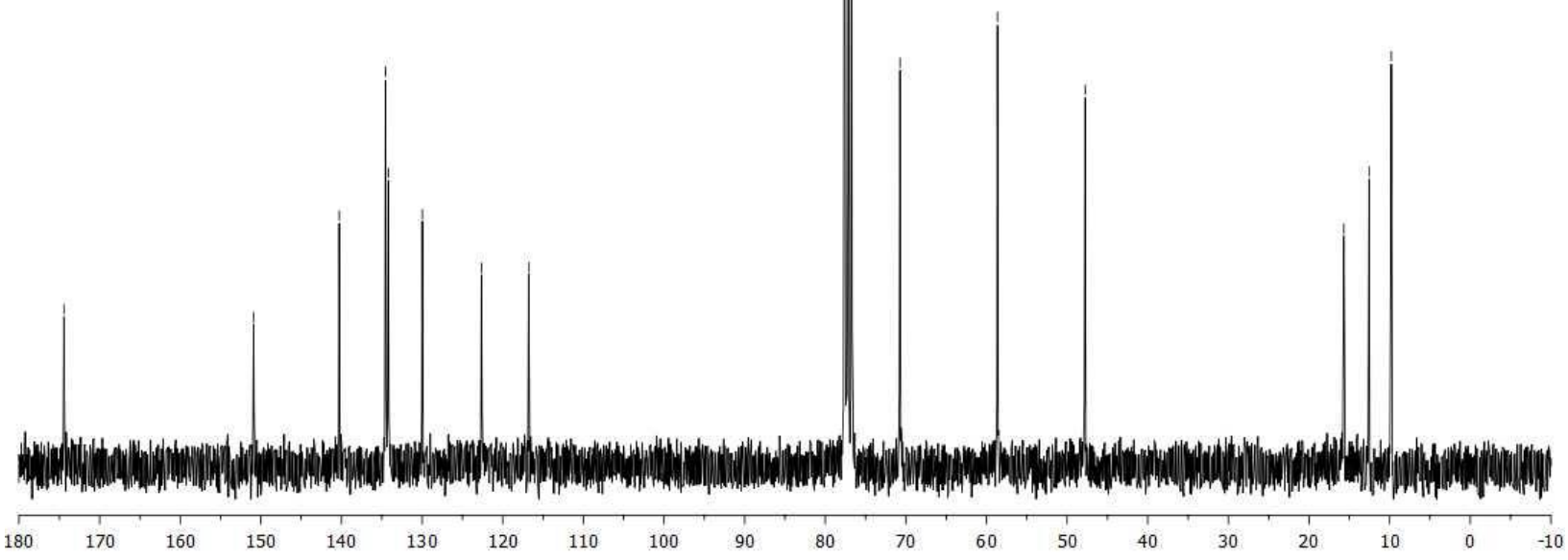


16bb' $\left({ }^{1} \mathrm{H} \mathrm{NMR}, 400 \mathrm{MHz}, \mathrm{CDCl}_{3}\right)$

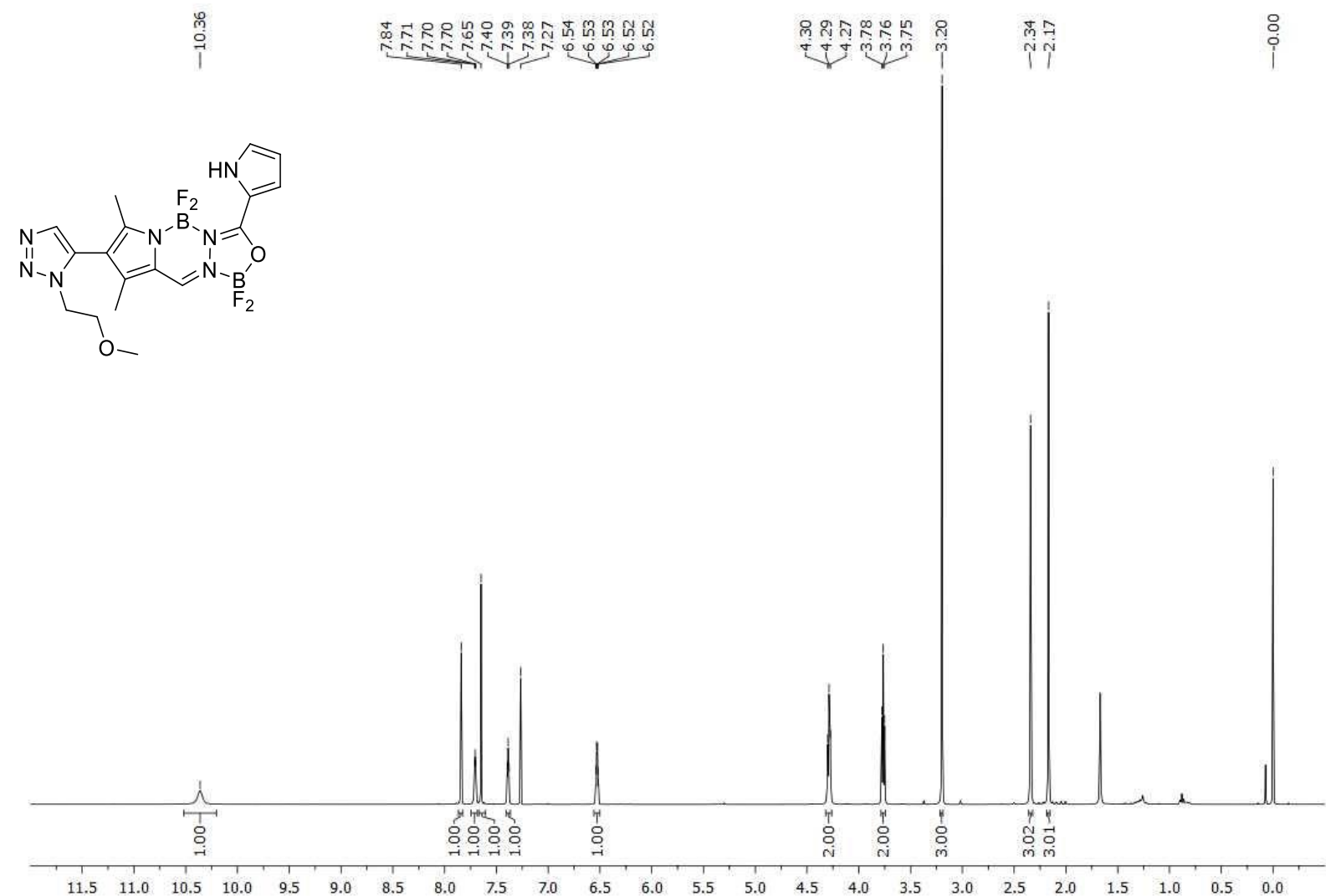

16bb' $\left({ }^{13} \mathrm{C}\left\{{ }^{1} \mathrm{H}\right\}\right.$ NMR, $\left.151 \mathrm{MHz}, \mathrm{CDCl}_{3}\right)$

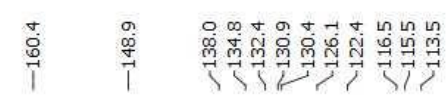
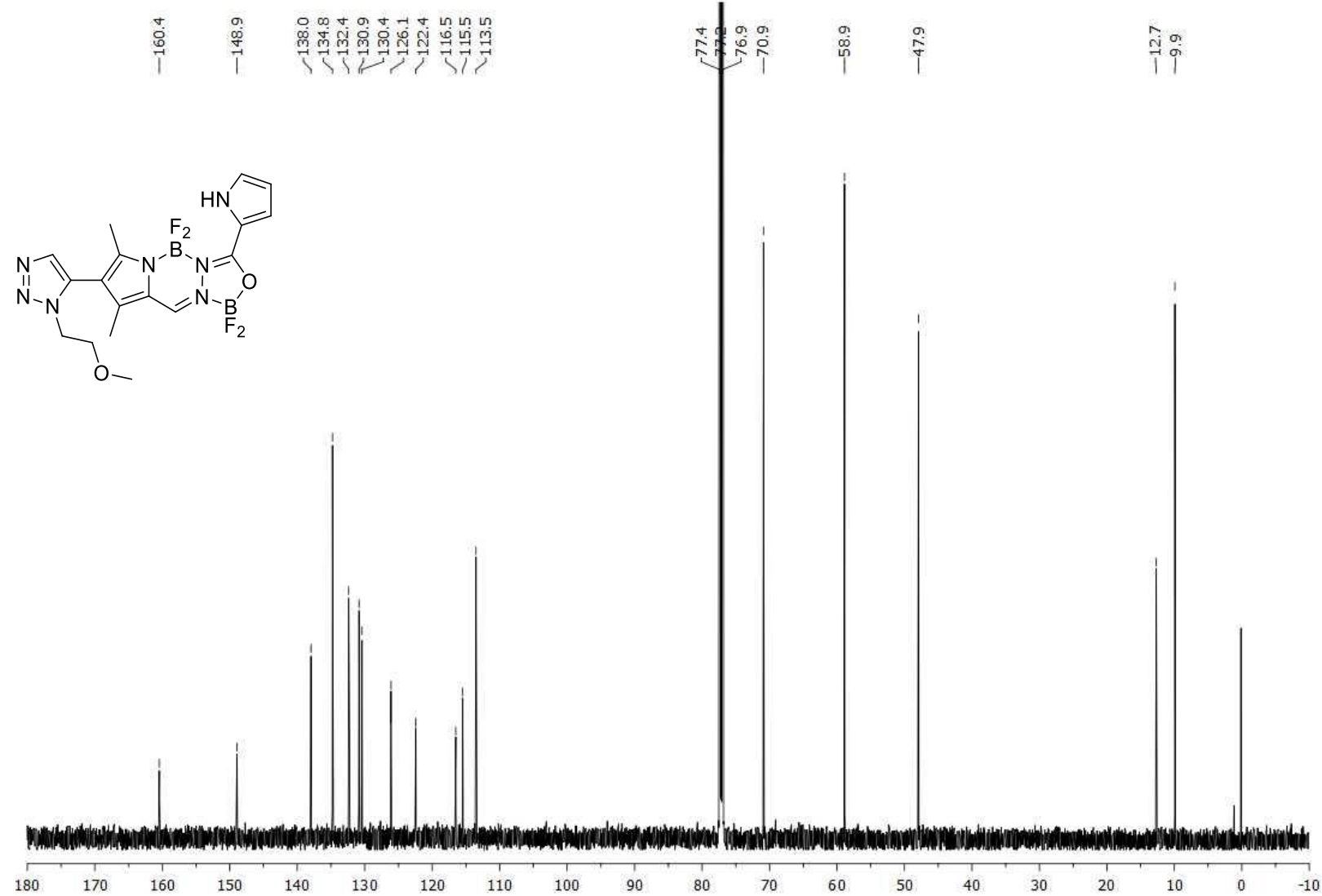
18aa' $\left({ }^{1} \mathrm{H} \mathrm{NMR}, 400 \mathrm{MHz}, \mathrm{CD}_{3} \mathrm{CN}\right)$

$\underset{\substack{f \\ i}}{\substack{t \\ i}}$

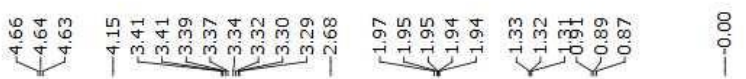
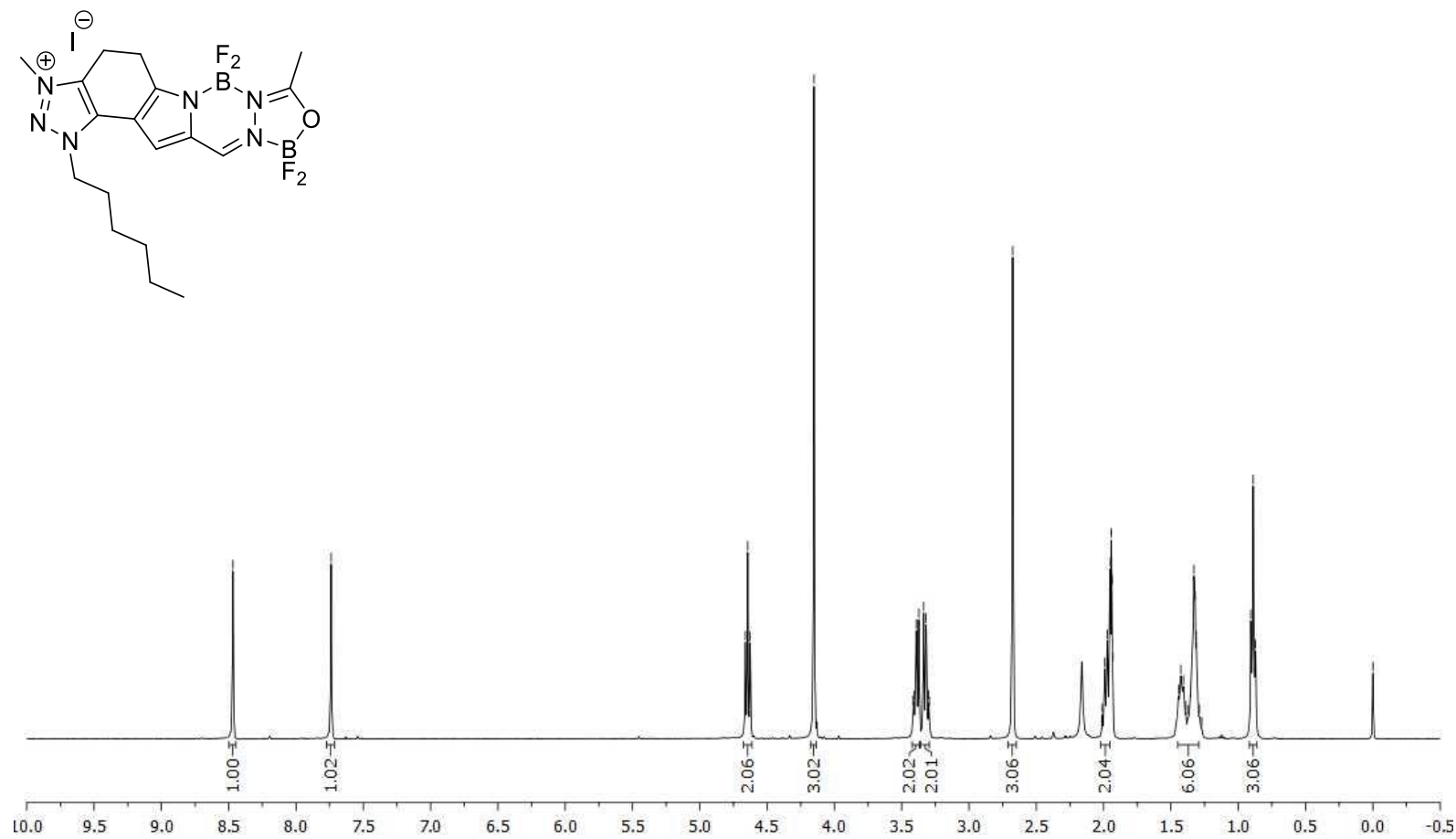

18aa' $\left({ }^{13} \mathrm{C}\left\{{ }^{1} \mathrm{H}\right\} \mathrm{NMR}, 101 \mathrm{MHz}, \mathrm{CD}_{3} \mathrm{CN}\right)$

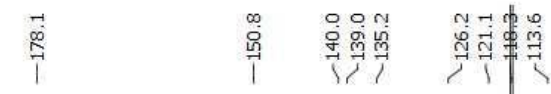

की
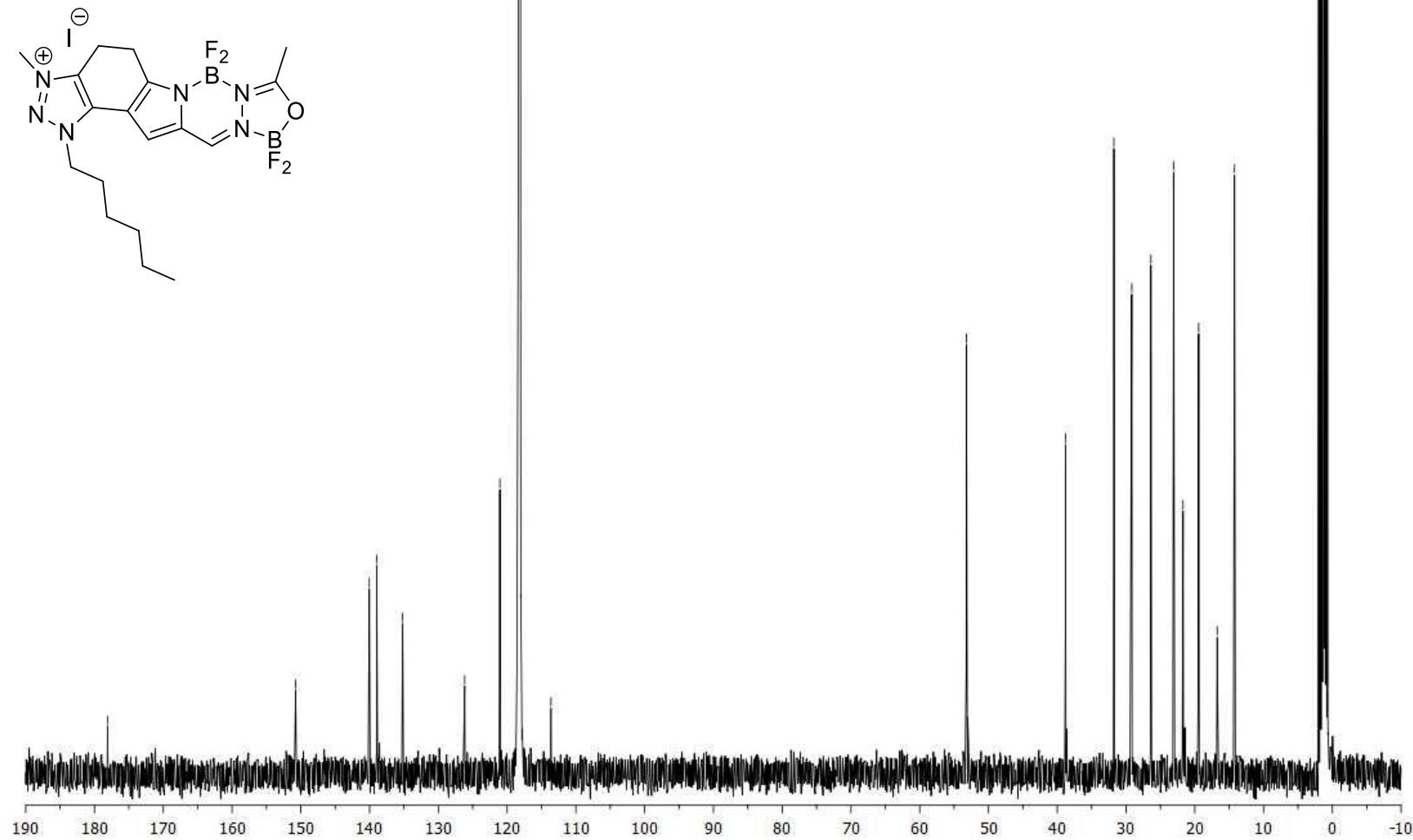
18ab' ( ${ }^{1} \mathrm{H}$ NMR, $\left.400 \mathrm{MHz}, \mathrm{CD}_{3} \mathrm{CN}\right)$

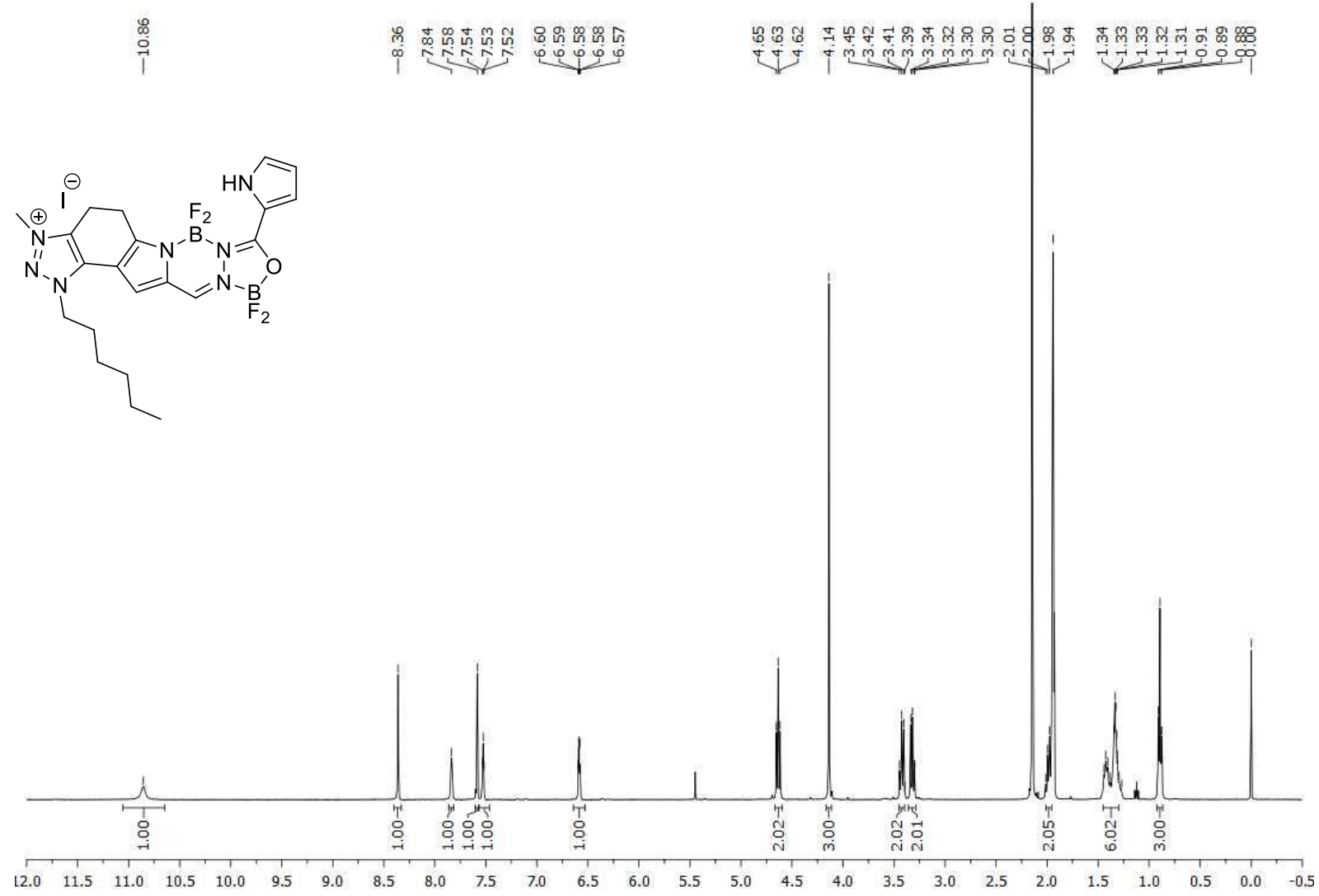

18ab' $\left({ }^{13} \mathrm{C}\left\{{ }^{1} \mathrm{H}\right\}\right.$ NMR, $\left.151 \mathrm{MHz}, \mathrm{CD}_{3} \mathrm{CN}\right)$

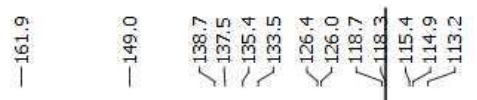

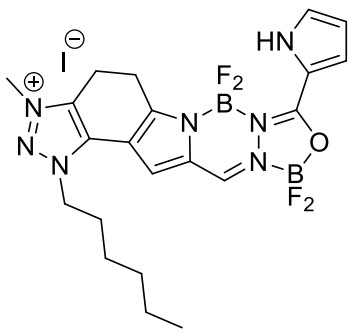

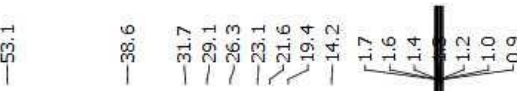

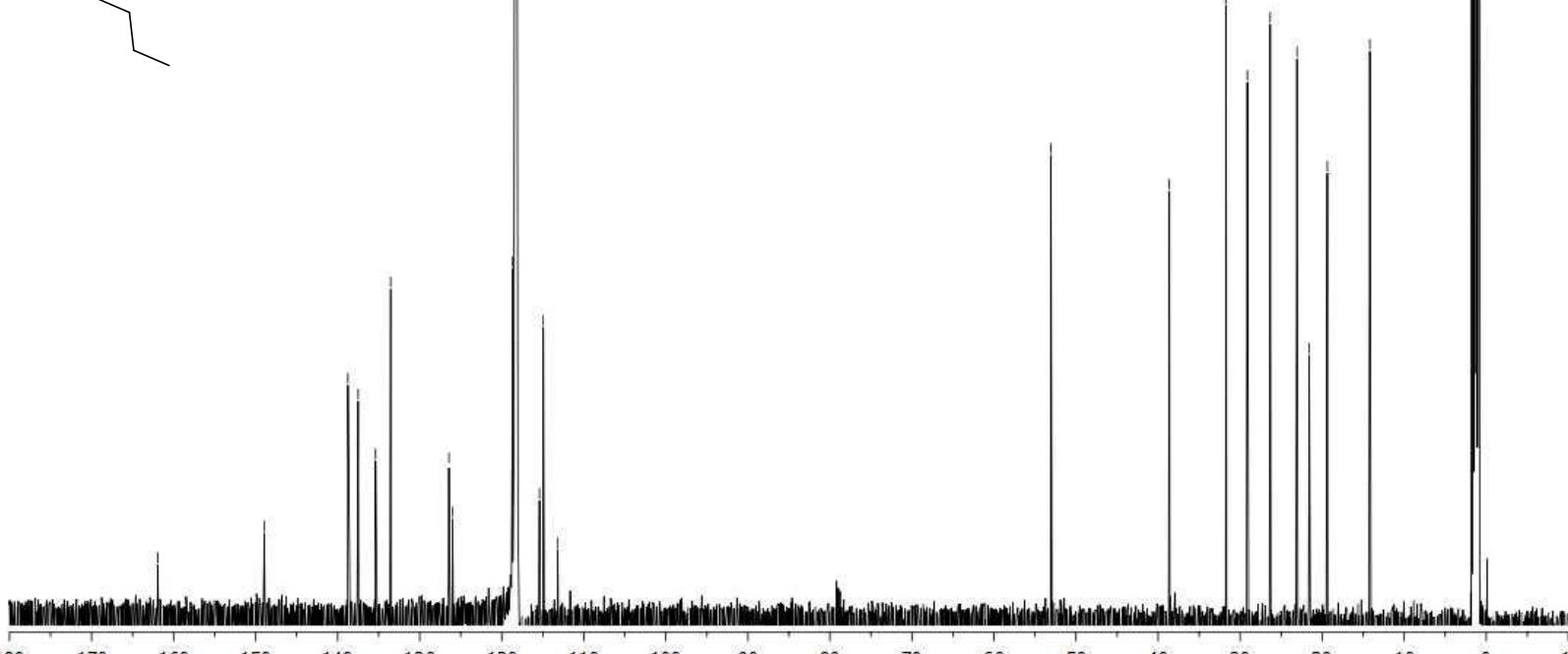

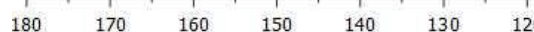


18ba' $\left({ }^{1} \mathrm{H} \mathrm{NMR}, 400 \mathrm{MHz}, \mathrm{CD}_{3} \mathrm{CN}\right)$

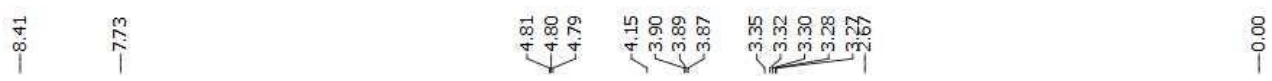
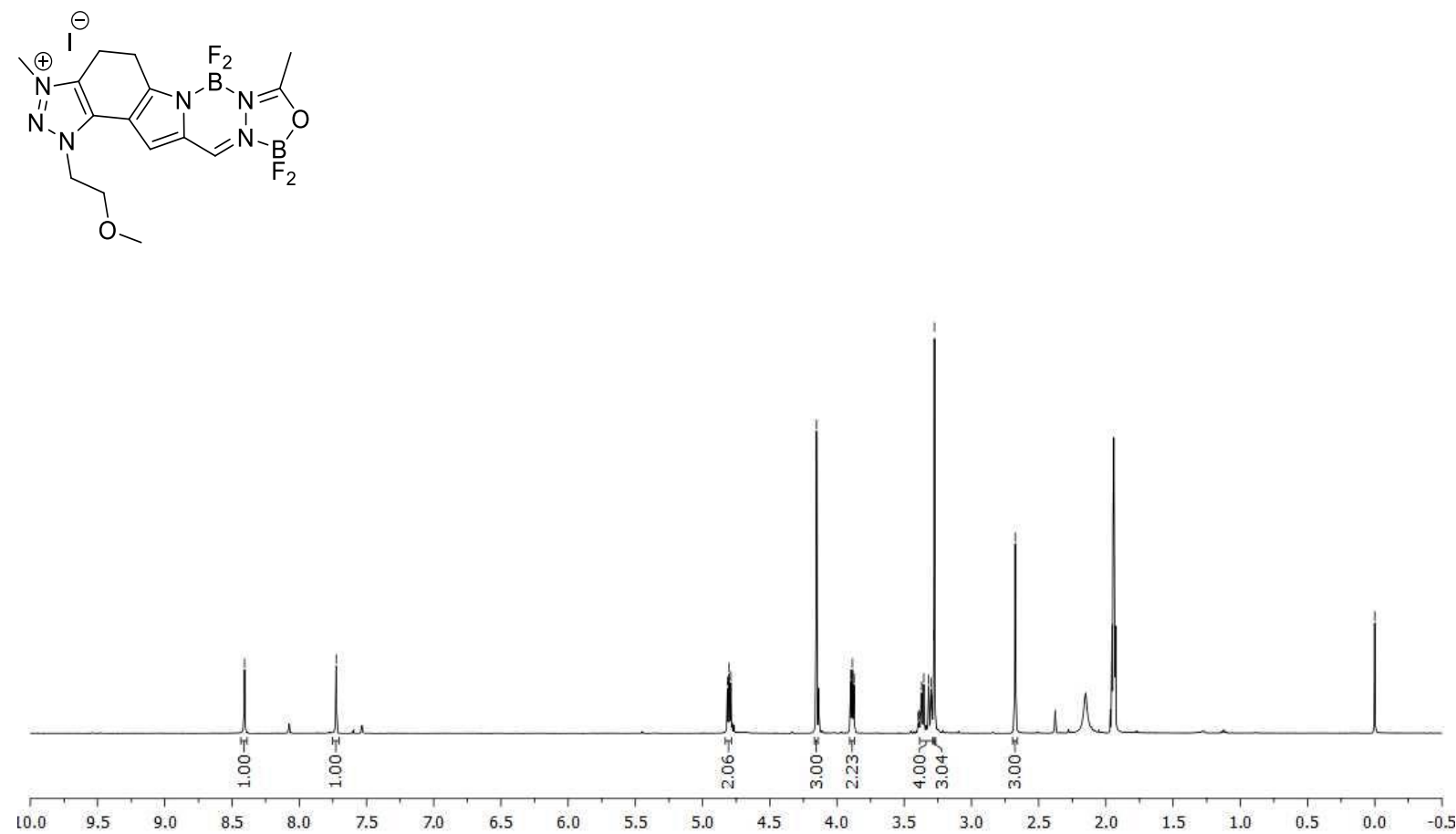

18ba' $\left({ }^{13} \mathrm{C}\left\{{ }^{1} \mathrm{H}\right\}\right.$ NMR, $\left.101 \mathrm{MHz}, \mathrm{CD}_{3} \mathrm{CN}\right)$

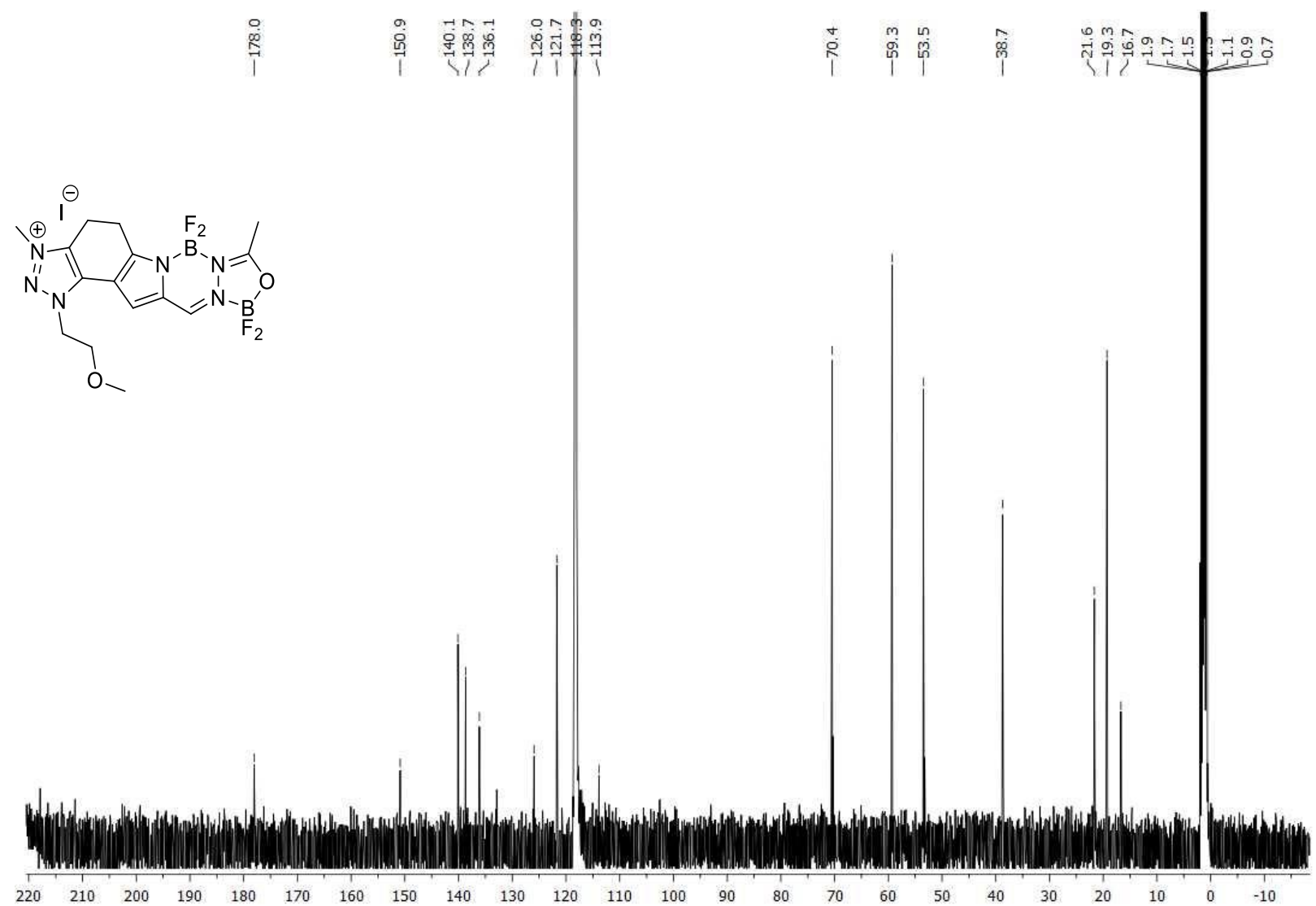


18bb' ( $\left.{ }^{1} \mathrm{H} \mathrm{NMR}, 400 \mathrm{MHz}, \mathrm{CD}_{3} \mathrm{CN}\right)$

$$
\stackrel{\infty}{\infty}
$$

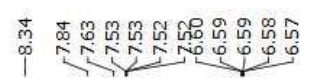
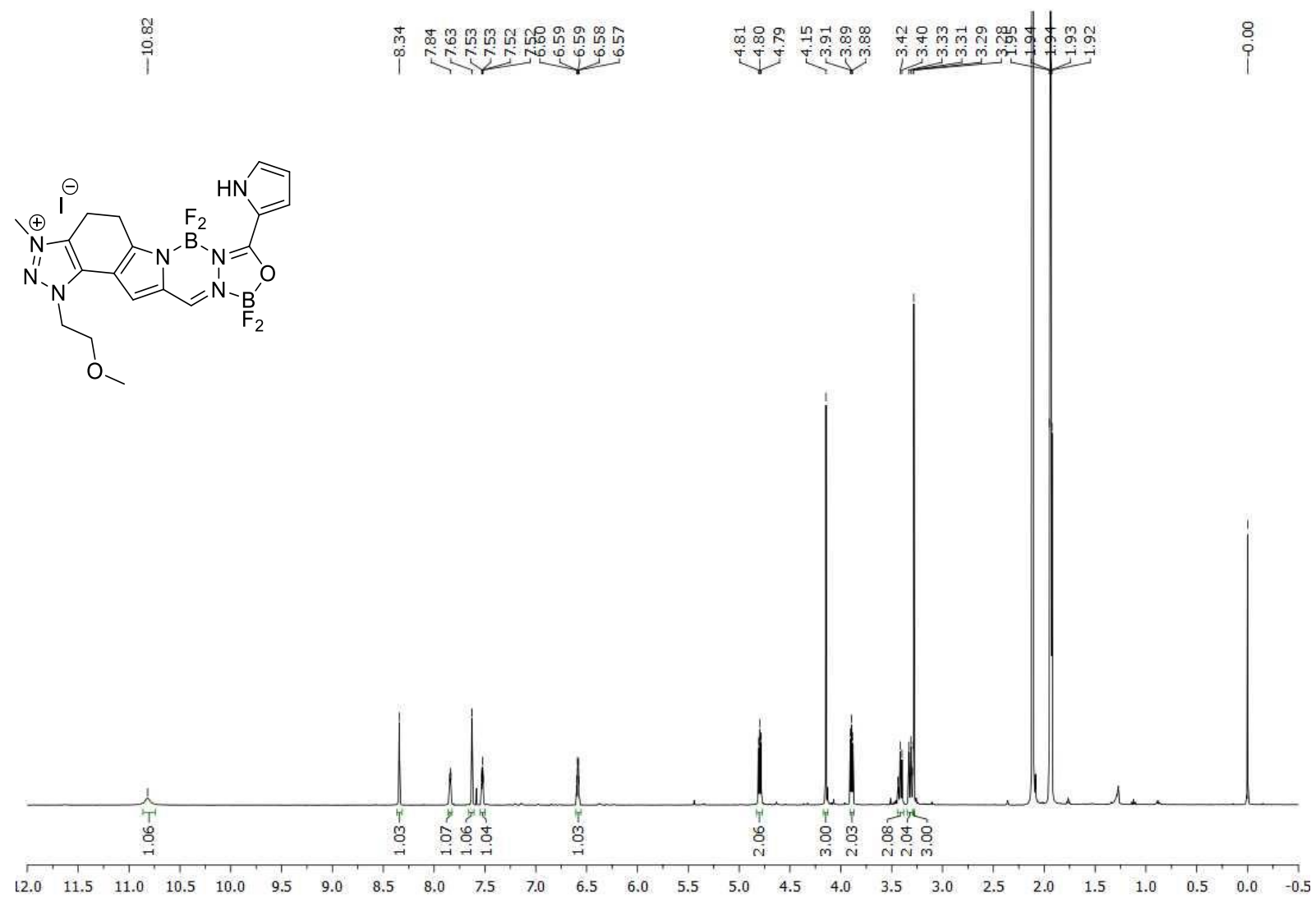

18bb' $\left({ }^{13} \mathrm{C}\left\{{ }^{1} \mathrm{H}\right\}\right.$ NMR, $\left.101 \mathrm{MHz}, \mathrm{CD}_{3} \mathrm{CN}\right)$

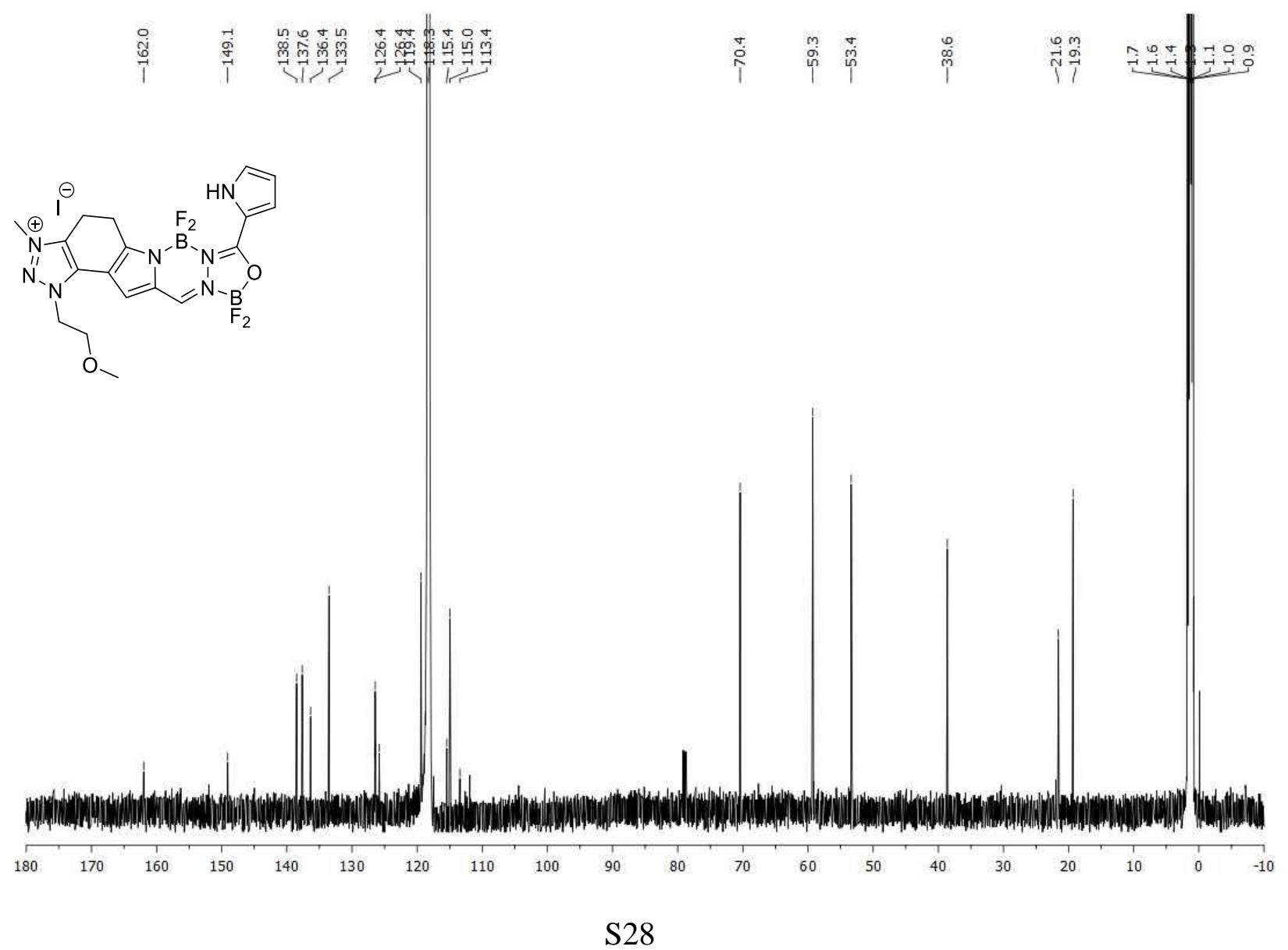


19aa' $\left({ }^{1} \mathrm{H} \mathrm{NMR}, 400 \mathrm{MHz}, \mathrm{CD}_{3} \mathrm{CN}\right)$
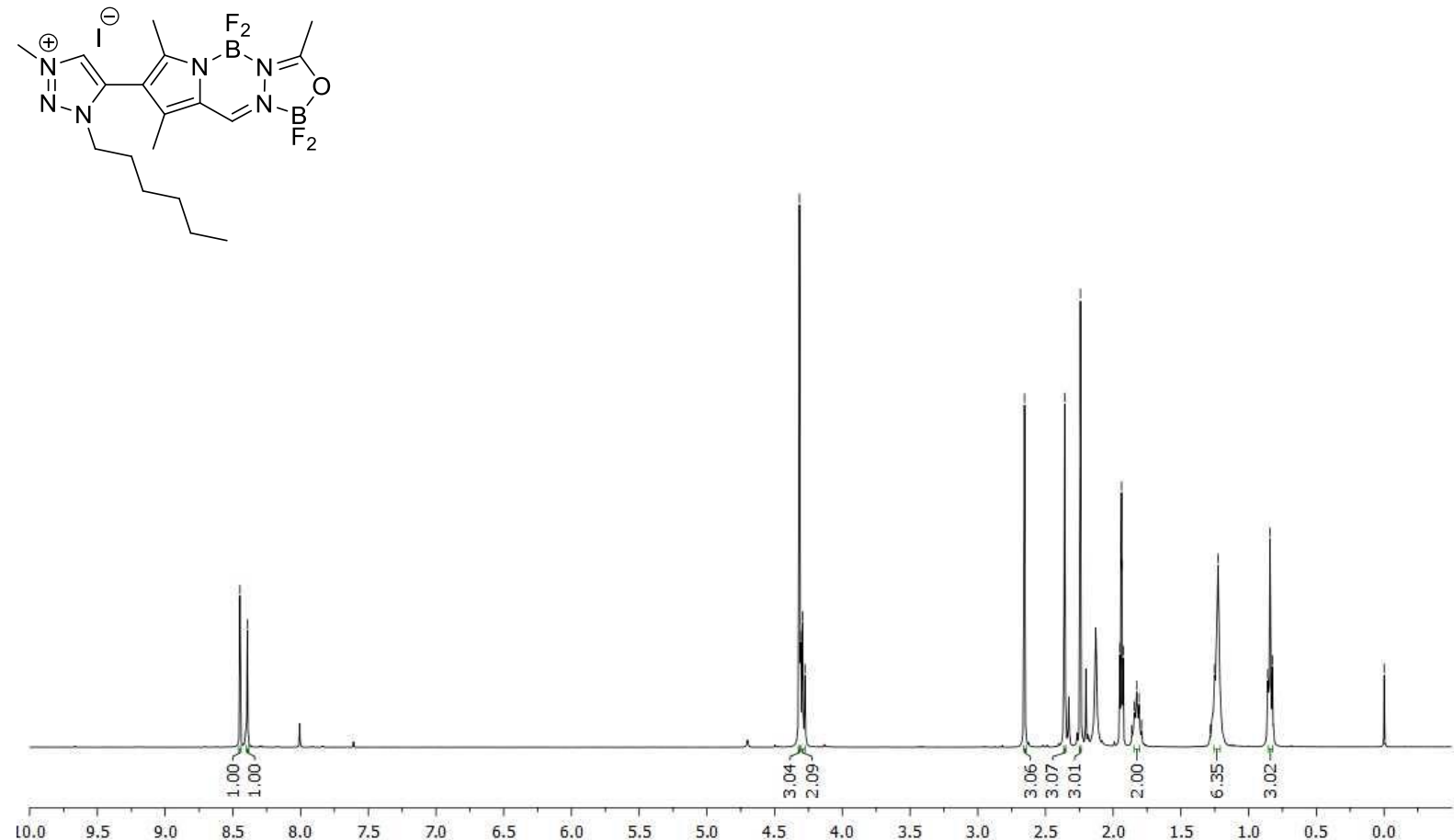

19aa' $\left({ }^{13} \mathrm{C}\left\{{ }^{1} \mathrm{H}\right\}\right.$ NMR, $\left.101 \mathrm{MHz}, \mathrm{CD}_{3} \mathrm{CN}\right)$

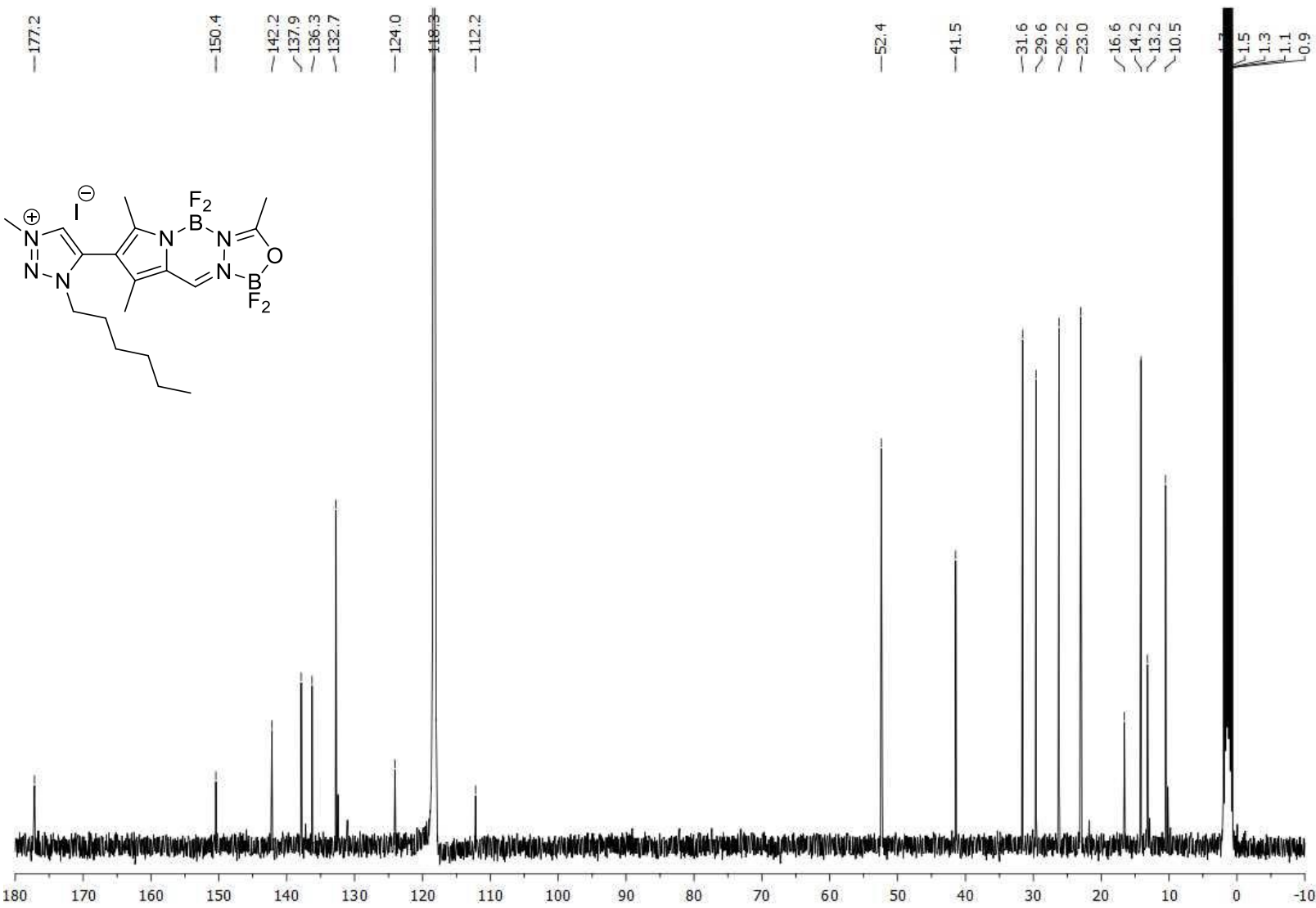


19ab' $\left({ }^{1} \mathrm{H} \mathrm{NMR}, 400 \mathrm{MHz}, \mathrm{CD}_{3} \mathrm{CN}\right)$
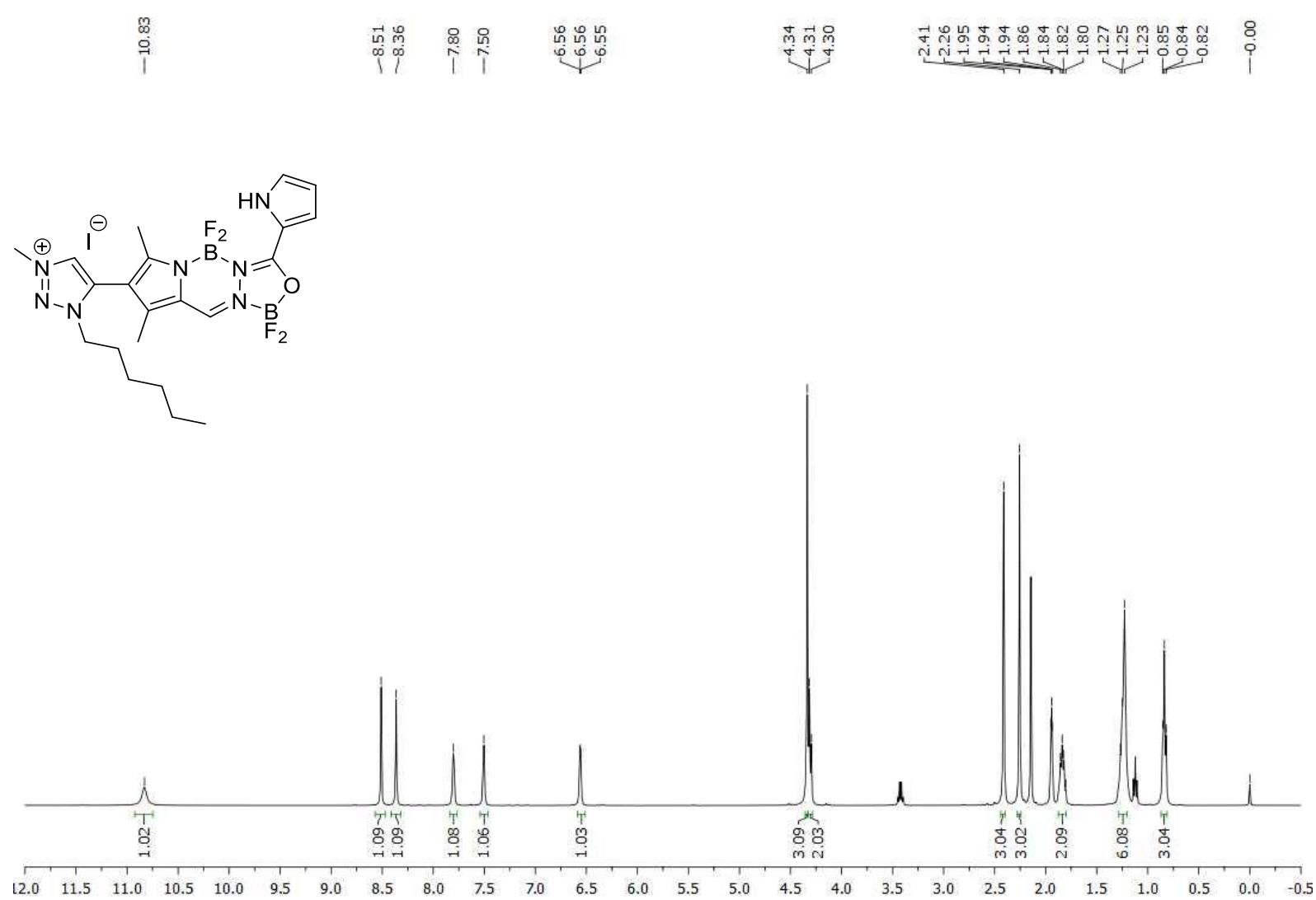

19ab' $\left({ }^{13} \mathrm{C}\left\{{ }^{1} \mathrm{H}\right\}\right.$ NMR, $\left.101 \mathrm{MHz}, \mathrm{CD}_{3} \mathrm{CN}\right)$

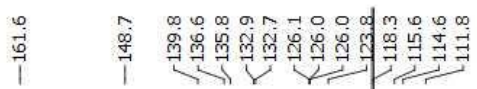

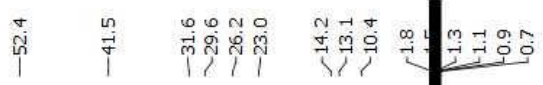
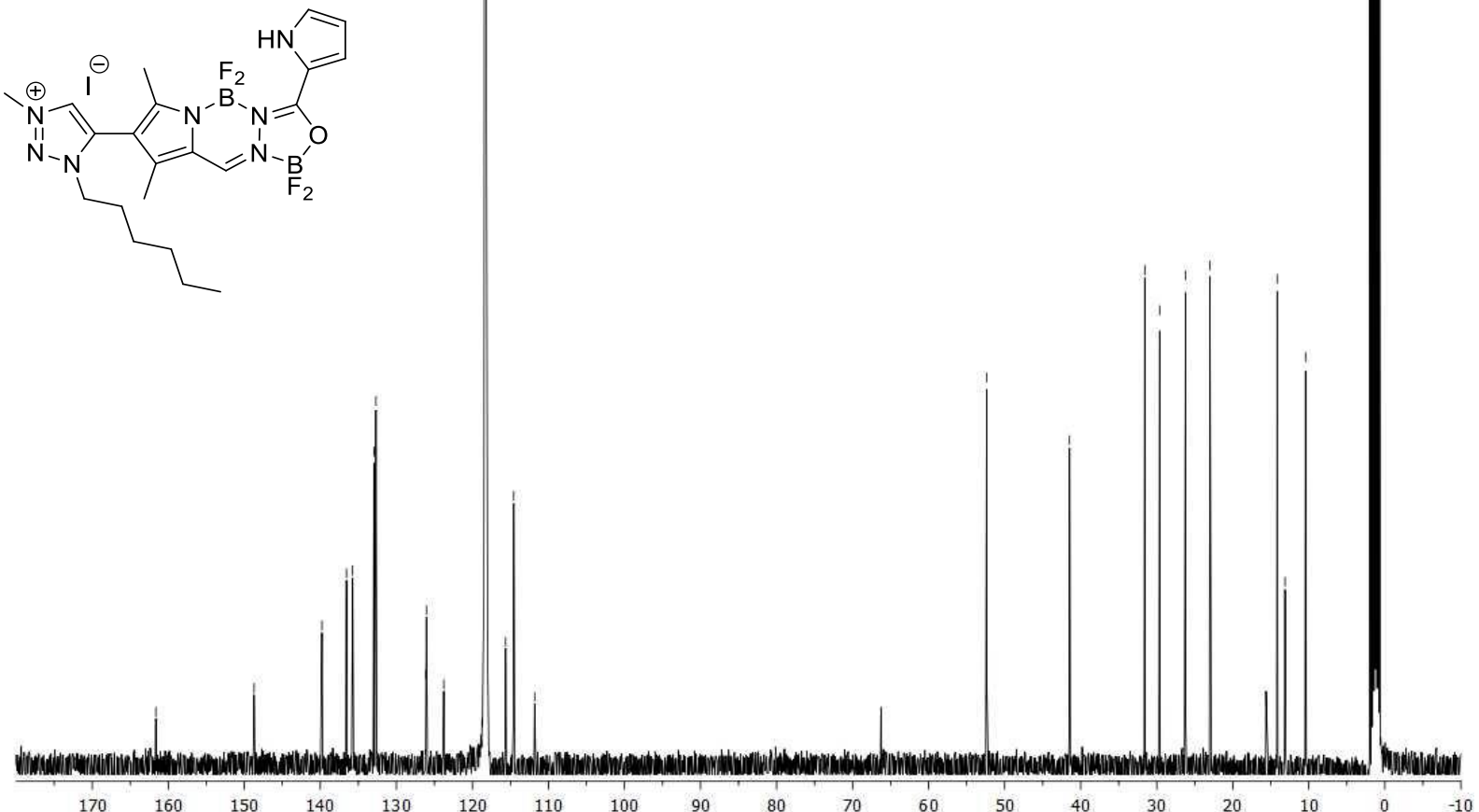
19ba' $\left({ }^{1} \mathrm{H} \mathrm{NMR}, 400 \mathrm{MHz}, \mathrm{CD}_{3} \mathrm{CN}\right)$

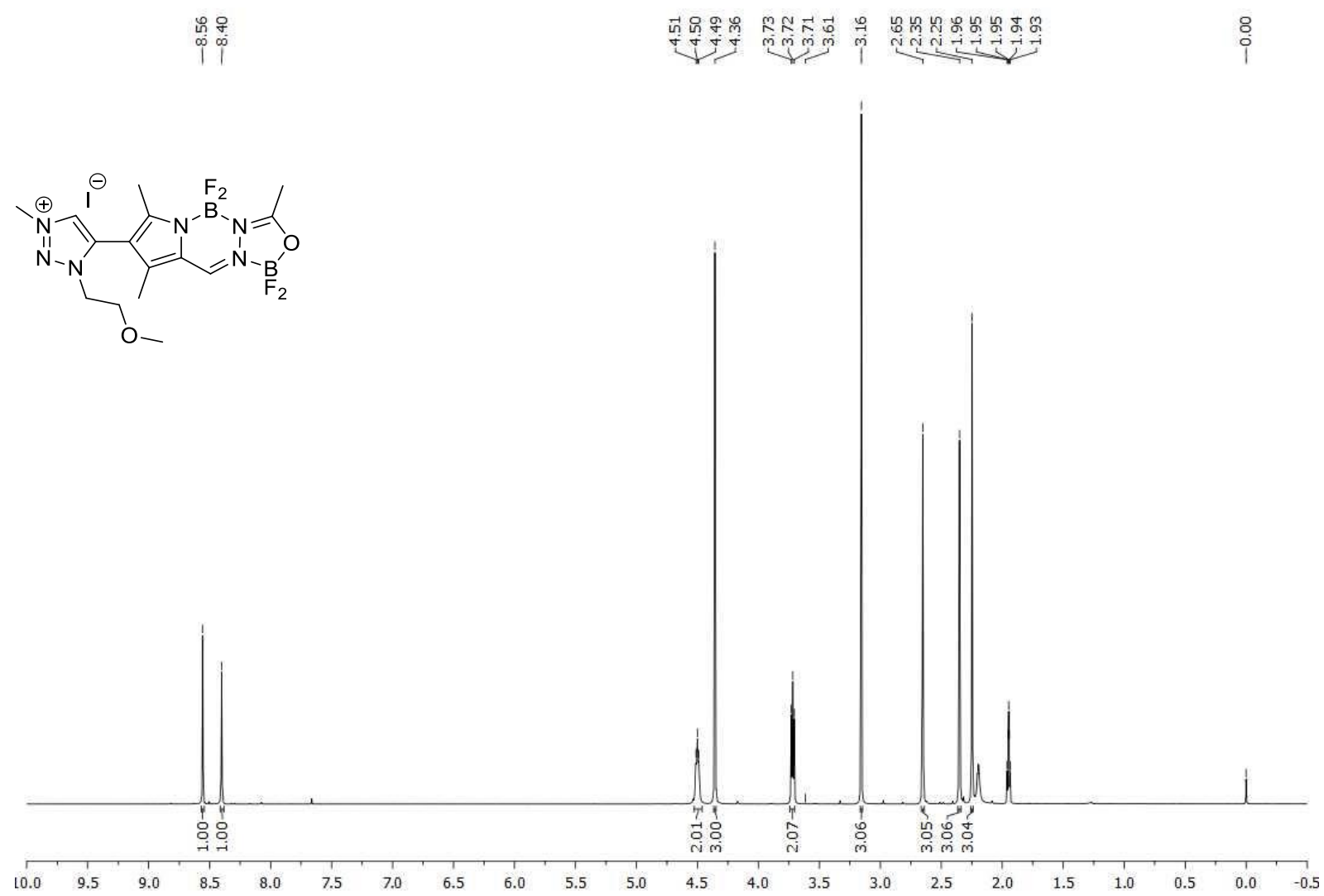

19ba' $\left({ }^{13} \mathrm{C}\left\{{ }^{1} \mathrm{H}\right\} \mathrm{NMR}, 101 \mathrm{MHz}, \mathrm{CD}_{3} \mathrm{CN}\right)$

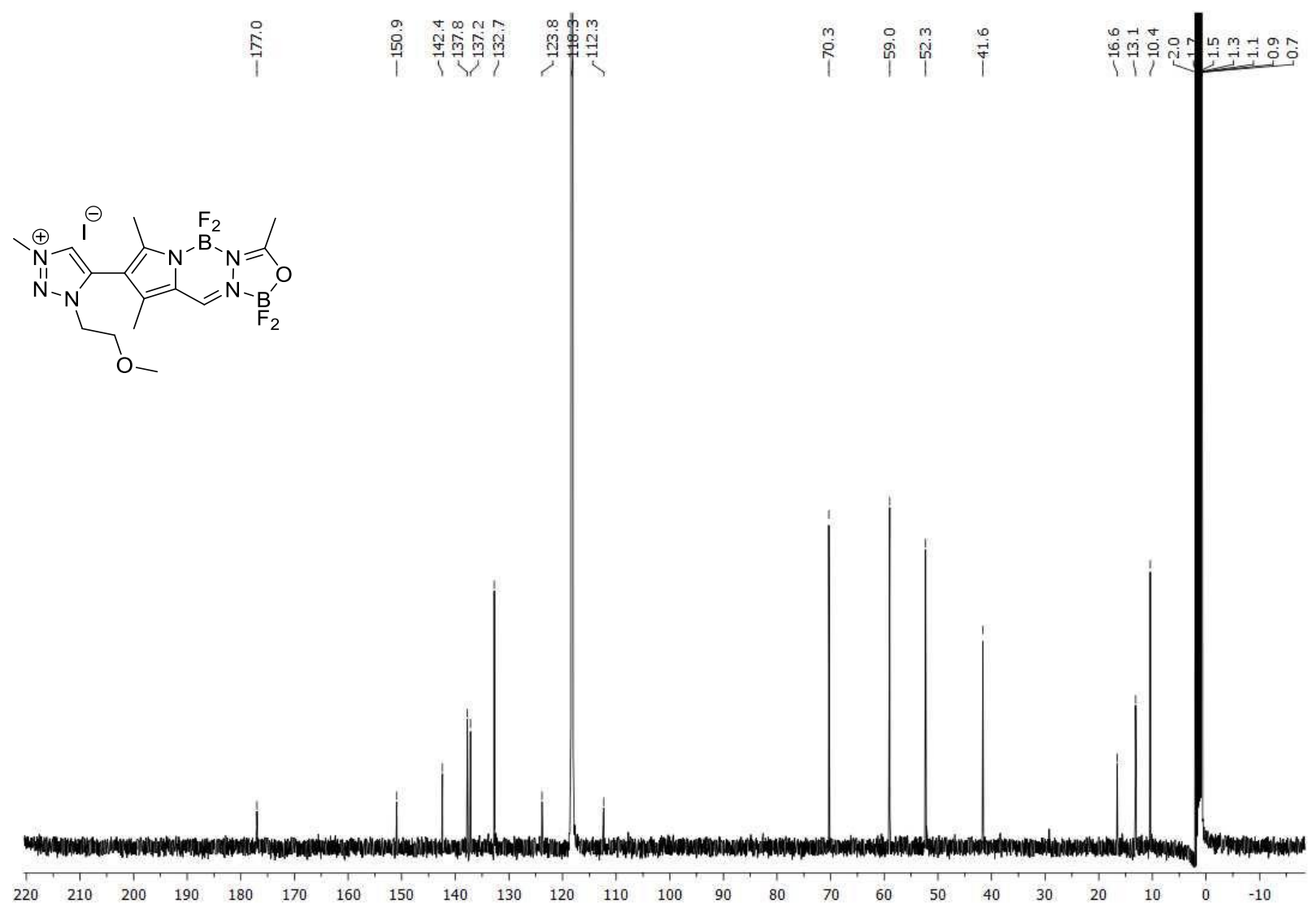


19bb' ( $\left.{ }^{1} \mathrm{H} \mathrm{NMR}, 400 \mathrm{MHz}, \mathrm{CD}_{3} \mathrm{CN}\right)$

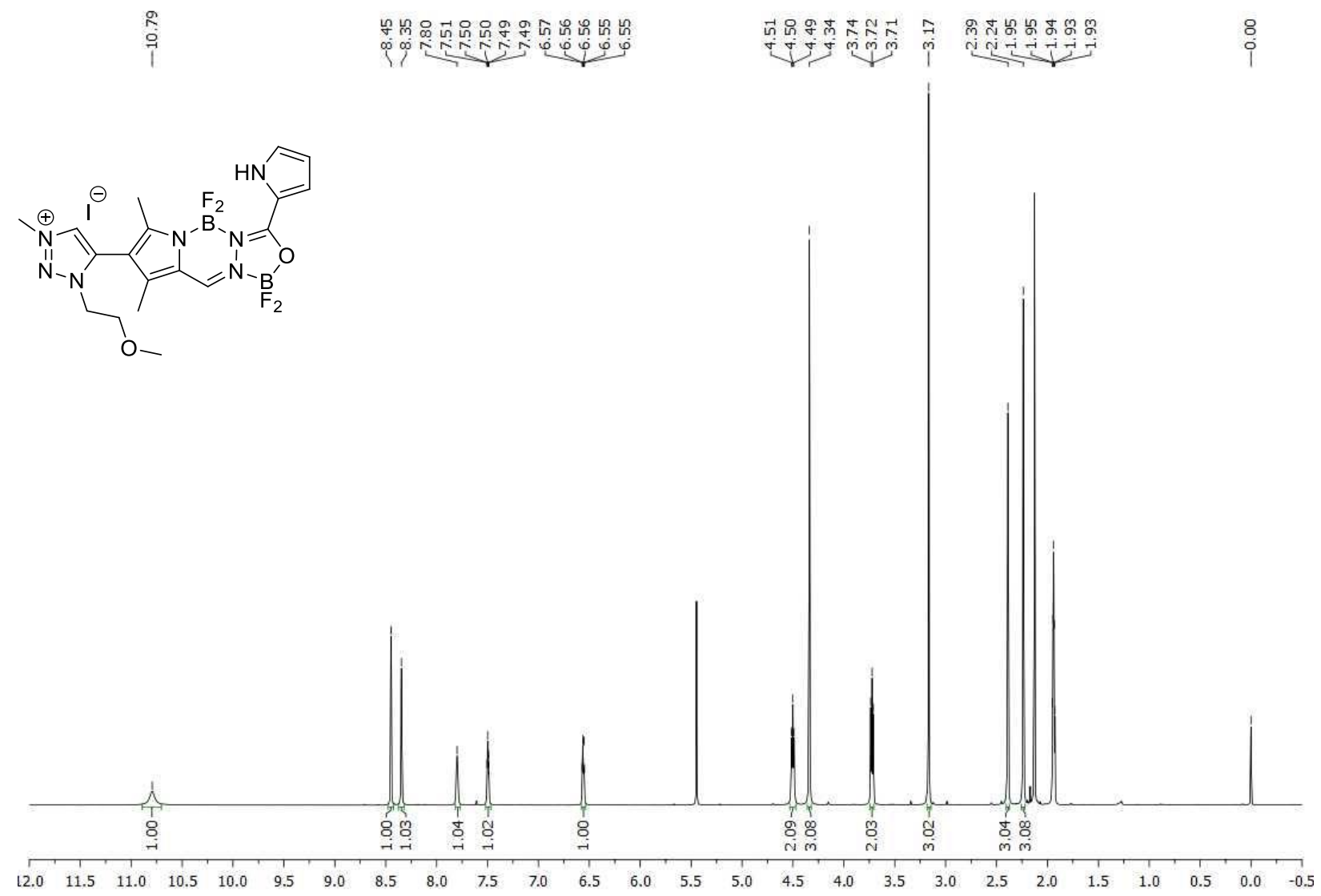

19bb' ( ${ }^{1} \mathrm{H}$ NMR, $\left.400 \mathrm{MHz}, \mathrm{D}_{2} \mathrm{O}\right)$

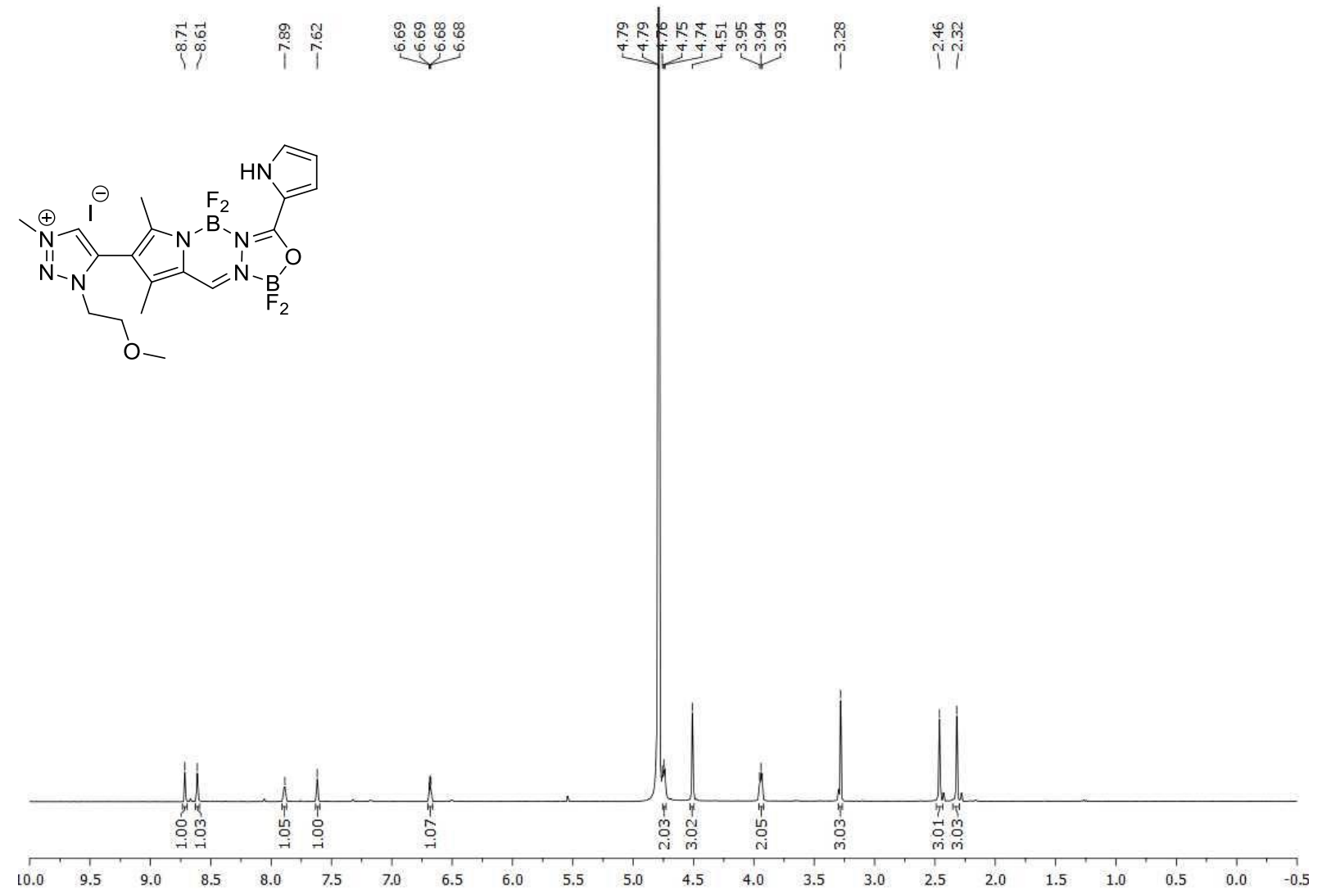


19bb' $\left({ }^{13} \mathrm{C}\left\{{ }^{1} \mathrm{H}\right\}\right.$ NMR, $\left.151 \mathrm{MHz}, \mathrm{CD}_{3} \mathrm{CN}\right)$

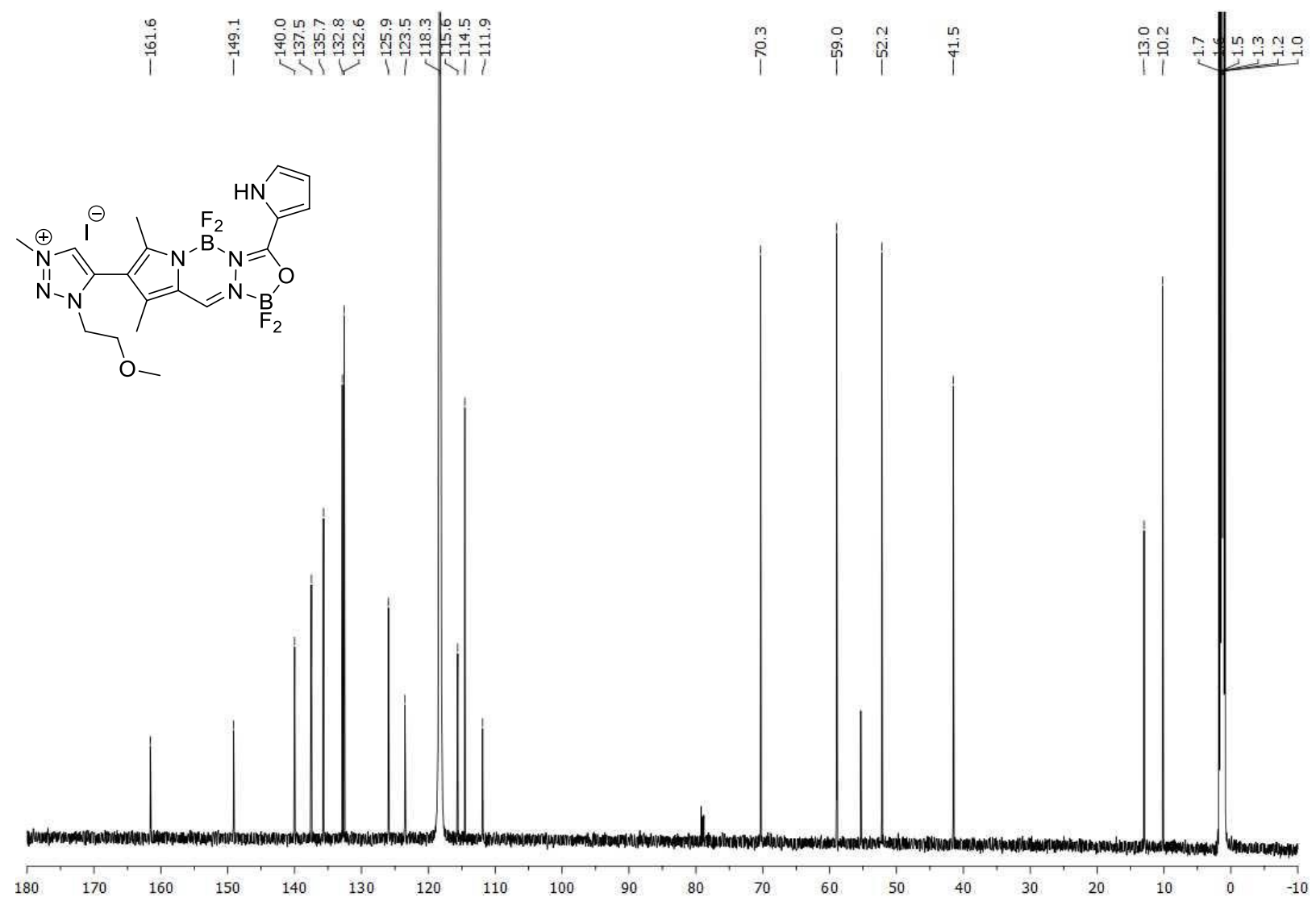

20bb' ( ${ }^{1} \mathrm{H}$ NMR, $\left.400 \mathrm{MHz}, \mathrm{CD}_{3} \mathrm{CN}\right)$

$\stackrel{\infty}{\stackrel{0}{1}}$

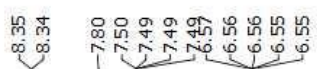

$\underbrace{-}$

i Tisingio

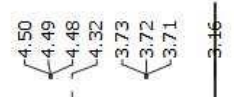

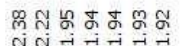

$\stackrel{8}{\circ}$

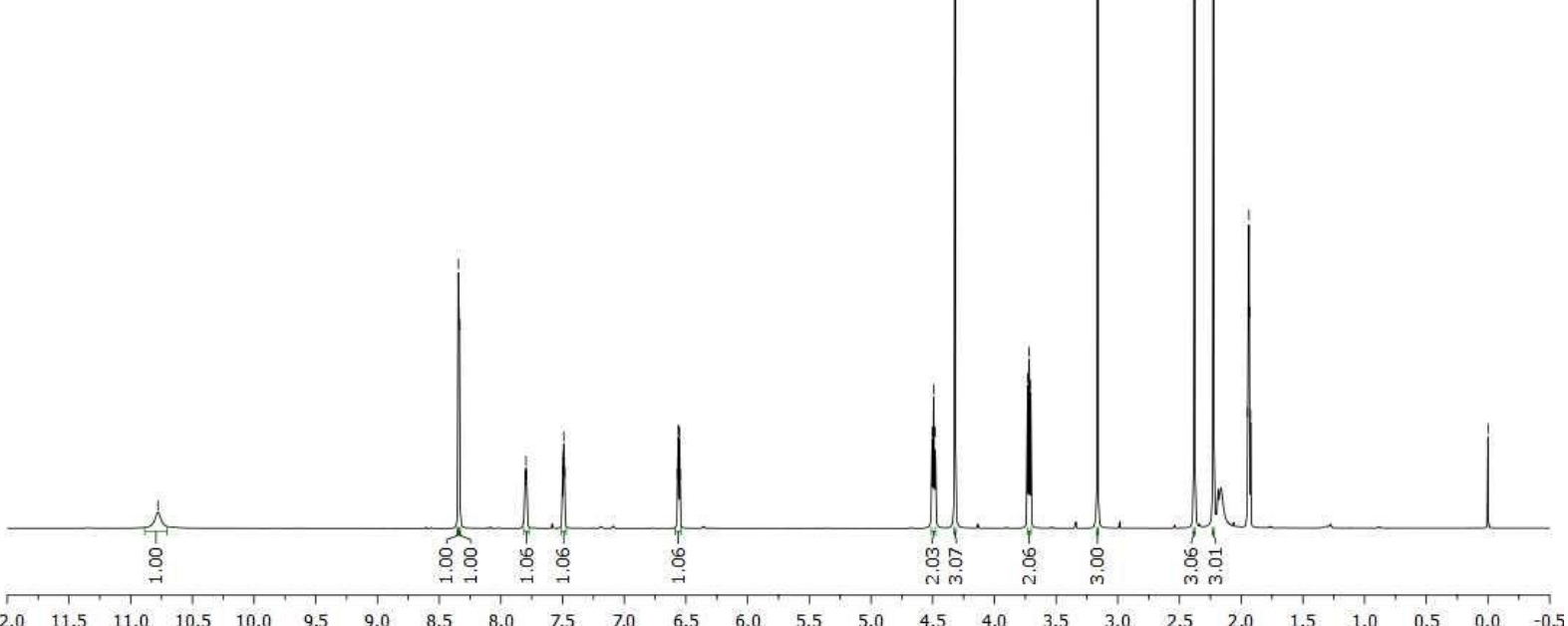


20bb' $\left({ }^{13} \mathrm{C}\left\{{ }^{1} \mathrm{H}\right\}\right.$ NMR, $\left.101 \mathrm{MHz}, \mathrm{CD}_{3} \mathrm{CN}\right)$

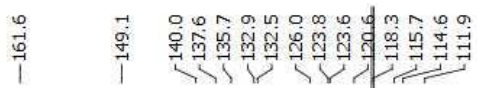

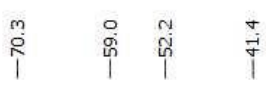

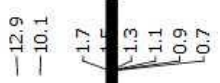

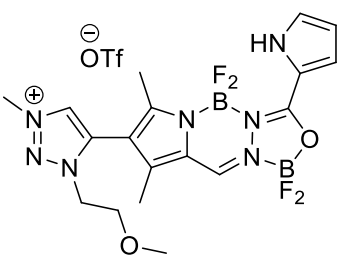

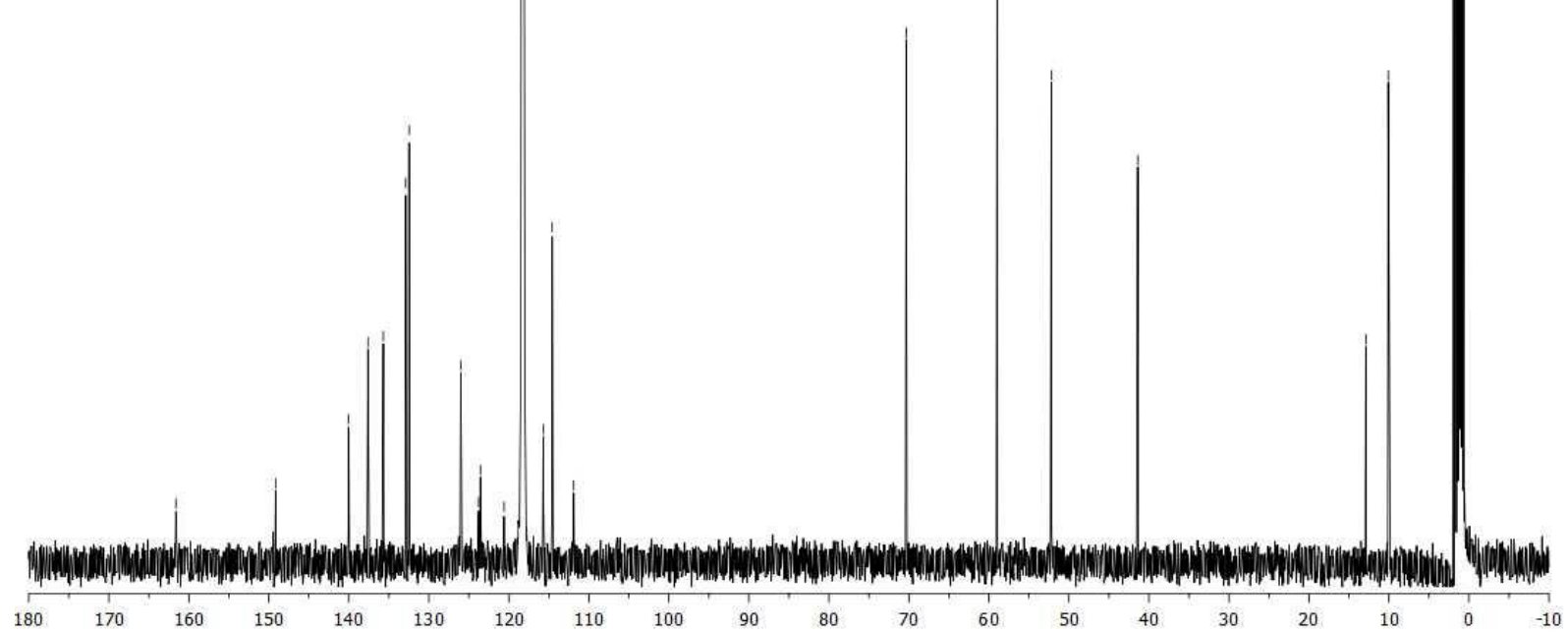

Suggested formation of BOPAHY 17aa' $\left({ }^{1} \mathrm{H}\right.$ NMR, $400 \mathrm{MHz}, \mathrm{CDCl}_{3}$ )

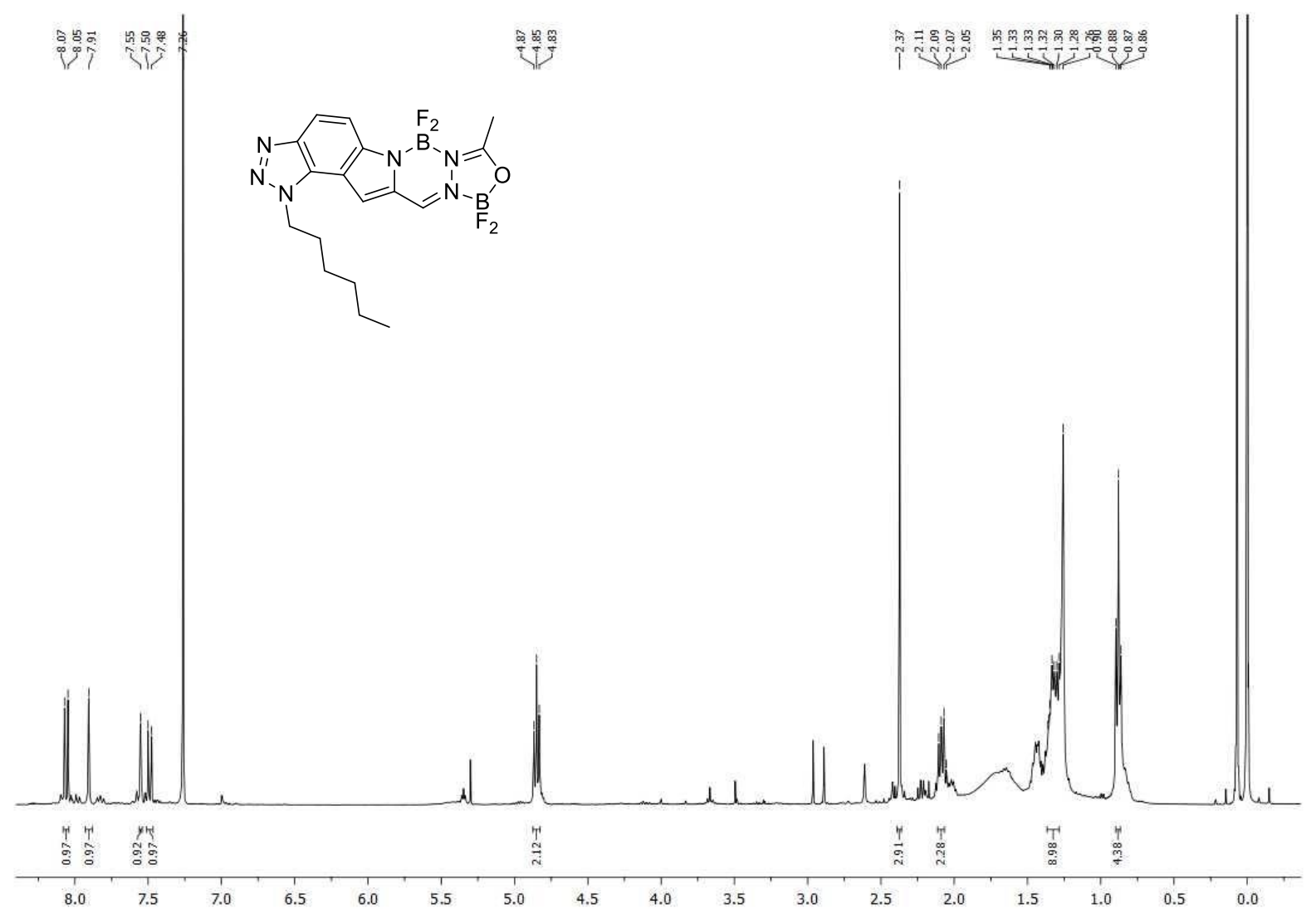

